INVESTIGATION OF THE SEDIMENT REMOVAL FREQUENCY

FOR WET-DETENTION STORMWATER MANAGEMENT PONDS

\author{
by \\ Rishon Richard \\ BEng in Mechanical Engineering, Ryerson University, 2010
}

\author{
A thesis \\ presented to Ryerson University \\ in partial fulfillment of the \\ requirements for the degree of \\ Master of Applied Science \\ in the Program of \\ Environmental Applied Science and Management
}

Toronto, Ontario, Canada, 2013

(C) Rishon Richard 2013 


\section{AUTHOR'S DECLARATION}

I hereby declare that I am the sole author of this thesis. This is a true copy of the thesis, including any required final revisions, as accepted by my examiners.

I authorize Ryerson University to lend this thesis to other institutions or individuals for the purpose of scholarly research.

I further authorize Ryerson University to reproduce this thesis by photocopying or by other means, in total or in part, at the request of other institutions or individuals for the purpose of scholarly research.

I understand that my thesis may be made electronically available to the public. 


\title{
Investigation of the Sediment Removal Frequency for Wet-Detention Stormwater Management Ponds
}

\author{
Rishon Richard \\ Master of Applied Science, 2013 \\ Environmental Applied Science and Management, Ryerson University
}

\begin{abstract}
The purpose of this study was to develop methodologies for determining the appropriate sediment removal frequency of wet-detention stormwater management facilities. Using data from a wet pond in the Town of Richmond Hill, a sediment accumulation model was developed using the US EPA's Stormwater Management Model (Version 5). Two different methodologies were then developed and applied to the facility. The first methodology is a real-time tool that provides the required time for sediment removal for a single cleanout cycle. The second methodology is analysis tool that relates cleanout frequency, annual cost and violations over a 50-year planning period. The results showed that the appropriate sediment removal frequency for the pond was approximately 16 to 17 years, and the annual cost of sediment removal ranged from $\$ 2,150$ to $\$ 2,372$, depending on the methodology used. It is recommended that these methodologies be considered for the planning and operation phases of stormwater ponds.
\end{abstract}




\section{ACKNOWLEDGEMENTS}

I would like to thank my thesis supervisor, Dr. James Li, and Dr. Darko Joksimovic for their guidance and direction.

I would also like to thank John Nemeth and William Withers from the Town of Richmond Hill for all their assistance, and Michael Thompson and the SERNAS Group for their involvement.

A special thank you to Drs. Ron Pushchak and Lynda McCarthy for their invaluable advice, and Drs. Arnold Yuan and Michal Bardecki for their time.

This research was made possible through the generous funding of the following organizations:

- $\quad$ The Town of Richmond Hill

- $\quad$ The SERNAS Group

- $\quad$ MITACS

- Ryerson University

- $\quad$ R.J. Burnside \& Associates Limited

- Natural Sciences and Engineering Research Council of Canada 


\section{DEDICATION}

To my Father and my family for their love and support. To my friends for being themselves. 


\section{TABLE OF CONTENTS}

AUTHOR'S DECLARATION ...................................................................................................... ii

ABSTRACT ............................................................................................................................................ii

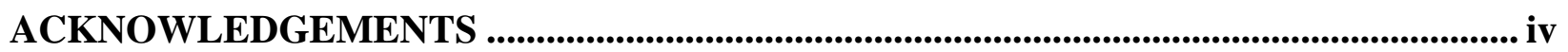

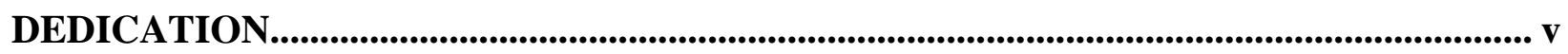

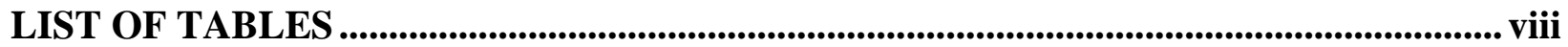

LIST OF FIGURES ................................................................................................................................. ix

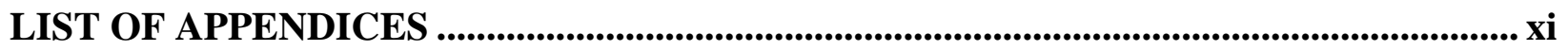

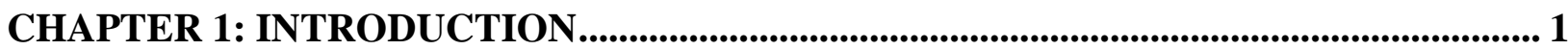

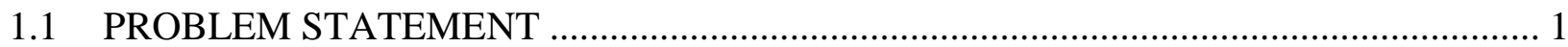

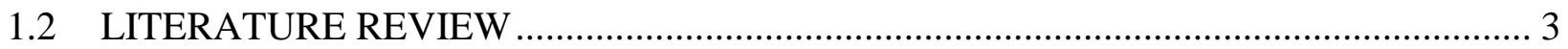

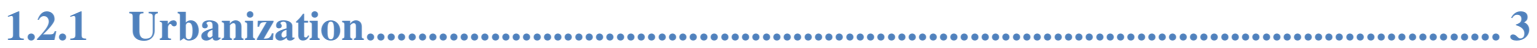

1.2.2 Urban Runoff ........................................................................................................................ 3

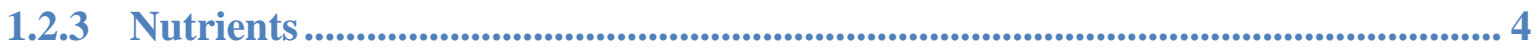

1.2.4 Metals............................................................................................................................... 4

1.2.5 Suspended Solids............................................................................... 5

1.3 THE EVOLUTION OF STORMWATER MANAGEMENT IN ONTARIO ....................... 6

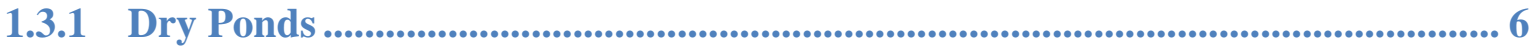

1.3.2 Wet Ponds..................................................................................................................... 6

1.3.2.1 Maintenance ........................................................................................... 7

1.3.2.2 Sediment Removal Forecasting ................................................................ 8

1.3.2.3 Sediment Removal and Disposal Regulations and Costs ........................... 9

1.3.2.4 Stormwater Models of Retention Ponds .................................................... 11

1.3.2.5 Methodologies for Determining Sediment Removal Frequency for Retention Ponds ............................................................................... 12

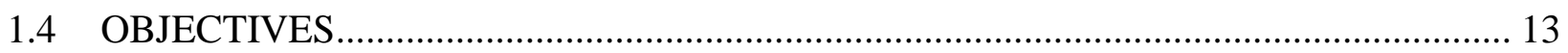

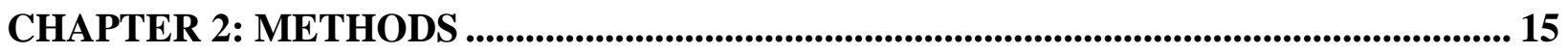

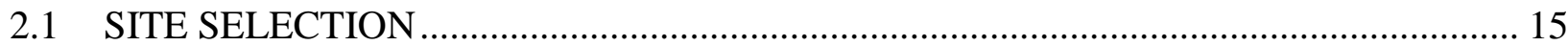

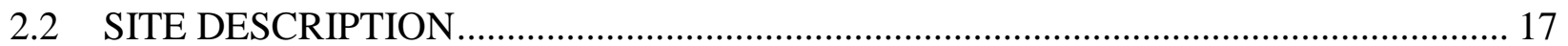

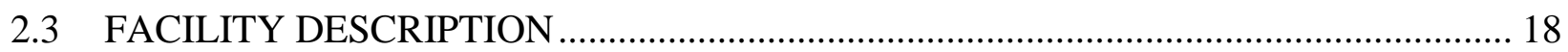

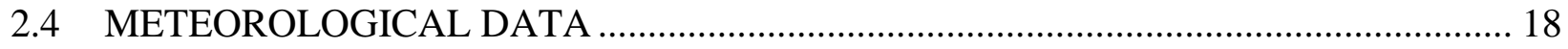

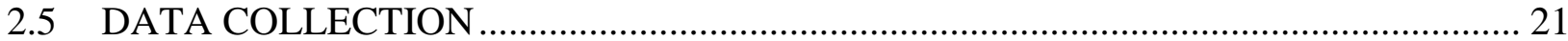

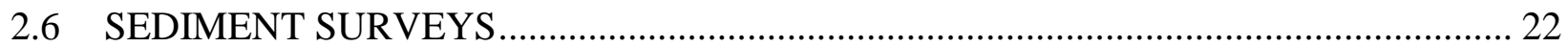

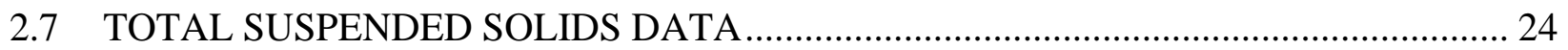

2.8 MATHEMATICAL/SOFTWARE SIMULATION …….................................................... 24 
CHAPTER 3: DEVELOPMENT OF THE SEDIMENT ACCUMULATION MODEL ..... 26

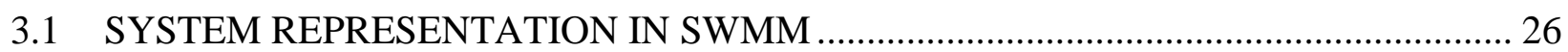

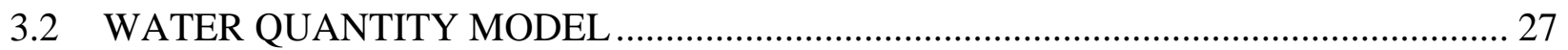

3.2.1 Determining Impervious Parameters ............................................................. 27

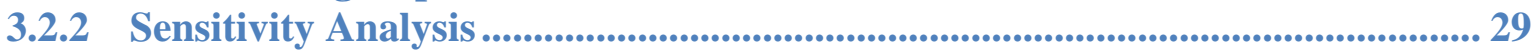

3.2.3 Calibration ............................................................................................... 30

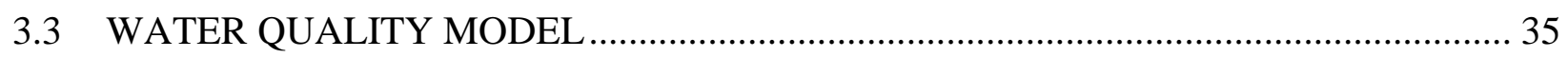

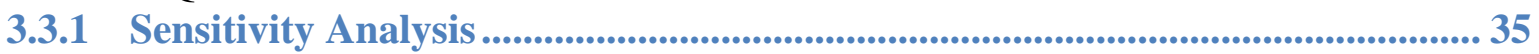

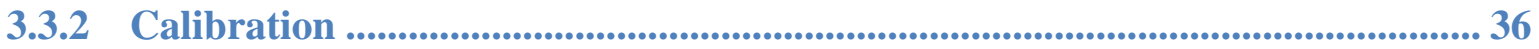

3.3.2.1 Buildup and Washoff Functions ........................................................... 36

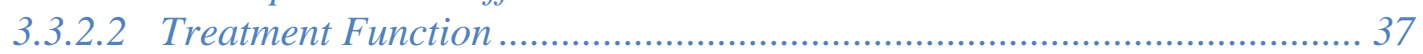

3.4 SEDIMENT ACCUMULATION FUNCTIONALITY ………....................................... 39

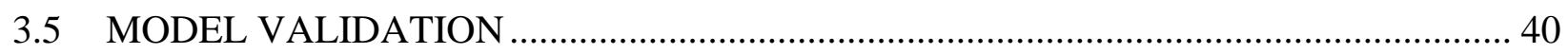

3.6 SEDIMENT ACCUMULATION MODEL FUNCTIONALITY …………...................... 44

CHAPTER 4: METHODOLOGIES FOR DETERMINING SEDIMENT REMOVAL

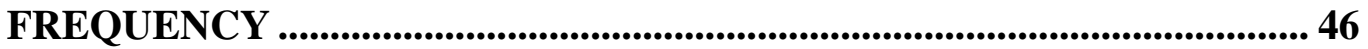

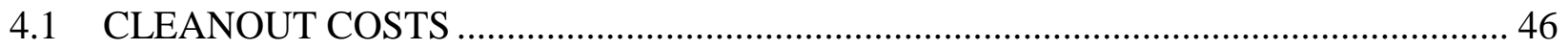

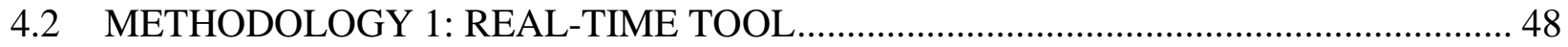

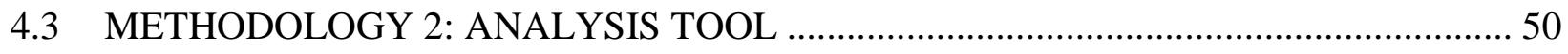

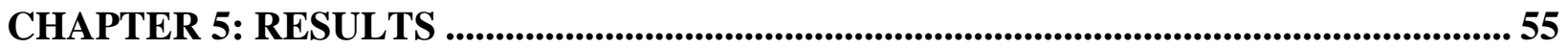

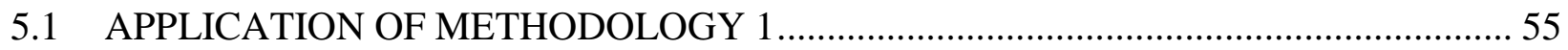

5.2 APPLICATION OF METHODOLOGY 2 ……………………............................... 57

CHAPTER 6: DISCUSSION ......................................................................................................... 61

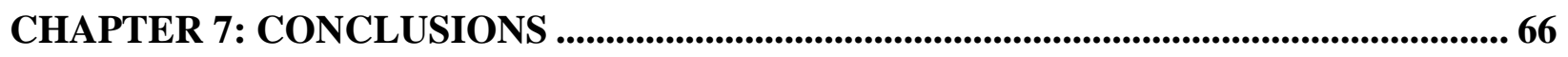

CHAPTER 8: RECOMMENDATIONS................................................................................... 68

8.1 OPTIMIZATION OF POND MAINTENANCE BY INCORPORATING OTHER

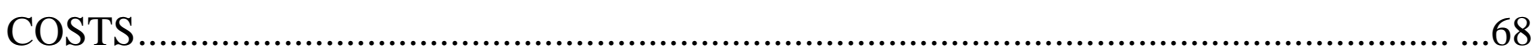

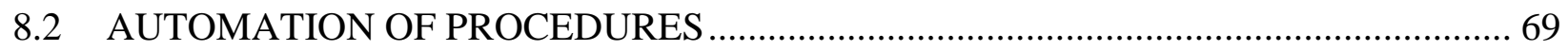

8.3 DEVELOPMENT OF INTEGRATED REAL-TIME, MONITORING SYSTEMS .......... 69

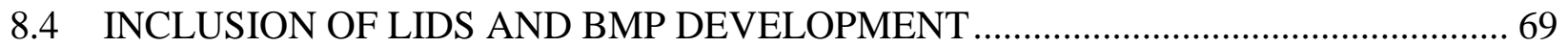

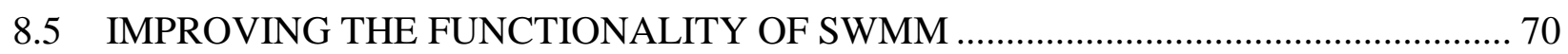

8.6 DETERMINING THE BUILDUP AND TRANSPORT OF OTHER

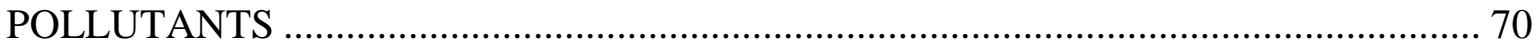

8.7 MODELLING THE IMPACTS OF CLIMATE CHANGE …………………….............. 71

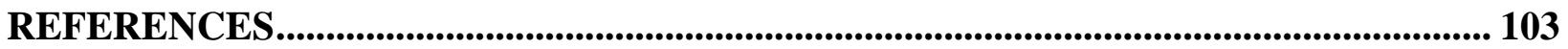




\section{LIST OF TABLES}

Table 1 - Continuous hourly raingauge data availability ..................................................... 20

Table 2 - Summary of material removed during cleanout in 2007 ........................................ 24

Table 3 - Percent zero impervious and percent impervious ................................................. 28

Table 4 - Summary of sensitivity analysis on SWMM parameters....................................... 30

Table 5 - Calibration summary of water quantity parameters ............................................ 31

Table 6 - Summary of sensitivity analysis on water quality parameters ............................... 36

Table 7 - Imported water quality parameters ….......................................................... 36

Table 8 - Summary of sediment accumulation calculations ............................................. 43 


\section{LIST OF FIGURES}

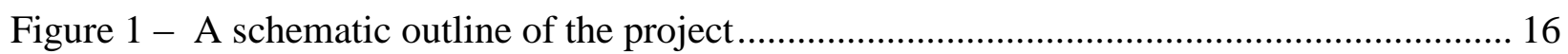

Figure 2 - Map outlining the location of the subcatchment within the Town of

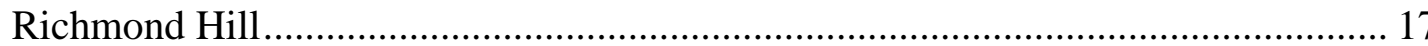

Figure 3 - A satellite picture showing the terrain and drainage area of the

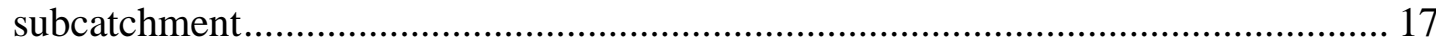

Figure 4 - Map of Operations and Buttonville raingauges and Wet Pond 410 ........................... 19

Figure 5 - Map of the Pearson and Buttonville raingauges and Wet Pond 410 ……………….. 19

Figure 6 - Sediment survey from 2006 showing the lengthwise cross-sectional average of the pond prior to cleanout........................................................................... 23

Figure 7 - Sediment survey from 2007 showing the lengthwise cross-sectional average of the pond after cleanout ........................................................................... 23

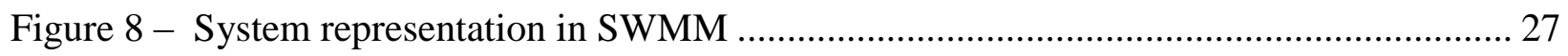

Figure 9 - Subcatchment with roofs in red and other impervious surfaces in black ................... 28

Figure 10 - Percent difference between model and measurements for rain events between Aug. 24, 2007 and May 30, 2009 ............................................................... 32

Figure 11 - Elevation difference between model and measurements for rain events between Aug. 24, 2007 and May 30, 2009 .............................................................. 32

Figure 12 - Initial water level of pond before rainfall events from June 2000-Oct. 2010 .

Figure 13 - Facility elevation versus time after a rainfall event showing a lack of proper drainage

Figure 14 - Facility elevation versus time after a rainfall event showing proper drainage

Figure 15 - Illustration showing how the pond profile changes over the years due to sediment accumulation

Figure 16 - Illustration of how the pond volume and sediment volume were calculated using rectangular columns

Figure 17 - Lengthwise cross-section of the pond in 2007 after cleanout .................................... 42

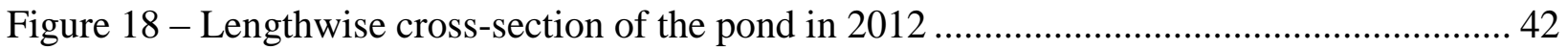




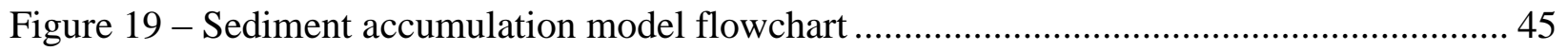

Figure 20 - Flowchart describing Methodology 1 ..................................................................... 49

Figure 21 - Schematic showing how the Annual Cost Estimator tool selects the

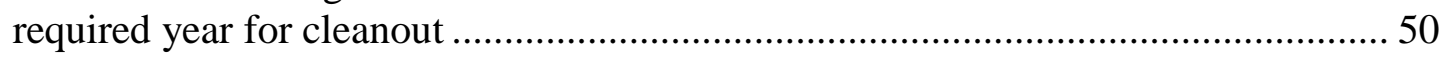

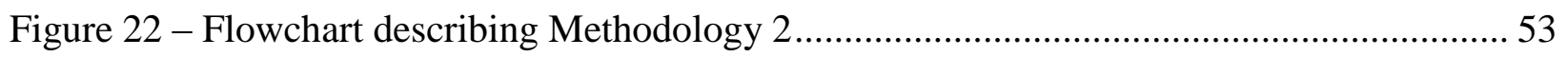

Figure 23 - Schematic showing how annual costs are calculated using Annual Cost

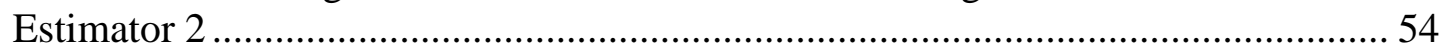

Figure 24 - Removal efficiency versus time for Facility 19-8 ………………………............. 55

Figure 25 - Annual cleanout cost versus years in operation for Facility 19-8 ............................. 56

Figure 26 - Performance of Facility 19-8 versus annual sediment removal cost......................... 57

Figure 27 - Years in violation of performance regulations versus the sediment removal frequency for Facility 19-8, over a 50-year planning period ........................ 58

Figure 28 - Number of years the facility is in violation of OMOE performance regulations versus the annual cost of sediment removal maintenance........................ 59

Figure 29 - Annual cost of sediment removal versus the cleanout frequency for

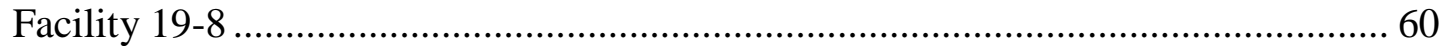

Figure 30 - Annual sediment entering Facility 19-8 versus annual rainfall over 50

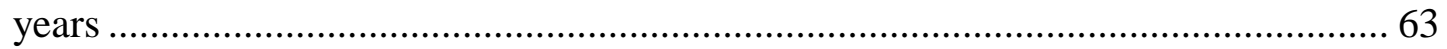

Figure 31 - Excessive and uncontrolled growth of vegetation in Facility 19-8 ........................... 65 


\section{LIST OF APPENDICES}

Appendix A - Parameters Used in SWMM Model................................................... 72

Appendix B - Water Quantity Model: Sensitivity Analysis Charts.................................. 77

Appendix C - Water Quality Model: Sensitivity Analysis Charts .................................. 83

Appendix D - Water Quantity Model: Calibration Charts ............................................ 87

Appendix E - Cleanout Frequency Charts............................................................. 92

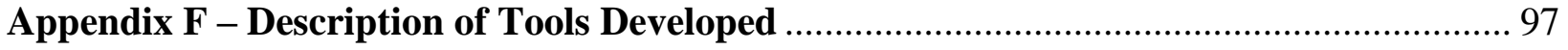




\section{CHAPTER 1: INTRODUCTION}

\subsection{PROBLEM STATEMENT}

Urbanization is known to significantly increase runoff rate and volume, sediment export, erosion, and habitat loss (Line \& White, 2007; Wong, Fletcher, Duncan, \& Jenkins, 2006). Urban runoff has been identified as one of the main sources contributing to the deterioration of water quality in receiving waterbodies (Lee \& Bang, 2000). Stormwater from urbanized areas commonly contains a wide range of contaminants including suspended solids, nutrients, heavy metals and polycyclic aromatic hydrocarbons (PAHs) (Ogunfowokan, Asubiojo, \& Fatoki, 2003) at concentrations that are significantly higher than runoff from undeveloped watersheds (Withgott, Brennan, \& Murck, 2010).

Stormwater management facilities (SWMFs), particularly wet ponds, play an important role in controlling urban runoff and improving water quality. Wet ponds, also known as retention basins, are man-made structures built to contain a permanent pool of water, in order to simulate the hydrology of a pond or lake ecosystem (Hogan \& Walbridge, 2007). Often located in urban areas, the main purpose of wet ponds is to remove pollutants and sediment from stormwater before discharging it into the natural environment. This is accomplished by holding runoff in these ponds for significant durations of time, allowing gravitational settling to naturally clarify the water of pollutants and sediment.

Sediment accumulation in stormwater ponds is both expected and desired, as it indicates that the pond is performing its intended function of removing both sediment and pollutants from urban runoff. However, increased sediment build-up decreases the water treatment efficiency of 
the pond. In order to meet government regulations on discharged water quality, municipalities must remove the excess sediment using mechanical or hydraulic dredging, which is an expensive undertaking. Predicting when maintenance will be required is a challenging task as sediment accumulation in ponds depends on a number of factors including rainfall intensity, rainfall duration, construction activities, street-sweeping, storage volume and drainage area characteristics (OMOE, 2003).

Currently, the most common way of determining the appropriate maintenance time is based on measuring sediment levels directly. Maintenance crews take field measurements of the sediment build-up and the data are plotted in a chart. Linear trend lines provide a rough estimation of sediment accumulation rates but they are often misleading, depending upon the factors described above. Some municipalities have already implemented Stormwater Utility Fees requiring residents to fund operation and maintenance activities (Van Vliet, 2003). This has obviously been met with resistance thus, other solutions are required.

One way to effectively manage stormwater ponds is to establish a method that can identify the appropriate sediment removal frequency for a given facility, based on minimizing cost while maintaining compliance with government-mandated performance standards. Such a method requires the development of a sediment accumulation model along with an analysis methodology as discussed in this thesis. 


\subsection{LITERATURE REVIEW}

The detrimental effects of urbanization and urban runoff are discussed in this section as they are the primary reasons why stormwater ponds are needed.

\subsubsection{Urbanization}

Urbanization has a profound impact on the natural hydrologic cycle by limiting groundwater recharge, re-routing and channelizing natural waterways, and by increasing runoff, flooding and erosion (Randolph, 2004). Corresponding increases in impervious surface area are known to significantly affect the hydrologic response of a watershed (Alley \& Veenhuis, 1983) and land development has been shown to increase runoff quantity (Line \& White, 2007). Urban runoff is of particular concern because it is generally highly contaminated (Sartor, Boyd, \& Agardy, 1974) and is discharged directly to receiving waterbodies, often without any treatment, causing biological, chemical, and physical issues (Wanielista \& Yousef, 1993).

\subsubsection{Urban Runoff}

Urban runoff is rainwater that falls on man-made impervious surfaces such as roofs, roads and parking lots, and drains to local waterbodies, often collecting pollutants and particles along the way. Most of these pollutants are the result of human activities and are continuously deposited onto urban surfaces by a variety of dry and wet deposition processes (Wanielista \& Yousef, 1993). It is estimated that runoff from these paved surfaces is 16 times more polluted than runoff from natural, undeveloped areas (Withgott, Brennan, \& Murck, 2010), and non-point source pollution resulting from urban runoff has been identified as one of the major causes of receiving water quality deterioration (Lee \& Bang, 2000). 
Common pollutants of urban surfaces include motor oils, road salts, animal waste, litter, nutrients, pesticides, bacteria, metals, and sediment. However, for the purposes of brevity, only contaminants that pertain to this research will be discussed. These pollutants are: nutrients, metals and sediments.

\subsubsection{Nutrients}

Nutrients in runoff, such as nitrogen and phosphorus, can cause eutrophication in receiving waterbodies (May \& Sivakumar, 2009). Eutrophication occurs due to excessive nutrient loading which causes a rapid growth of algae, commonly known as an algal bloom. When the algae die, their decomposition creates oxygen-depleting conditions within the waterbody, which is often fatal for other aquatic organisms including fish (Wanielista \& Yousef, 1993). This phenomenon occurs in surface waters all around the world (May \& Sivakumar, 2009) and kills fish, sea birds and marine mammals. Biotoxins caused by eutrophication may also accumulate in seafood, posing a hazard to human health (Gabric \& Bell, 1993).

\subsubsection{Metals}

Urban runoff has been found to contain 10 to 100 times the concentration of metals as compared to sanitary sewage (Wanielista \& Yousef, 1993). This is because automobile emissions are the main source of metal contamination on urban surfaces. Metal contaminants in general, are particularly troublesome due to their persistence and toxicity (Nie, Li, Yao, Feng, \& Zhang, 2008). Furthermore, since many heavy metals are particle-bound to sediment, they end up in stormwater facilities. 
Studies conducted by Sartor, Boyd and Agardi (1974) found that the most prevalent metal contaminants in urban runoff were lead and zinc. Other metal contaminants found in lower concentrations include arsenic (Wanielista \& Yousef, 1993), mercury (Sartor, Boyd, \& Agardy, 1974), copper, cadmium, chromium, and nickel (Westerlund \& Viklander, 2006). Interestingly, certain metals found in rain, such as copper and cadmium, may make up a large part of the same pollutants in runoff (Wanielista \& Yousef, 1993).

\subsubsection{Suspended Solids}

Suspended solids are regarded as the principal pollutant in urban runoff (Pyatt, 2003) and are defined as organic and inorganic particles that are greater than $0.4 \mu \mathrm{m}$ in size. High levels of suspended solids in runoff (greater than $120 \mathrm{mg} / \mathrm{L}$ ) have been shown to cause a wide array of detrimental effects in receiving waters. Suspended solids can cause turbidity, thereby blocking sunlight and impairing the growth and activity of photosynthetic organisms (Aryal \& Lee, 2009). This disruption in the aquatic food chain decreases the diversity and population of other species (Wanielista \& Yousef, 1993). Suspended solids have also been shown to clog fish gills (Aryal \& Lee, 2009), reduce the size of spawning areas and decrease overall aesthetic quality (Wanielista \& Yousef, 1993). The toxicity of sediment is further increased by the sorption of particle-bound pollutants such as heavy metals and nutrients, making the study of sediment even more important. 


\subsection{THE EVOLUTION OF STORMWATER MANAGEMENT IN ONTARIO}

This section describes the history of stormwater management in Ontario, from the construction of dry ponds to the widespread adoption of wet ponds as the preferred end-of-pipe control. The maintenance of wet ponds and sediment removal is also discussed.

\subsubsection{Dry Ponds}

In the early 1980s watershed plans were adopted in Ontario, with the Master Drainage Plan being the most prominent, particularly in matters pertaining to stormwater runoff (Ontario Ministry of the Environment [OMOE], 1993). At that time, floodplain management, runoff quantity control, and erosion/flood control were the main concerns, resulting in the construction of dry ponds across Ontario, which are highly effective in resolving these issues (OMOE, 2003). These stormwater facilities are end-of-pipe controls, meaning they receive water from a subdivision or lot and discharge it to a natural waterbody. Dry ponds do not contain a permanent pool of water and temporarily hold stormwater for a day or two.

\subsubsection{Wet Ponds}

Also known as retention basins, wet ponds are man-made stormwater facilities that always contain a permanent pool of water (Wanielista \& Yousef, 1993) and are often located in urban areas. Today, they are the most important (Toronto and Region Conservation Authority [TRCA], 2010) and common end-of-pipe stormwater management facility (SWMF) in Ontario (OMOE, 2003) due to their effectiveness in removing contaminants from stormwater (Narayanan \& Pitt, 2006). They are so effective that many municipalities now rely on wet ponds as the cornerstone of their stormwater management plans (TRCA, 2010). 
The main purpose of a wet pond is to remove pollutants and sediment from stormwater before it is discharged into the natural environment. This is accomplished by holding runoff in these ponds for significant durations of time, allowing gravitational settling to naturally clarify the water of particle-bound pollutants and sediment (Westerbeek-Vopicka, 2009). In regions where nutrient loading into receiving waters is an issue, retention basins can be planted with certain species of vegetation to alleviate this problem (OMOE, 2003). Through biological uptake, macrophytes are able to remove nutrients and heavy metals present in runoff (Triboit et al., 2010) while other suspended solids are primarily removed through sedimentation processes (Westerbeek-Vopicka, 2009).

Wet ponds also serve other functions including recharging groundwater, providing a habitat for wildlife, increasing green-space, and improving aesthetic values of a neighbourhood (Narayanan \& Pitt, 2006; OMOE 2003). Due to their numerous benefits, the implementation of wet ponds is considered as one of the Best Management Practices (BMPs) for controlling stormwater runoff and quality (Behera, Papa, \& Adams, 1999).

\subsubsection{Maintenance}

As with any other stormwater management facility, wet ponds require maintenance (OMOE, 2003). Typical maintenance activities include vegetation control, landscaping, debris removal, pipe repairs and sediment removal (Narayanan \& Pitt, 2006). Of these, sediment removal by means of mechanical or hydraulic dredging, is one of the most important as sediment build-up in wet ponds decreases their overall capacity to hold water and reduces their efficiency, in terms of controlling pollution (Yousef, Hvitved-Jacobsen, Sloat, \& Lindeman, 1994). For this 
reason, and in order to comply with government regulations, municipalities must remove the sediment periodically (Graham \& Lei, 2000). However, maintenance guidelines provided by the Ontario Ministry of the Environment in Section 53 of the Water Resources Act, do not address the issue of sediment removal frequency. Therefore, the current practice is to service these ponds based on meeting regulatory wet pond performance guidelines, the availability of funds, and sediment accumulation levels.

\subsubsection{Sediment Removal Forecasting}

Because sediment removal is a capital-intensive yet necessary undertaking, it is important to determine when it will be required. However, forecasting clean-out maintenance is difficult because it depends on a number of factors, some of which may change abruptly. These factors include, but are not limited to: storage volume, rainfall intensity and duration, construction activities, street-sweeping, and characteristics of the pond drainage area (OMOE, 2003).

The rate of sediment loading into a pond due to specific activities can be quantified, if data are available. For example, studies have shown that construction activities increase sediment loading by a factor of 20 to 20,000 compared to the background sedimentation rate (Krasnova, 2004). Street sweeping has shown to reduce total suspended solids in ponds by 30 percent (Bannerman, 2007). To quantify all the factors that influence sedimentation rates requires data from a large number of ponds. However, this is difficult to obtain due to the lack of monitoring.

Sediment surveys are used to estimate when maintenance will be required by converting sediment depth into lost pond volume. Surveys conducted in subsequent years can provide additional data that can be used to extrapolate when the loss in pond volume, and therefore 
removal efficiency, will breach government regulations (Graham \& Lei, 2000). However, this method has some limitations because monitoring and inspection practices of SWM ponds have not yet been standardized (Drake \& Guo, 2008), and it does not take into account the sources of the incoming sediment. Sediment loading rates can vary between measurement intervals, increasing or decreasing the forecasted maintenance time (Greenland International Consulting Inc., 1999). Additionally, sediment loading rates are unique to location. To further complicate matters, it is also unknown if the sediment accumulation rates used during the design of stormwater ponds are still accurate today (Drake \& Guo, 2008). In general, it is recommended that most ponds are cleaned out every fifteen to twenty-five years (Schueler, 1994) with the OMOE suggesting 10 years as a minimum design target (OMOE, 1994).

\subsubsection{Sediment Removal and Disposal Regulations and Costs}

The total cost of sediment removal from a wet pond is difficult to predict as well, since most SWMFs in North America have only been in operation for slightly longer than a decade and have not been cleaned out since construction (Drake \& Guo, 2008). Surveys of estimated pond service costs to municipalities have been conducted, but the data are insufficient to provide correlations between pond characteristics, sediment accumulation rates and maintenance costs. Literature describes annual maintenance costs as a percentage of construction costs, or as a function of the pond's design storage volume, or as a function of the subcatchment area. Annual maintenance costs are approximately 8 percent for stormwater ponds that cost $\$ 10,000$ to construct, or 4 percent for ponds that cost $\$ 100,000$ to construct (Erickson, Gulliver, Kang, Weiss, \& Wilson, 2010). Narayanan and Pitt (2006) present annual maintenance costs in the 
range of $\$ 2,096-\$ 10,288$ for 6-11.5 acre sized ponds, respectively, and cost functions ranging from \$43-61/acre served.

Although sediment removal data from other types of waterbodies are available, their application to stormwater ponds is limited due to significant variations in pollutant loading, sediment characteristics and erosion. For example, stormwater ponds do not receive combined sewer overflow (CSO) discharges or large amounts of silt from rivers, unlike some lakes and bays. Other factors that prevent direct correlations include tides, wind and freshwater runoff as they have been shown to spatially and temporally affect contaminant concentrations within large waterbodies (Schoellhamer, Mumley, \& Leatherbarrow, 2007).

The issues of classifying contaminated sediment and subsequent disposal are governed by Regulation 347 of the Environmental Protection Act (EPA). The Regulation requires municipalities to perform the leachate test in order to classify sediment that is removed from a pond. The test uses the U.S. EPA Toxicity Characteristic Leaching Procedure (TCLP) Test Method 1311 to determine the concentration of approximately a hundred toxic substances in solid, multiphase or liquid wastes (Environment Canada, 2002). Regulation 347 also requires the slump test to classify extracted sediment as either solid or liquid waste, depending on the amount of water present. Sediment with high water content might need to be dewatered or bulked which further increases the cost of disposal.

Additionally, the Guideline for Use at Contaminated Sites in Ontario determines where sediment can be disposed, based on pollutant concentration levels within the sediment. Sediment that is relatively pollutant free may be spread over agricultural lands while more polluted 
sediments might be used in residential, commercial or industrial zones or parklands. Heavily contaminated sediments may have to be placed in a landfill (Graham \& Lei, 2000). Because sediment from ponds contains low levels of organic matter compared to sewage, it cannot be placed on agricultural lands (Triboit et al., 2010). Case studies have shown that sediment removal and disposal costs can range from $\$ 14$ per cubic meter to $\$ 669$ per cubic meter based on the level of contamination, as it is significantly more expensive to dispose of polluted sediment (Graham \& Lei, 2000). The uncertainties in predicting disposal costs are further exacerbated by the widespread lack of cleanout experience highlighted by surveys of municipalities (Drake \& Guo, 2008).

\subsubsection{Stormwater Models of Retention Ponds}

Numerous stormwater quality models have been built to predict the performance of various treatment measures, each with different assumptions, objectives and applications (Wong, Fletcher, Duncan, \& Jenkins, 2006). They are expected to become important analysis tools (Barbé, Cruise, \& Mo, 1996) as the best models can be used to help manage combined sewer overflows, determine which BMPs should be used and where, and prepare impact assessments involving changes in land-use (Obropta \& Kardos, 2007).

Stormwater models are classified as being either deterministic or stochastic. Deterministic models attempt to emulate real processes by using causal relationships, where the outcome depends on past events, while stochastic models use statistical probability distributions to achieve the same results (Obropta \& Kardos, 2007). Examples of deterministic models include 
the Stormwater Management Model (SWMM), Hydrologic Simulation Program Fortran and Storage, Treatment, Overflow, Runoff Model (STORM).

Many monitoring studies have shown that stormwater ponds are effective in trapping pollutants in urban runoff (Schueler, 1994), with a large majority of research involving pollutant removal efficiency (Westerbeek-Vopicka, 2009). Numerous methods have been also been developed to model erosion and sediment loading from urbanized regions (Wilson \& Barfield, 2009); however, studies of sediment quality and pollutant fate within the ponds are lacking (Westerbeek-Vopicka, 2009). The general assumption is that the pollutants are trapped within the sediment at the bottom of the pond in a layer of muck and are removed along with the sediment during a clean-out (Schueler, 1994).

\subsubsection{Methodologies for Determining Sediment Removal Frequency for Retention Ponds}

There are two main approaches to determining when stormwater ponds need to be cleaned out: optimization models and maintenance forecasting.

An optimization model requires at least one objective function and a set of constraints in the form of mathematical equations. The objective function is a performance measure, meaning it represents a quantifiable variable, like cost for example. Optimizing the objective function is to find either the maximum or minimum value of the variable as required (Murty, 2003). Systems with more than one objective function are known as multiobjective models. They require simultaneous optimization of all the functions. A number of different optimization techniques have been developed including linear programming, heuristic models, dynamic programming and genetic algorithms, with dynamic programming being the most common in related literature. 
Studies incorporating optimization models have thus far primarily focussed on factors such as water quality, pollution control (Behera et al., 1999), treatment efficiency, pond geometry, and land cost (Rathnam, Cheeralaiah, \& Jayakumar, 2004). Additionally, the optimization models that have been developed only take into account a few of the factors described above.

The second approach of maintenance forecasting has become the domain of consultants, due to the complexity of technical details involved (Drake \& Guo, 2008). Most techniques involve the use of a stormwater model along with sediment accumulation data for the facility, from sediment surveys. These models are particularly helpful in selecting cost-effective measures to decrease sediment loading (Wilson \& Barfield, 2009).

It is useful, therefore, to develop a methodology that can predict when maintenance will be required for a facility, by taking local factors such as sedimentation rates and performance into account. The methodology must also be flexible, meaning it can be applied to any wet pond, regardless of geographical location. By incorporating various maintenance costs, a decisionmaker can determine an appropriate pond maintenance program. A successful methodology will minimize the cost for municipalities to maintain stormwater management ponds, while ensuring the ponds meet regulatory performance standards. However, the question stands whether such a comprehensive, flexible and accurate methodology can be created.

\subsection{OBJECTIVES}

The primary objective of this thesis is to develop a methodology that can determine the appropriate sediment removal frequency for a wet pond by taking a number of factors into account, such as local rainfall data, subcatchment characteristics and detention facility properties, 
along with performance measures such as pollutant removal efficiency and clean-out costs. A case study project in the Town of Richmond Hill is used to illustrate the methodology.

Most of the literature available on stormwater ponds quantifies treatment efficiency by measuring water quality upstream and downstream of the facility, while knowledge of the pollutant removal mechanisms within the ponds is lacking. Additionally, research involving optimization models takes into account either performance based on facility design, or cost.

Many gaps in the literature are due to data limitations, as the vast majority of ponds in Ontario are not monitored frequently. This makes analysis difficult. For example, data records often specify the time since the last cleanout of a pond in years, whereas months or days are preferred in order to preserve accuracy. Similarly, sediment depth measurements might be taken infrequently or only at one location within a pond, making analysis difficult. Additionally, changes in land-use or construction of another stormwater facility within the drainage area will affect sedimentation rates in the pond. These gaps in data, however, can be avoided by selecting a facility with adequate monitoring, located in an established neighbourhood. Furthermore, the data may not always be applicable as certain areas might be under-represented in literature. For example, numerous studies have been conducted on ponds in northern Europe, while very few have been conducted in southern Europe (Triboit et al., 2010). Geographical issues arise when trying to utilize pond data from different regions as sediment, rainfall and pollutant data can vary significantly depending on location. For these reasons, a methodology that can be applied to any facility, regardless of location, needs to be developed. 


\section{CHAPTER 2: METHODS}

This chapter provides an overview of the case study project in the Town of Richmond Hill, describes the site selection process, and the site itself. Descriptions of all the collected data and the methods used to collect them, are also included in this chapter. A schematic outline of the project is shown in Figure 1.

\subsection{SITE SELECTION}

A stormwater pond was chosen based on: the date of the last cleanout was known; sediment depth measurements were taken at various locations within the pond; street-sweeping records were available and street-sweeping operations had not changed in the surrounding areas since the construction of the pond; and other stormwater facilities have not been built within the pond's drainage area, since the construction of the pond. By ensuring that the chosen pond meets these criteria, data limitation problems mentioned in the sections above can be avoided. If some of the data listed above is unavailable, the methodologies discussed below can still be used, but the accuracy of the model will decrease. After consultations with the staff of the Water Resources \& Stormwater Operations of the City of Richmond Hill, Stormwater Management Facility 19-8, also known as Wet Pond 410, was chosen. 


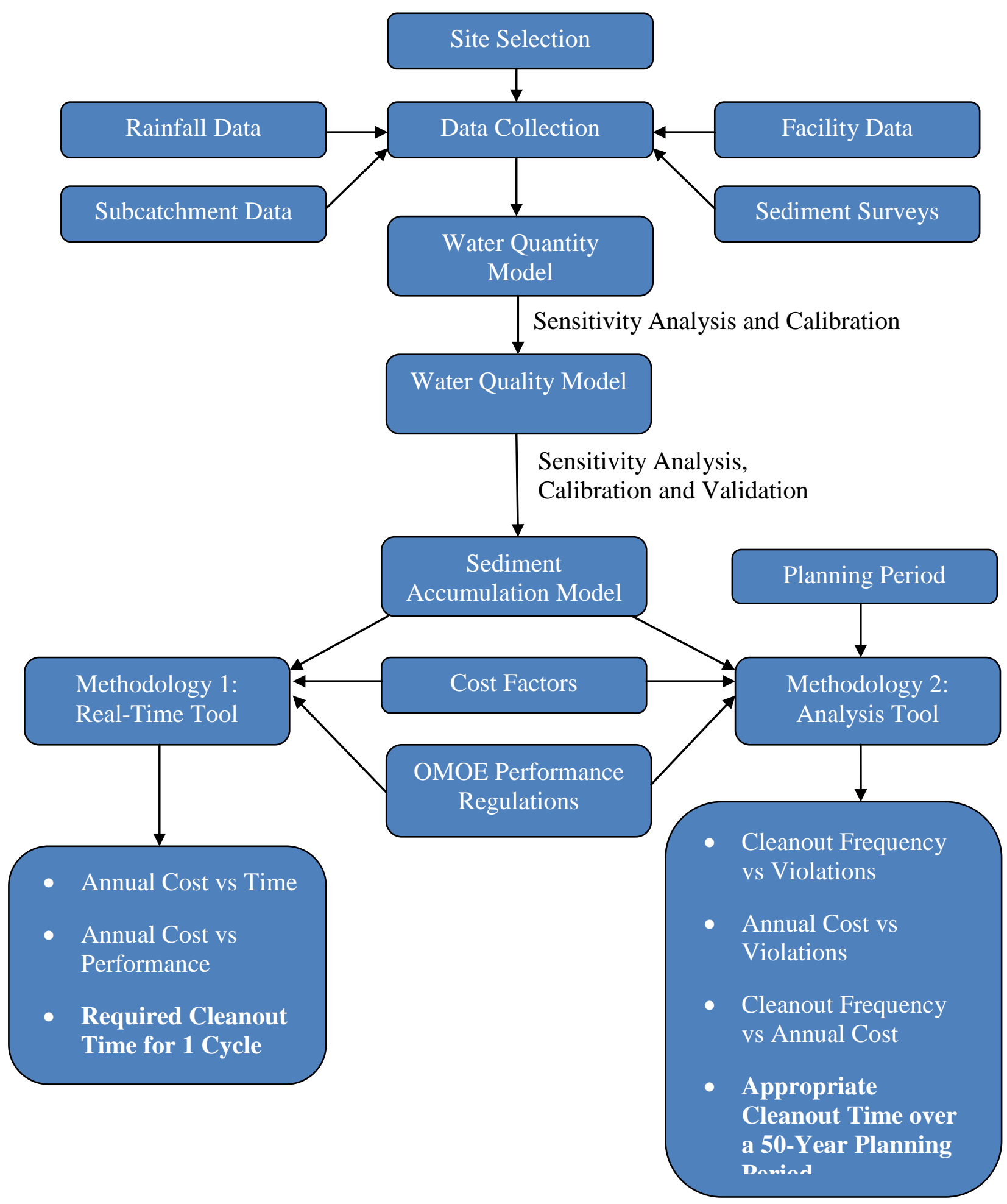

Figure 1 - A schematic outline of the project 


\subsection{SITE DESCRIPTION}

Facility 19-8 is located at the south-east of Bayview Avenue and Elgin Mills Road, in the Town of Richmond Hill, as shown in Figure 2. It drains a 10.45 hectare $\left(0.1045 \mathrm{~km}^{2}\right)$ residential catchment as shown in Figure 3. The primary soil type within the drainage area is sandy loam, and other fine-particle fractions. The pond itself, however, is located on clay loam.

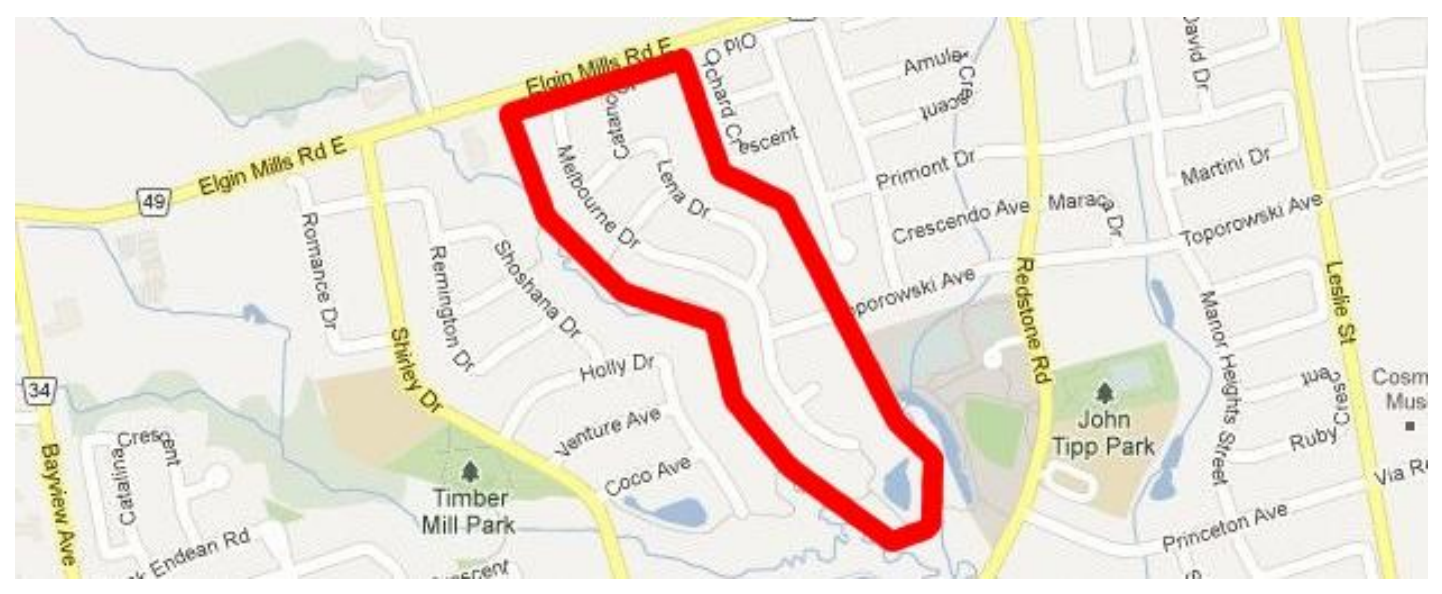

Figure 2 - Map outlining the location of the subcatchment within the Town of Richmond Hill

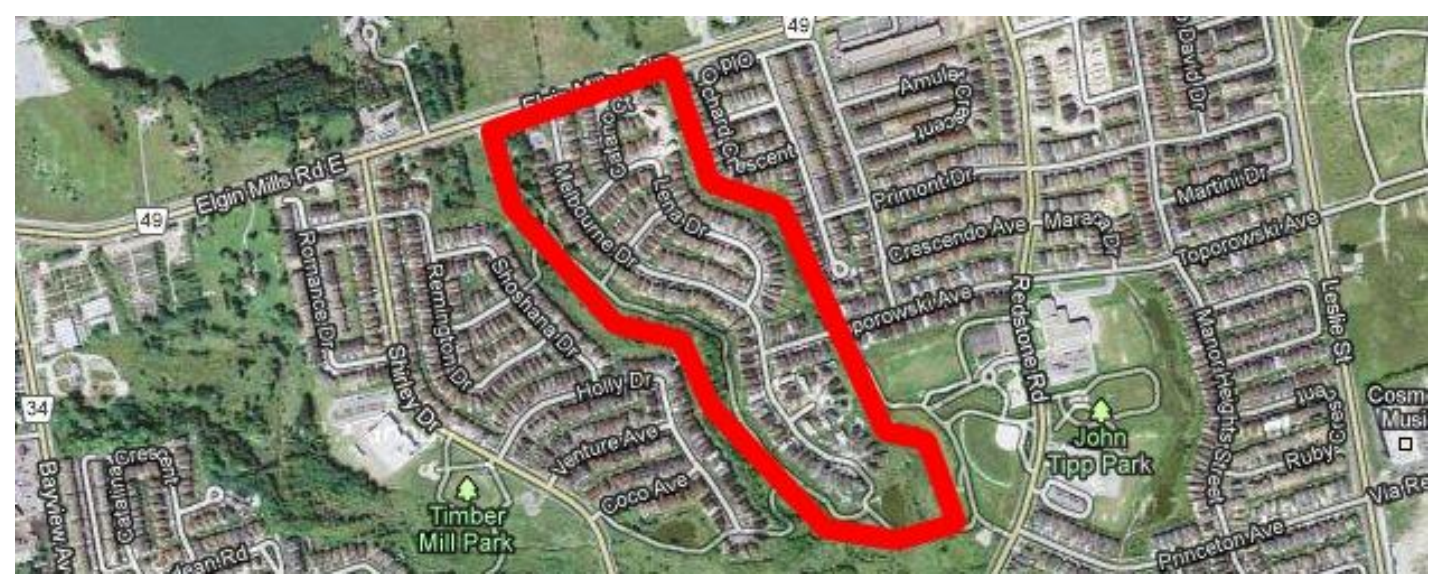

Figure 3 - A satellite picture showing the terrain and drainage area of the subcatchment 


\subsection{FACILITY DESCRIPTION}

Wet Pond 410 drains a residential subcatchment and has a design volume of $4786 \mathrm{~m}^{3}$. It was designed with one inlet, a sediment forebay, and one outlet. The inlet structure consists of a concrete pipe with a $2.0 \mathrm{~m}$ diameter, while the outlet consists of a reverse-sloped pipe with two orifices: the 5-year outlet is $0.08 \mathrm{~m}$ in diameter while the 10 -year outlet is $0.288 \mathrm{~m}$ in diameter. The facility also has a trapezoidal overflow weir which acts as an emergency spillway.

During construction in 1998, an unknown amount of soil and sediment was deposited within the facility by the developer. In 2006, a detailed sediment survey of the pond was carried out by the Town. Later that year, the pond was cleaned out by the developer prior to assumption by the town, as a standard practice. However, the developer opted to remove not only the sediment that had accumulated within the facility but also excavated additional soil from the sides and bottom of the pond. This is not an uncommon practice. The purpose of this is two-fold: to increase the storage capacity of the pond, thereby providing additional protection against flooding, and to increase the time before sediment removal maintenance is required. In 2007, the town carried out another sediment survey on the facility.

\subsection{METEOROLOGICAL DATA}

Continuous hourly precipitation data were collected from gauges at three neighbouring stations: Operations, Buttonville Airport and Pearson Airport. The Operations gauge is the closest in proximity to the pond and is located $0.75 \mathrm{~km}$ north of the study site, as shown in Figure 4. The Buttonville gauge is located $3.9 \mathrm{~km}$ south-east from the site, while the Pearson gauge is significantly further away at $30 \mathrm{~km}$ south-west, as shown in Figure 5. 


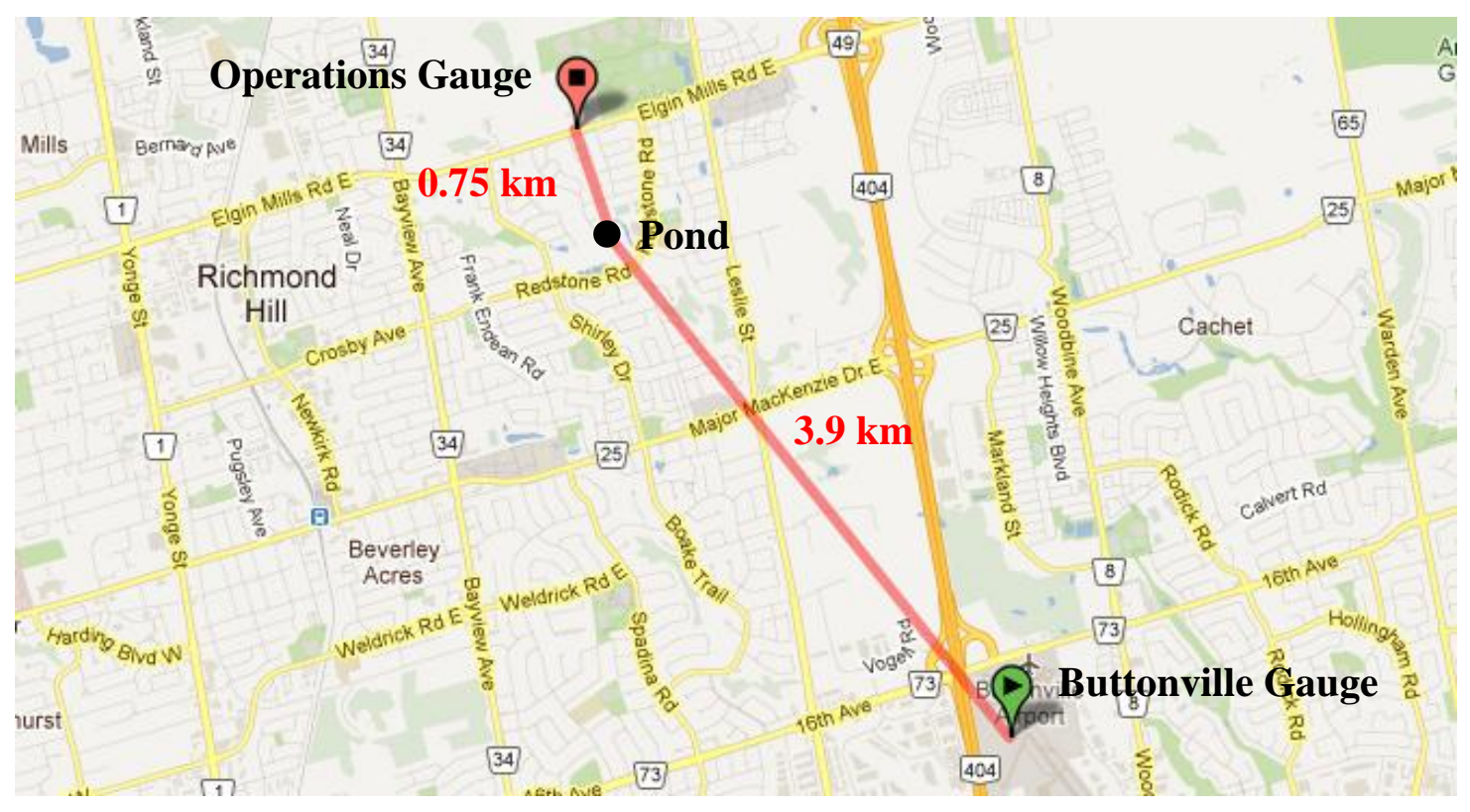

Figure 4 - Map of Operations and Buttonville raingauges and Wet Pond 410

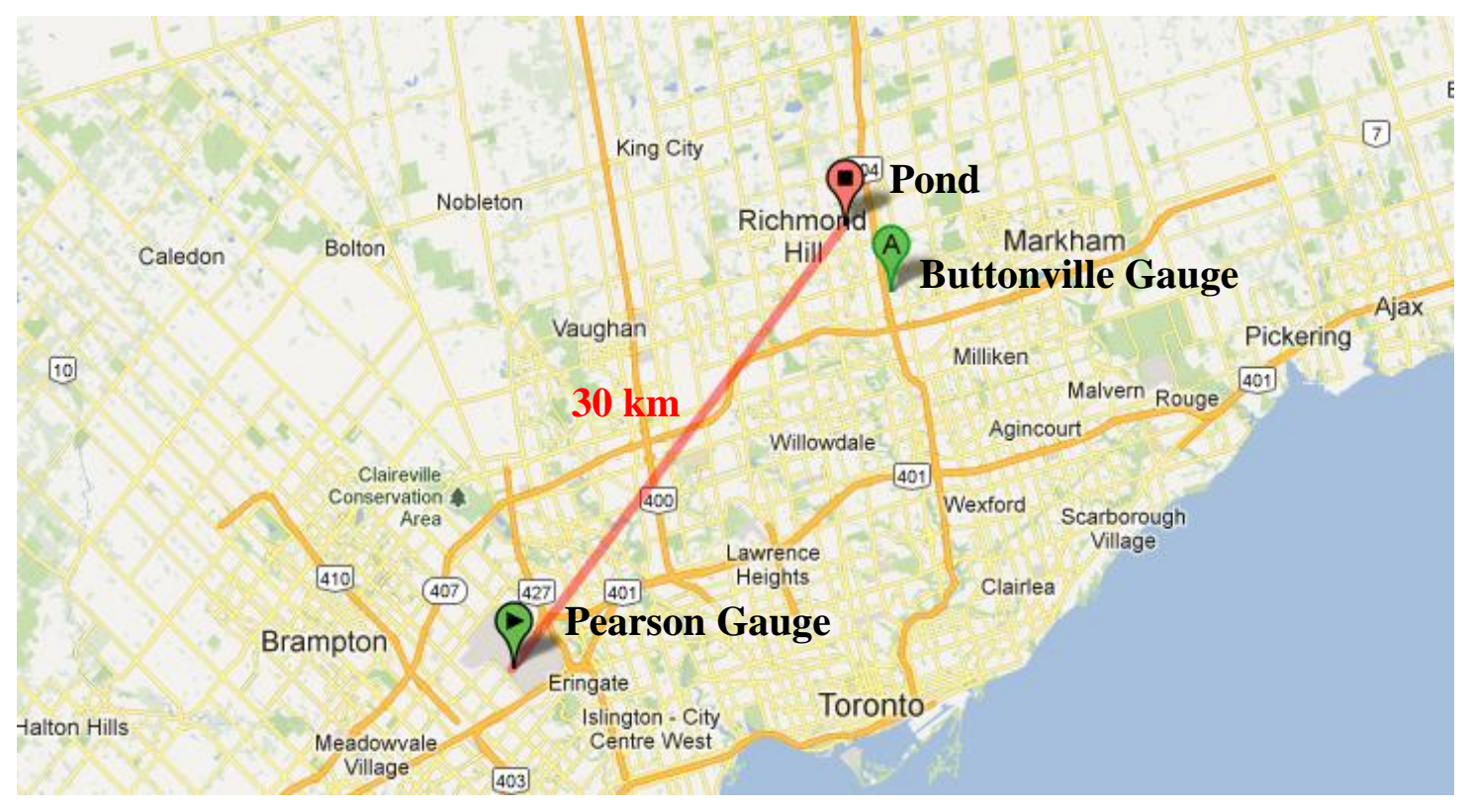

Figure 5 - Map of the Pearson and Buttonville raingauges and Wet Pond 410 
Precipitation data were collected for the period between 1998 and 2011; however, each station has years of missing data as shown in Table 1. Also, the sediment model needs to account for the lack of data during the winter months as most stations do not collect data from November to March. Additionally, the stations have random months of data missing, likely due to instrumentation errors. This means that the sediment accumulation model needs to have some flexibility in order to account for these scenarios.

To account for the missing months of rainfall data, the sediment accumulation model calculates the average buildup during for the months with data and multiplies that value for the months without data to account for the missing accumulation. The annual accumulation is then calculated by adding the buildup for the months with data to the buildup during the months without rainfall data.

Table 1-Continuous hourly raingauge data availability

\begin{tabular}{|c|c|c|c|c|c|}
\hline \multirow[t]{2}{*}{ Gauge } & \multicolumn{5}{|c|}{ Years } \\
\hline & 1960-1994 & 1995-1998 & $1998-2003$ & 2004 & $2007-2011$ \\
\hline Toronto - Pearson Airport & \multirow{3}{*}{\multicolumn{5}{|c|}{ 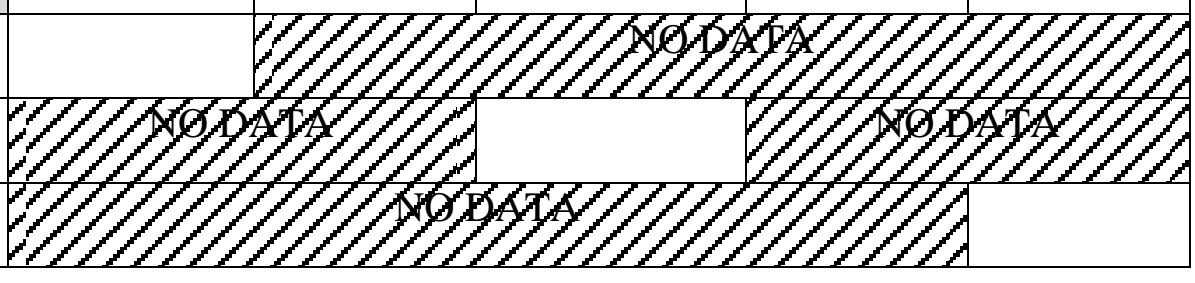 }} \\
\hline Buttonville Airport & & & & & \\
\hline Operatic & & & & & \\
\hline
\end{tabular}




\subsection{DATA COLLECTION}

The data used in this project come primarily from the Town of Richmond Hill in Ontario, as the municipality has had monitoring systems for SWMFs in place for a number of years. The data listed below were used to build the model. Catchment and pond characteristics can be found in the design brief which is available from municipalities. Historic rainfall records are available online from governmental websites.

- Catchment characteristics:

○ Predominant land use in the surrounding areas

○ Tributary area imperviousness (\%)

○ Soil types

○ SWMF drainage area maps and storm-sewer network maps

○ Construction activities in surrounding areas

○ Street-cleaning/street-sweeping frequency (days) and effectiveness (\%)

- Rainfall records

○ Continuous hourly precipitation data $(\mathrm{mm} / \mathrm{h})$

○ Dataset should ideally encompass the duration of the pond's operational history

- Pond characteristics:

- Sediment accumulation data $\left(\mathrm{m}^{3}\right)$

○ Time since last clean-out (months)

○ SWMF characteristics (forebay, number of cells)

- Storage volume $\left(\mathrm{m}^{3}\right)$

○ Surface area $\left(\mathrm{m}^{2}\right)$ 


\subsection{SEDIMENT SURVEYS}

Three sediment surveys were completed on the facility: one just prior to clean-out in 2006, one the following summer in 2007, and one in 2012. The purpose of the first two surveys was to determine the amount of sediment and soil removed from the pond. The purpose of the third sediment survey conducted in 2012 was to determine the rate of sediment accumulation within the facility, by directly comparing 2012 data to 2007 data.

Standard disk-and-rod techniques were utilized by Richmond Hill employees to take measurements of the sediment depth in a grid pattern. Ten transects of the pond were taken, with ten measurements per transect. The depth to the bottom of the pond was only measured once per transect, at the midpoint. This provides a profile of the bottom of the pond from inlet to outlet, which is useful in determining whether any changes have occurred to the facility itself.

The data were placed into a spreadsheet and the pond's cross-section was graphed as shown in Figure 6 and Figure 7, for 2006 and 2007, respectively. Comparing the two figures, it becomes clear how the profile of the pond was modified during clean-out. A sediment forebay is clearly absent in the 2006 profile but, due to the additional excavation by the developer, is quite apparent in the 2007 profile. Calculations using a rectangular approximation technique, as described in Section 3.5, show that approximately $1,523 \mathrm{~m}^{3}$ were excavated from Facility $19-8$ as summarized in Table 2. Note that because of the approximation technique used, the value of the volume as measured from the pond bottom is highly inflated. It will not accurately reflect the actual volume of sediment in the pond if the volume as measured from the top of the sediment is 
subtracted. However, because the same technique is used to calculate the volume as measured from the pond bottom for both years, the difference between them is accurate.

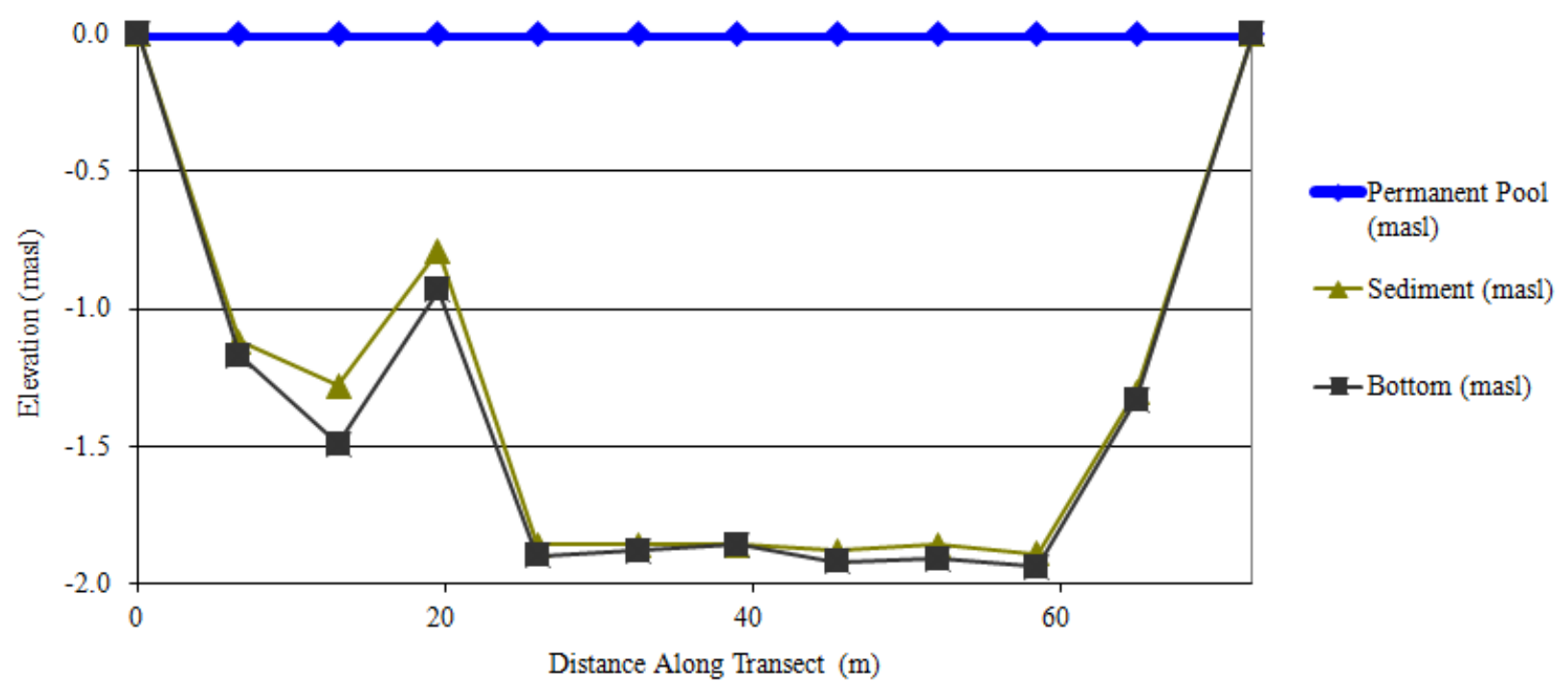

Figure 6 - Sediment survey from 2006 showing the lengthwise cross-sectional average of the pond prior to cleanout

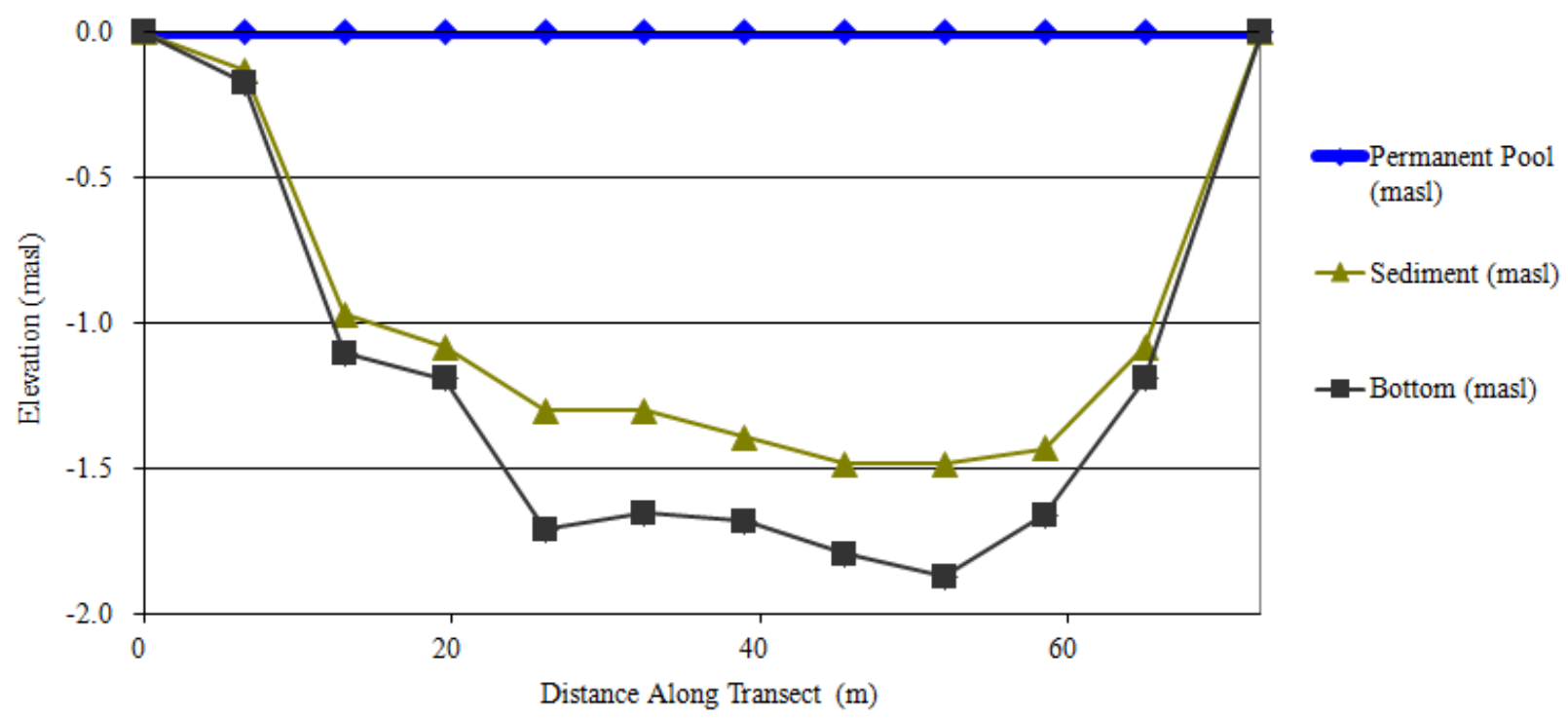

Figure 7 - Sediment survey from 2007 showing the lengthwise cross-sectional average of the pond after cleanout 
Table 2 - Summary of material removed during cleanout in 2007

\begin{tabular}{|c|c|c|}
\hline Year & $\begin{array}{c}\text { Volume as Measured From } \\
\text { Top of Sediment }\left(\mathrm{m}^{3}\right)\end{array}$ & $\begin{array}{c}\text { Volume as Measured } \\
\text { From Pond Bottom }\left(\mathrm{m}^{3}\right)\end{array}$ \\
\hline 2006 & 1463.42 & 5416.45 \\
\hline 2007 & 2065.37 & 6337.50 \\
\hline Difference & 601.95 & 921.05 \\
\hline Total Material Removed $\left(\mathrm{m}^{3}\right)$ & \multicolumn{2}{|c|}{$1,523.00$} \\
\hline
\end{tabular}

\subsection{TOTAL SUSPENDED SOLIDS DATA}

Discrete grab samples were taken inside the pond within an hour of a large rainfall event, and showed a TSS range of 1-98 $\mathrm{mg} / \mathrm{L}$, depending on the rainfall event. Since only a few events were monitored for TSS over the course of a few years, these values were used only to verify that the model was producing TSS values that were within the acceptable range.

\subsection{MATHEMATICAL/SOFTWARE SIMULATION}

The primary software used in this project was the Storm Water Management Model (SWMM) Version 5.0.021 provided by the US Environmental Protection Agency (EPA). This software was chosen for a number of reasons. First, it has been used in thousands of studies already (United States Environmental Protection Agency, 2010) and is excellent at simulating non-point pollution sources and the transport of chemicals and pollutants through the urban water cycle. This makes it aptly suited for implementing the mathematical model developed in this project. The software has the ability to incorporate various hydrologic processes including precipitation events, surface flow processes, and water infiltration into soil and subsoil regions. 
Particularly useful is the ability of SWMM to model artificial channels and pipes much like the ones found at the inlet and outlet of stormwater management ponds.

As mentioned previously, this undertaking consisted of two parts: first, SWMM was used to create a sediment accumulation model, and second, two methodologies were developed to determine the maintenance frequency based on cost and performance. 


\section{CHAPTER 3: DEVELOPMENT OF THE SEDIMENT ACCUMULATION MODEL}

This chapter describes the steps involved in developing the sediment accumulation model. Note that the sediment accumulation model consists of two distinct parts: a water quantity model and a water quality model. First, SWMM was used to model the hydrology of the subcatchment. A sensitivity analysis was then performed on each parameter to see which ones were insensitive variables and which ones affected the output the most. The model was calibrated using the measured rainfall and runoff data. The water quality model was then built on top of the quantity model using the pollutant editor in SWMM to apply pollutant buildup, washoff and treatment functions. A sensitivity analysis was performed, followed by calibration using data from another study of ponds in the Richmond Hill area. The model was validated by comparing model results to sediment accumulation data from the pond cleanouts.

\subsection{SYSTEM REPRESENTATION IN SWMM}

The entire subcatchment and drainage system was modelled in SWMM, with each component modelled as an object with unique properties, as shown in Figure 8. In this model, rainfall on the subcatchment is converted into runoff which drains to the stormwater pond. The treated runoff is then proceeds through the orifices or weir, and is then discharged from an outfall. During a simulation, SWMM dynamically calculates and updates the hydrogeologic processes and pollutant loads at each point in the system, and allows the user to view the results in a variety of formats. 


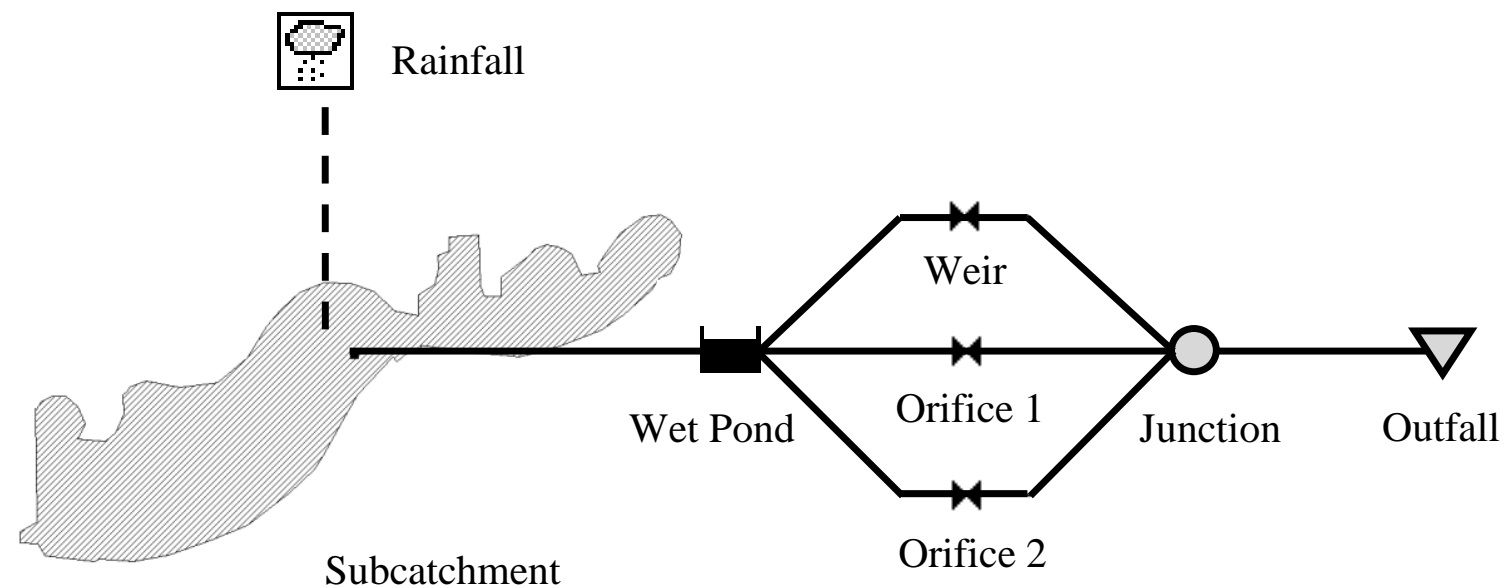

Figure 8 - System representation in SWMM

\subsection{WATER QUANTITY MODEL}

The numerical values used in the model for the subcatchment, pond, and drainage systems were taken from the design brief and soil surveys (Town of Richmond Hill, 1997), with the exception of the percent pervious and impervious area, which were calculated as described in the section below.

\subsubsection{Determining Impervious Parameters}

The parameter, “\% Zero Imperv” in SWMM is defined as the percent of impervious area with no depression storage. This includes roads, sidewalks and driveways. Roofs are not included, as in this particular subcatchment, downspouts have been disconnected and roofs now drain to lawns. The parameter "\% Imperv" on the other hand, consists of all impervious surfaces, including roofs.

In order to determine the pervious and impervious surface area of the subcatchment, the following methodology was used. First, a high resolution, visible light, satellite image of the 
subcatchment was acquired. Then using imaging software, impervious surfaces such as roads, sidewalks and driveways were coloured in black, while roofs were coloured in red, as shown in Figure 9. Using the histogram tool, the number of red and black pixels can be compared to the total number of pixels in the subwatershed to determine the appropriate parameter. A summary of the calculations and values are shown in Table 3.

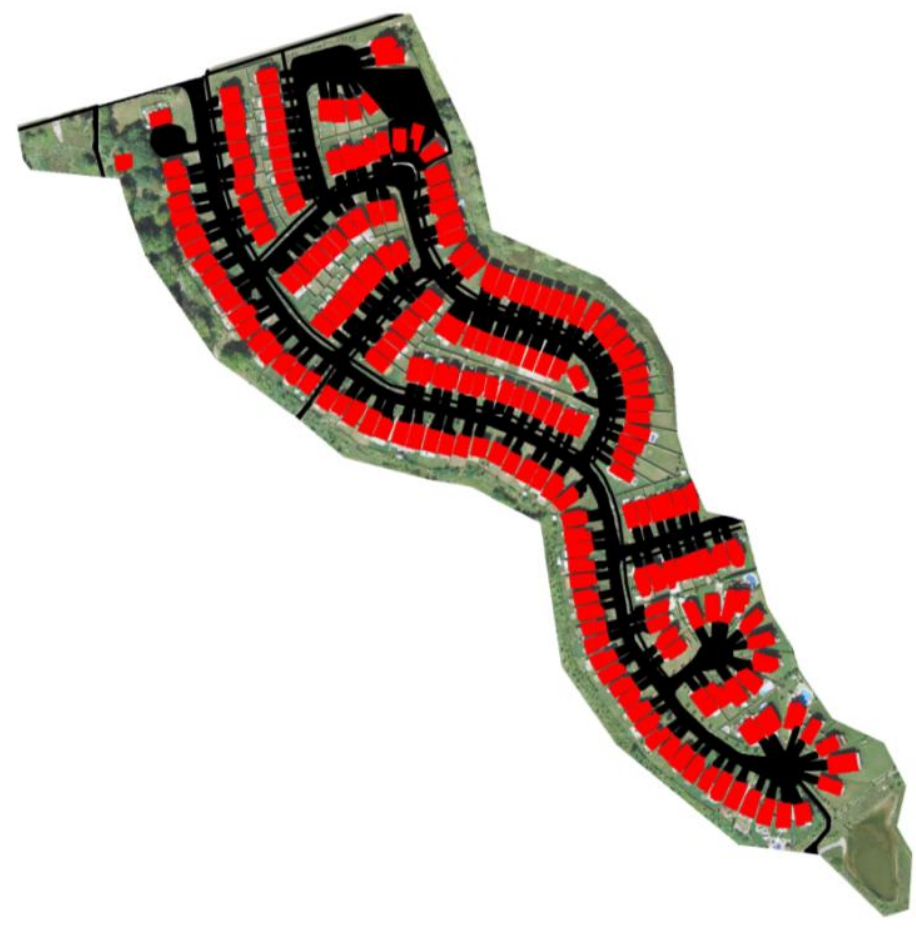

Figure 9 - Subcatchment with roofs in red and other impervious surfaces in black

Table 3 - Percent zero impervious and percent impervious

\begin{tabular}{|c|c|c|}
\hline Parameter & (Coloured Pixels/Total Pixels)*100 & Value \\
\hline$\%$ Zero Imperv & $(187919 / 840169) * 100$ & $22.4 \%$ \\
\hline$\%$ Imperv & $(410802 / 840169) * 100$ & $48.9 \%$ \\
\hline
\end{tabular}




\subsubsection{Sensitivity Analysis}

Sensitivity analysis was performed on 33 variables in the water quantity model. This was accomplished by holding all the parameters constant except for the parameter being tested, and running a simulated rainfall event. The percent change in output, in this case the peak water level (commonly referred to as the peak head) in the pond, was then recorded. Usually in a sensitivity analysis, the input parameter is tested within a range of $\pm 25 \%$ of the recommended value (James, 2005); however, due to the large variability in acceptable input values, a range of $\pm 50 \%$ was used instead. Of the 33 parameters tested, only 11 were shown to directly affect the peak head, and these parameters showed a high degree of linearity with the output. The sensitivity analysis graphs can be found in Appendix B, while the summarized results are shown in Table 4. Note that the summarized results are only meant to show the extent of each parameter's influence on the output. The variables that had the most effect on the output were the subcatchment area, the percent of impervious area, the invert elevation in the pond, the initial depth of water in the facility, and the conductivity of the soil in the pond. 
Table 4 - Summary of sensitivity analysis on SWMM parameters

\begin{tabular}{|l|c|c|}
\hline \multirow{4}{*}{ Parameter Category } & Parameter & $\begin{array}{c}\text { Maximum Percent } \\
\text { Change in Output }\end{array}$ \\
\hline Subcatchment Properties & Area & 0.059 \\
\cline { 2 - 3 } & Width & 0.0015 \\
\cline { 2 - 3 } & Slope & 0.00066 \\
\cline { 2 - 3 } & \% Imperv & 0.059 \\
\cline { 2 - 3 } & N-Imperv & 0.00084 \\
\cline { 2 - 3 } & Dstore-Imperv & 0.0021 \\
\cline { 2 - 3 } & \%Zero-Imperv & 0.00070 \\
\hline Storage Unit Properties & Invert Elevation & 0.27 \\
\cline { 2 - 3 } & Initial Depth & 0.29 \\
\cline { 2 - 3 } & Conductivity & 0.11 \\
\cline { 2 - 3 } & Discharge Coefficient & 0.0032 \\
\hline
\end{tabular}

\subsubsection{Calibration}

The water quantity model was calibrated on an event-based method. For each rainfall event, the water level from the model was compared to historical facility elevation data. More specifically, both the shape of the graphs of the water elevation data, and the peak head, were compared. The calibration graphs can be found in Appendix D, while the summarized results are shown in Table 5. 
Table 5 - Calibration summary of water quantity parameters

\begin{tabular}{|c|c|c|}
\hline Rainfall Event & $\begin{array}{c}\text { Percent Difference Between } \\
\text { Peak Water Level in Model } \\
\text { and Measurements (\%) }\end{array}$ & $\begin{array}{c}\text { Elevation Difference Between } \\
\text { Model and Measurements (m) }\end{array}$ \\
\hline August 24-27, 2007 & 0.0292 & 0.0624 \\
\hline Sept. 5-7, 2007 & 0.0458 & 0.0979 \\
\hline Oct. 6-9, 2007 & 0.0697 & -0.0200 \\
\hline Sept. 13-16, 2008 & 0.0094 & 0.0053 \\
\hline Sept. 30 - Oct. 2, 2008 & 0.0025 & 0.0068 \\
\hline Oct. 24-27, 2008 & 0.0032 & -0.1172 \\
\hline Nov. 14-17, 2008 & 0.0548 & -0.0400 \\
\hline May 9-12, 2009 & 0.0187 & -0.0338 \\
\hline May 27-30, 2009 & 0.0416 & \\
\hline
\end{tabular}

Calibration showed that while the percent difference between the model and the measured values was very low, as shown in Figure 10 the actual elevation difference was too high, as shown in Figure 11. 


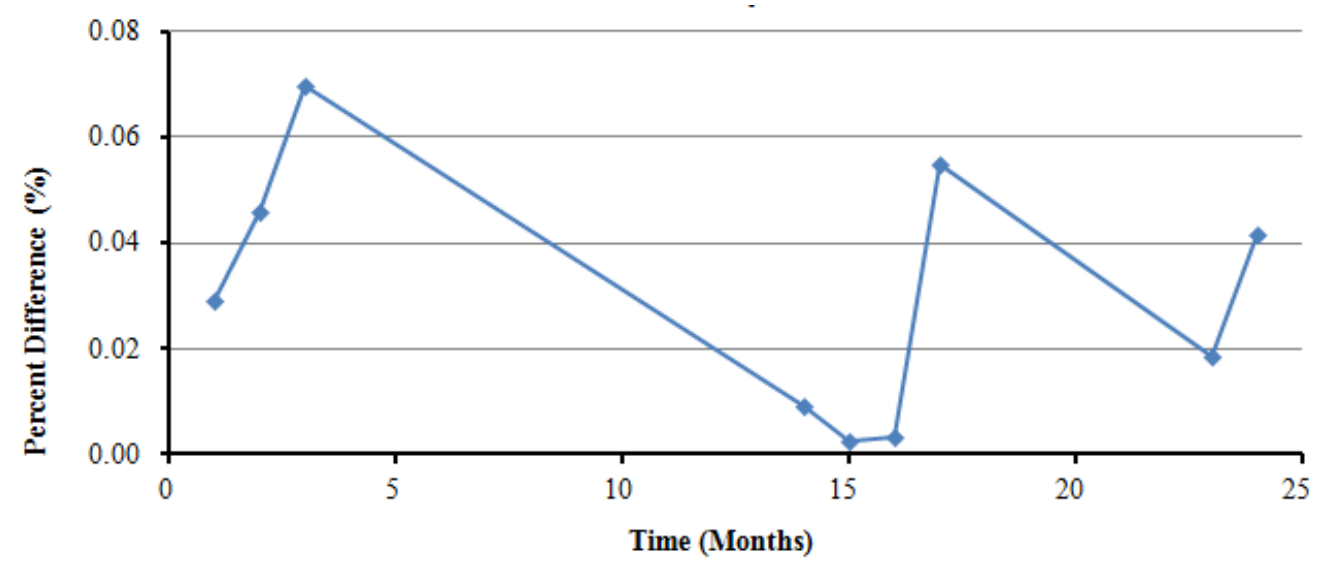

Figure 10 - Percent difference between model and measurements for rain events between Aug.

24, 2007 and May 30, 2009

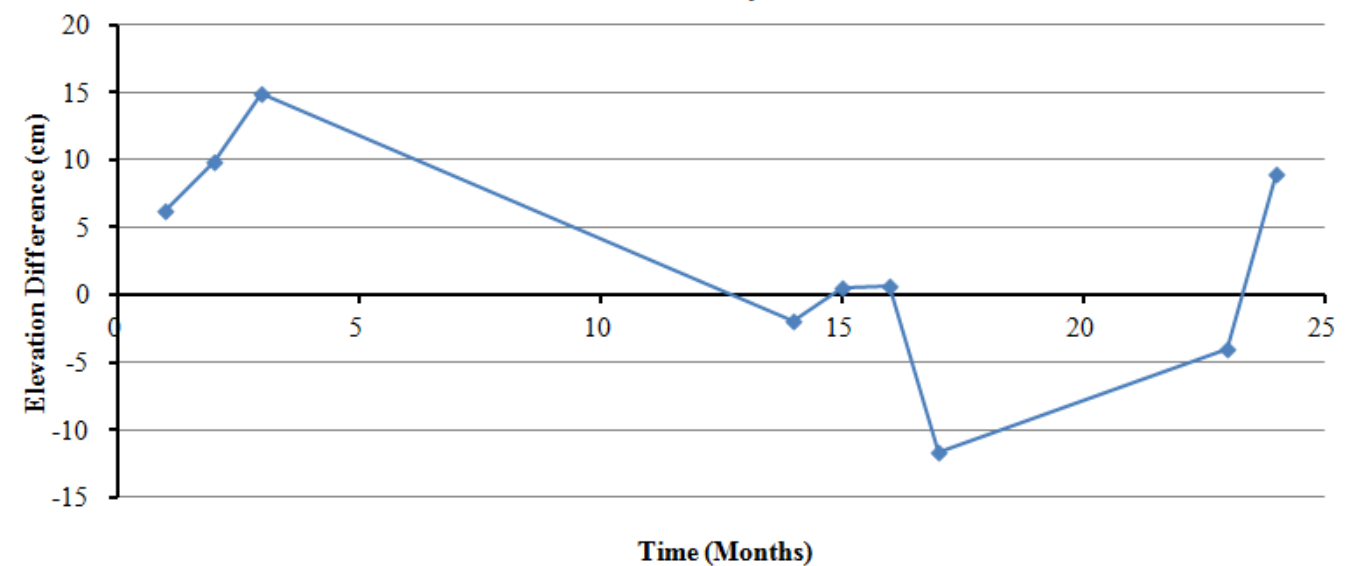

Figure 11 - Elevation difference between model and measurements for rain events between Aug. 24, 2007 and May 30, 2009

Another issue recognized during event-based calibration of the sediment accumulation model was the fluctuation in the initial water level in the facility. Further inspection showed that prior to cleanout in 2007, the average initial water level of the pond was often more than $0.3 \mathrm{~m}$ higher than the permanent pool design elevation of $213.5 \mathrm{~m}$. After cleanout, however, this problem does not arise, as shown in Figure 12. 


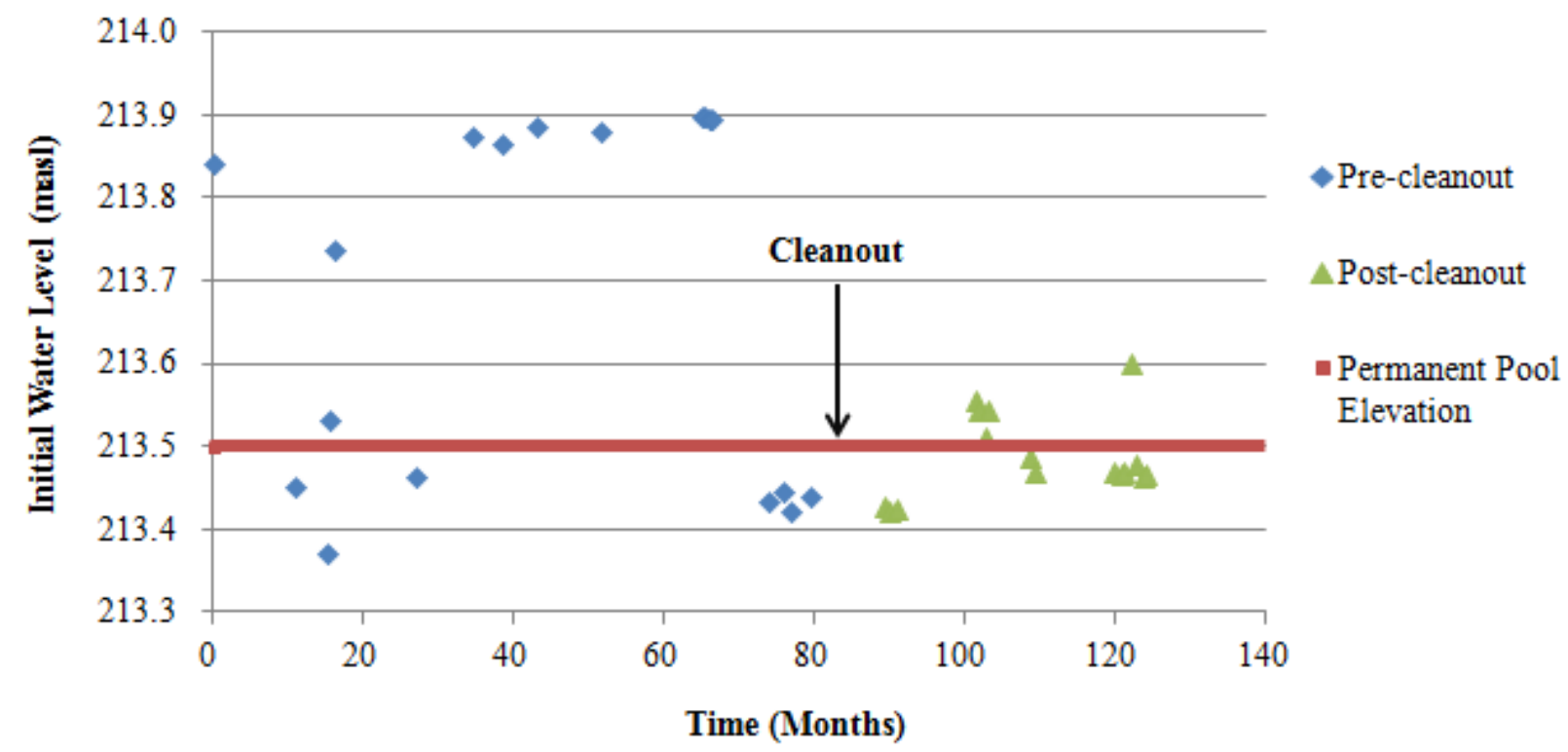

Figure 12 - Initial water level of pond before rainfall events from June 2000-Oct. 2010

These issues were occurring because the model did not take into account the change in pond geometry due to sediment accumulation over the years. Because SWMM does not inherently support dynamic changes to the pond profile, the problem was rectified by adding a tool to the final sediment accumulation model that uses the annual sediment buildup to update the pond profile. More information about this Pond Geometry Calculator tool can be found in Section 3.4 and in Appendix F. Prior to cleanout in 2007, the water level in the facility stayed elevated after a rainfall event, as shown in Figure 13. This finding was unusual as the pond was designed to drain to the permanent pool level within the drawdown time of 95 hours, as shown in Figure 14. After consultations with officials from Richmond Hill, it was determined that the most likely cause was debris or sediment blocking the discharge orifices. This scenario is difficult to account for within a stormwater model, as blockages occur unpredictably. However, there is no such issue after the cleanout in 2007, indicating that sediment buildup likely played a role as well. 


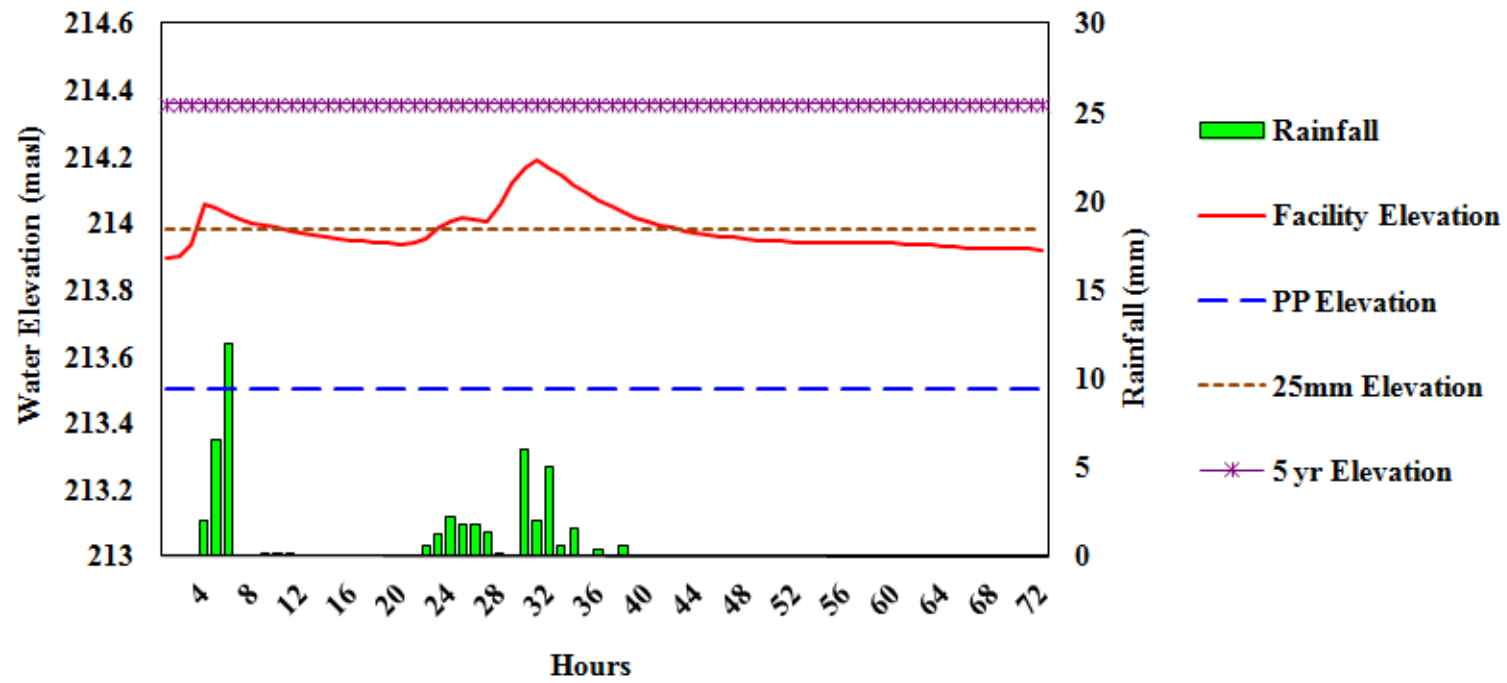

Figure 13 - Facility elevation versus time after a rainfall event showing a lack of proper drainage

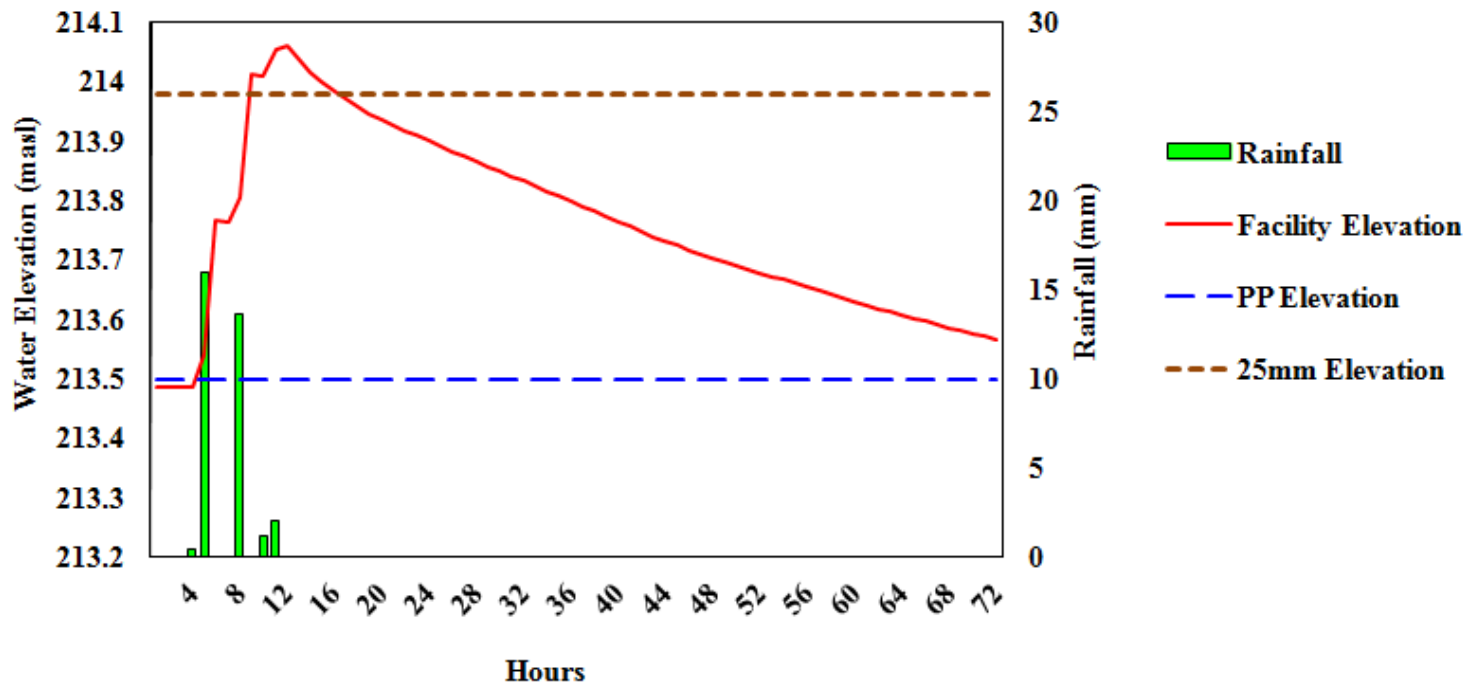

Figure 14 - Facility elevation versus time after a rainfall event showing proper drainage 


\subsection{WATER QUALITY MODEL}

As adequate water quality data were unavailable for this facility, the particle size distribution and the water quality parameters were taken from another study of ponds in Richmond Hill conducted by Krasnova in 2004.

\subsubsection{Sensitivity Analysis}

Sensitivity analysis was performed on 12 variables in the water quantity model. This was accomplished by holding all the parameters constant except for the parameter being tested, and running a simulated rainfall event. The percent change in output, in this case the maximum total suspended solids (TSS) concentration in the pond, was then recorded. Again, due to the large variability in acceptable input values, a range of $\pm 50 \%$ was used. Of the 12 parameters tested, only 6 were shown to directly affect the TSS concentration. The sensitivity analysis graphs can be found in Appendix $\mathrm{C}$, while the summarized results are shown in Table 6. Note that the summarized results are only meant to show the extent of each parameter's influence on the output. The variables that had the most effect on the output were the washoff exponent, washoff coefficient and the maximum buildup of sediment per unit area. Of the parameters tested, only two showed significant non-linearity: the days since last swept, and the rate constant of buildup of sediment per unit area per day. 
Table 6 - Summary of sensitivity analysis on water quality parameters

\begin{tabular}{|c|c|}
\hline Parameter & $\begin{array}{c}\text { Maximum Percent } \\
\text { Change in Output }\end{array}$ \\
\hline Availability & 0.87 \\
\hline Last Swept & 1.71 \\
\hline Max. Buildup & 10.39 \\
\hline Rate Constant & 1.59 \\
\hline Washoff Coefficient & 9.03 \\
\hline Washoff Exponent & 25.33 \\
\hline Cleaning Efficiency & 0.87 \\
\hline
\end{tabular}

\subsubsection{Calibration}

\subsubsection{Buildup and Washoff Functions}

The water quality model was calibrated using parameters from a study of ponds in Richmond Hill conducted by Krasnova in 2004. This calibration method was chosen due to a lack of continuous TSS data at the pond inlet and outlet. The imported parameters are listed in Table 7.

Table 7 - Imported water quality parameters

\begin{tabular}{|c|c|}
\hline Parameter & Calibrated Value \\
\hline Max Buildup & 222 \\
\hline Rate Constant & 1 \\
\hline Washoff Coefficient & 0.133 \\
\hline Washoff Exponent & 1.122 \\
\hline
\end{tabular}


The exponential buildup and washoff functions are shown below as Equations 1 and 2, respectively.

$$
B=C_{1}\left(1-e^{-C_{2} t}\right)
$$

Equation 1

Where $\boldsymbol{B}$ is the buildup in $\mathrm{kg} / \mathrm{ha}, \boldsymbol{C}_{\boldsymbol{1}}$ is the maximum possible buildup in $\mathrm{kg} /(\mathrm{curb} \cdot \mathrm{m}), \boldsymbol{C}_{\boldsymbol{2}}$ is the buildup rate constant in units of days ${ }^{-1}$, and $t$ is the time in days.

$$
W=C_{1} q^{C_{n}} B
$$

Equation 2

Where $W$ is the washoff load in $\mathrm{kg} / \mathrm{hr}, \boldsymbol{C}_{\boldsymbol{1}}$ is the washoff coefficient, $\boldsymbol{q}$ is the runoff rate per unit area in $\mathrm{mm} /(\mathrm{hr} \cdot \mathrm{ha}), \boldsymbol{C}_{2}$ is the washoff exponent, and $\boldsymbol{B}$ is the total pollutant buildup mass in $\mathrm{kg}$.

\subsubsection{Treatment Function}

An exponential decay treatment function was used to calculate the removal and settling of suspended solids within the pond. This equation is recommended in the SWMM Applications Manual, and is shown below (United States Environmental Protection Agency, 2009):

$$
C_{t+\Delta t}=C^{*}+\left(C_{t}-C^{*}\right) e^{-\left(\frac{k}{d}\right) \Delta t}
$$

Equation 3

Where $C_{t}$ is the TSS concentration at time $t$ in $\mathrm{mg} / \mathrm{L}, C^{*}$ is the concentration of nonsettleable suspended solids in $\mathrm{mg} / \mathrm{L}, \boldsymbol{k}$ is a fitting parameter that corresponds to the settling velocity of the suspended solid particles in $\mathrm{m} / \mathrm{s}, \boldsymbol{d}$ is the water depth in meters, and $\Delta t$ is the time step in seconds. By assuming that a wet pond functions similarly to a primary clarifier in a water 
treatment plant, a value of $45 \mathrm{mg} / \mathrm{L}$ was used for C* (Wahlberg \& Tarpey, 2003). The parameter $\boldsymbol{k}$ or $\boldsymbol{\omega}$ can be calculated using Stoke's Law, as shown below:

$$
\begin{array}{ll}
k=\omega=\frac{g D^{2}\left(\rho_{s}-1\right)}{18 v} & \text { Equation } 4
\end{array}
$$

Where $\boldsymbol{g}$ is the acceleration due to gravity $\left(9.81 \mathrm{~m} / \mathrm{s}^{2}\right), \boldsymbol{D}$ is particle diameter, $\rho_{\boldsymbol{s}}$ is the specific gravity of the sediment particles and $\boldsymbol{\nu}$ is the kinematic viscosity of water $\left(1.004 \times 10^{-6}\right.$ $\left.\mathrm{m}^{2} / \mathrm{s}\right)$. Because detailed sediment quality data were not available for this facility, the particle size distribution (PSD) from another study of wet ponds within Richmond Hill was used to determine $\rho_{\boldsymbol{s}}$ and $\boldsymbol{D}$. The PSD shows that approximately $95 \%$ of the total sediment entering the pond consists of particles smaller than $40 \mu \mathrm{m}$, corresponding to clay and silt (Krasnova, 2004). Since MOE guidelines target particles that are at least $40 \mu \mathrm{m}$ in size (Pyatt, 2003), it can be assumed that smaller particles are not adequately trapped within the forebay. The remaining $5 \%$ of particles that are larger than $40 \mu \mathrm{m}$ can be classified as sand, corresponding to a $\rho_{\boldsymbol{s}}$ value of 2.65 , with a median size $(D)$ of $200 \mu \mathrm{m}$. Substituting these values into Equation 4 provides a settling velocity of $0.0358 \mathrm{~m} / \mathrm{s}$. Equation 3 is then implemented as a treatment function in the SWMM sediment accumulation models as shown below:

$$
\mathrm{C}=45+(\mathrm{TSS}-45) * \mathrm{e}^{(0.0358 * \mathrm{DT} / \mathrm{DEPTH})} \quad \text { Equation } 5
$$

Where $\mathbf{C}$ is the outlet concentration in $\mathrm{mg} / \mathrm{L}$, DT is the routing time step in seconds, DEPTH is the dynamic water depth above the node invert in meters, and TSS is the dynamic suspended solids concentration. At each time step, SWMM uses the equation above to update the suspended solids concentration within the storage unit. 


\subsection{SEDIMENT ACCUMULATION FUNCTIONALITY}

Although SWMM is a very powerful tool, it lacks the capability to model sediment buildup in the pond, during a simulation. This is not a significant issue when running eventbased simulations; however, for continuous, long-term simulations, the program must be stopped in order to incorporate sediment buildup into the model. For this reason, a tool was created to convert the annual sediment mass loading provided by SWMM, into a volumetric value. The tool then uses frustums to convert the sediment volume into a new pond profile, to be used for the following year's model. Figure 15 shows how the pond geometry changes over time, as sediment builds up within the facility. A complete description of the Pond Geometry Calculator tool can be found in Appendix F. 


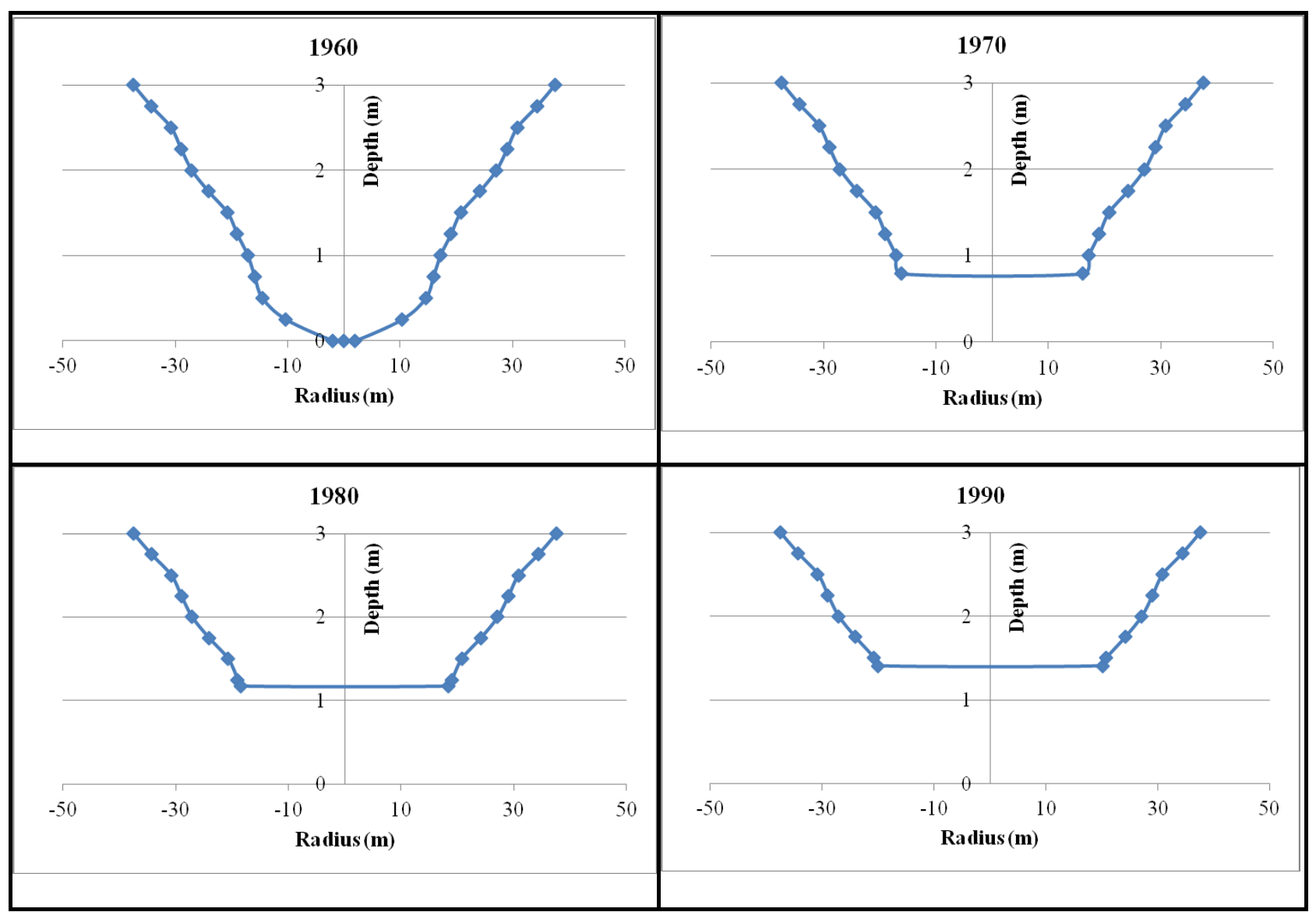

Figure 15 - Illustration showing how the pond profile changes over the years due to sediment accumulation

\subsection{MODEL VALIDATION}

In order to validate the model, the sediment buildup from SWMM was compared to the actual buildup in the pond between the years of 2007 and 2012. Historical rainfall data for these years were input into the sediment accumulation model, and a continuous simulation was performed. This six-year time period was chosen because a cleanout occurred in 2007, and sediment surveys were performed in both 2007 and 2012, providing an accurate picture of the 
pond geometry. The amount of sediment accumulation within the pond was calculated as shown below.

The sediment surveys were performed using a disk-and-rod method, which measured the depth to the sediment. Ten transects of the pond were taken, with ten measurements per transect, providing a grid with 100 data points. If each point is approximated as a rectangular column, the volume of water above the sediment can be calculated, as shown in Figure 16.

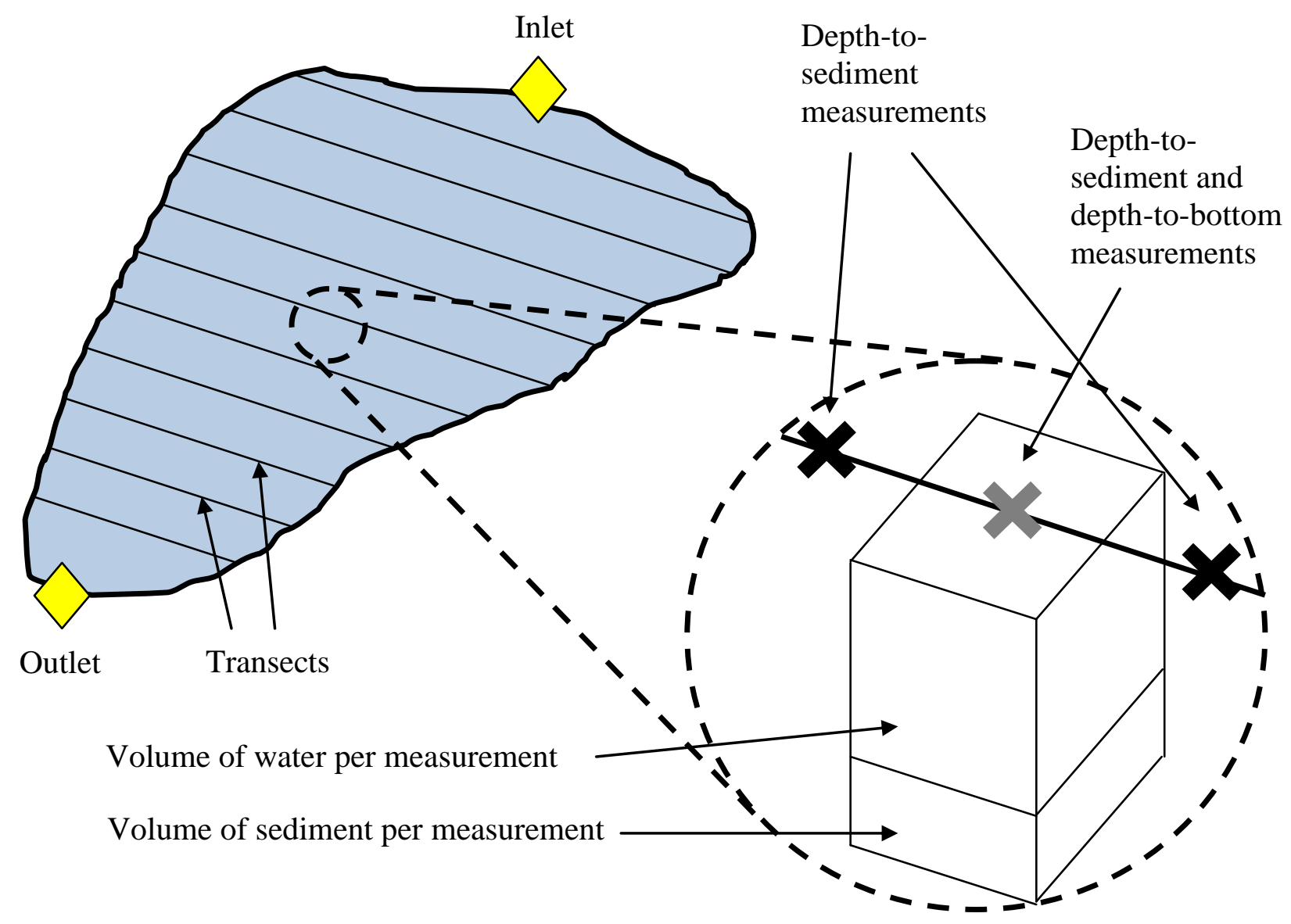

Figure 16 - Illustration of how the pond volume and sediment volume were calculated using rectangular columns 
Adding the volume of the individual water columns together then provides the total volume of water within the facility, and the loss in water volume over time correlates to the amount of sediment buildup in the pond. However, the bottom of the pond had changed as well over the years, as shown in Figure 17 and Figure 18. The elevation units are meters above sea level.

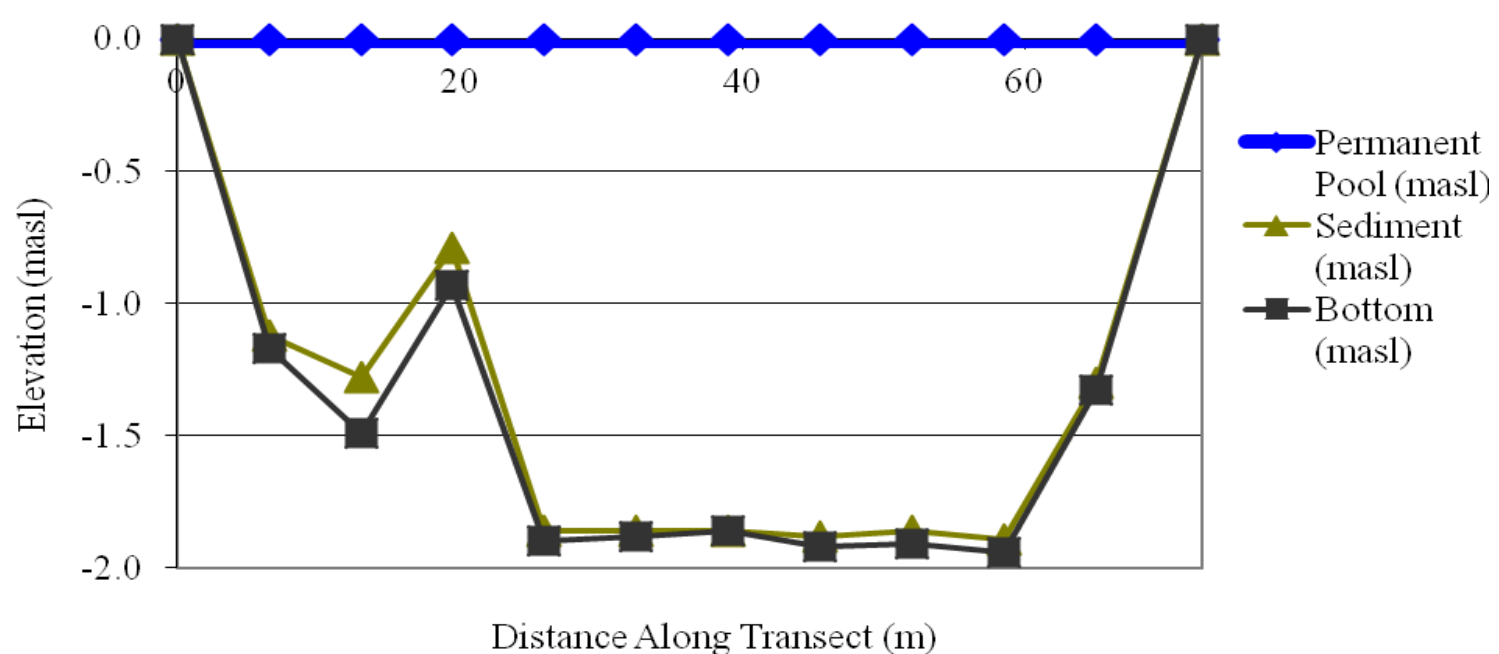

Figure 17 - Lengthwise cross-section of the pond in 2007 after cleanout

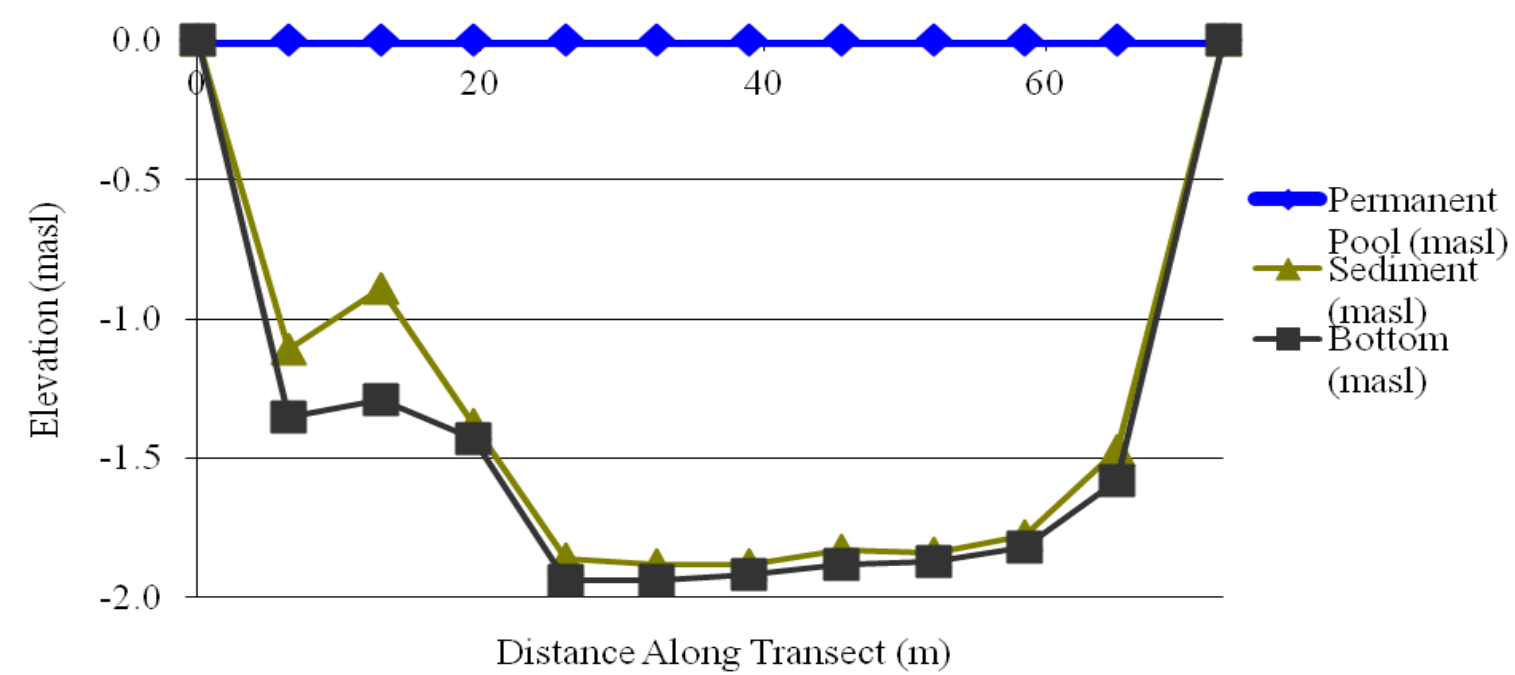

Figure 18 - Lengthwise cross-section of the pond in 2012 
In order to estimate the volumetric change of the facility's capacity between 2007 and 2012, the same rectangular column technique was applied. However, because only one measurement of the bottom was taken per transect, this provides a very rough approximation when applied over the width of the pond. Nevertheless, Table 8 shows that between 2007 and 2012, $236.06 \mathrm{~m}^{3}$ of sediment was captured in the facility, while the sediment accumulation model shows a buildup of $260.15 \mathrm{~m}^{3}$. The percent difference between the model and measurements is $9.71 \%$, which indicates that the model is generally in good agreement with the measurements. The measured accumulation rate of $47.21 \mathrm{~m}^{3} /$ year or $4.52 \mathrm{~m}^{3} / \mathrm{ha} /$ year is similar to data collected from other ponds in Richmond Hill, which have sedimentation rates between 3.2 $\mathrm{m}^{3} / \mathrm{ha}$ and $5.1 \mathrm{~m}^{3} /$ ha (Pyatt, 2003; Renata, 2004). Other case studies of ponds in Ontario show average sedimentation rates between $0.2 \mathrm{~m}^{3} /$ ha/year and $5.8 \mathrm{~m}^{3} /$ ha/year (Greenland International Consulting Inc., 1999).

Table 8 - Summary of sediment accumulation calculations

\begin{tabular}{|c|c|c|}
\hline Year & $\begin{array}{c}\text { Volume as Measured From } \\
\text { Top of Sediment }\left(\mathrm{m}^{3}\right)\end{array}$ & $\begin{array}{c}\text { Volume as Measured } \\
\text { From Pond Bottom }\left(\mathrm{m}^{3}\right)\end{array}$ \\
\hline 2007 & 2065.37 & 6337.50 \\
\hline 2012 & 2015.21 & 6523.40 \\
\hline \hline Difference & 50.16 & 185.90 \\
\hline Total Sediment Accumulation $\left(\mathrm{m}^{3}\right)$ & \multicolumn{2}{|c|}{236.06} \\
\hline
\end{tabular}




\subsection{SEDIMENT ACCUMULATION MODEL FUNCTIONALITY}

The sediment accumulation model consists of a number of individual tools that work together in the manner shown in Figure 19. First, the annual rainfall and the pond storage curve are input directly into SWMM. The simulation is run for one year and provides both the annual mass of sediment into the facility, and the annual mass of sediment treated. These two values are then placed into a spreadsheet that requires the user to input the number of months of missing rainfall data. It then calculates the annual removal efficiency, the annual sediment buildup and the cumulative sediment buildup from previous years (if applicable). It also converts the sediment accumulation from mass to volume. The cumulative sediment volume is then input into the Pond Geometry Calculator to create a new pond profile which is used in the following year's model. The entire process is repeated for as many years as desired. In this manner, the sediment accumulation within a facility can be modelled using a continuous, long-term simulation, and is very similar to the methodology proposed by the Ontario Ministry of the Environment in its 2003 Stormwater Management Planning and Design Manual. Additional information on each tool can be found in Appendix F. 


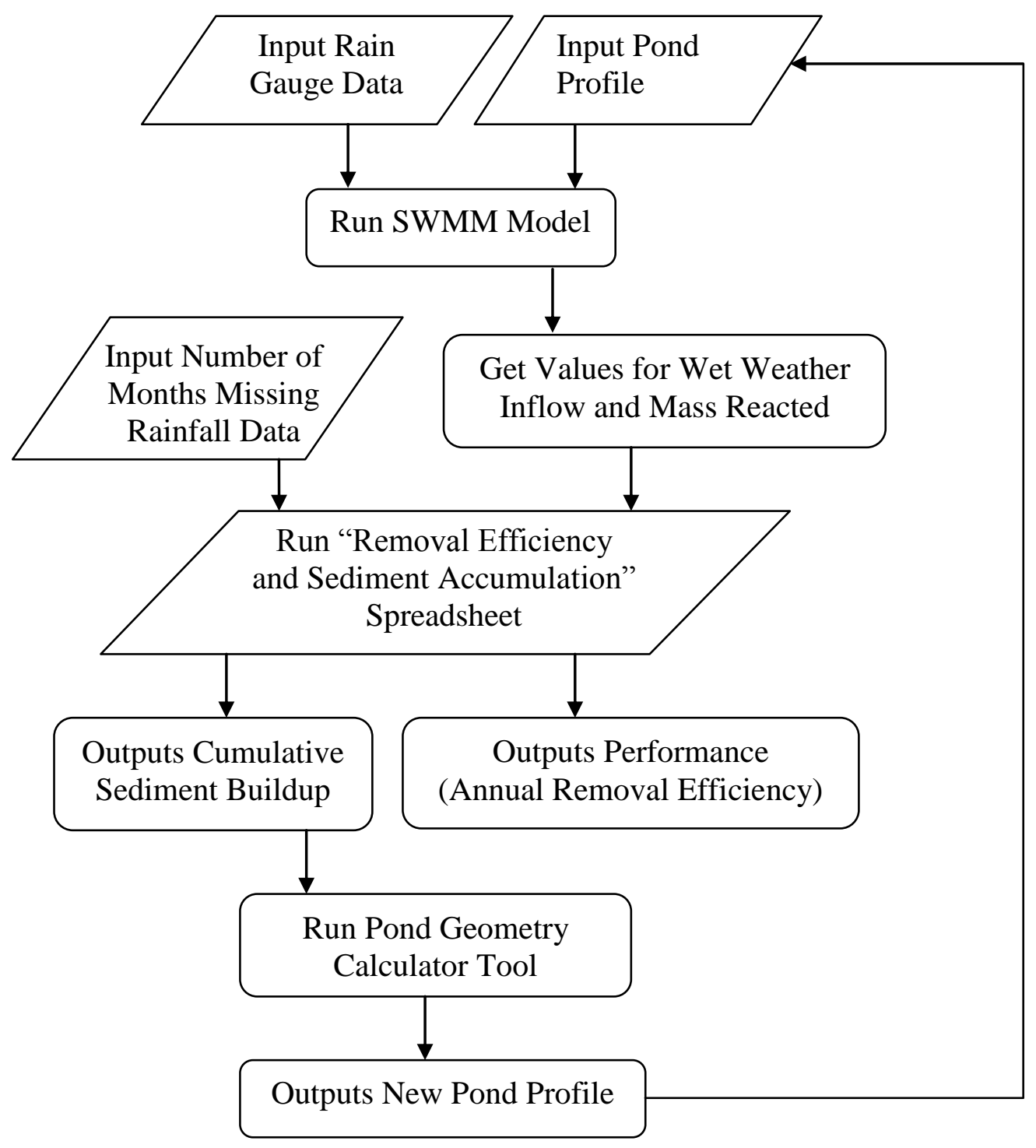

Figure 19 - Sediment accumulation model flowchart 


\section{CHAPTER 4: METHODOLOGIES FOR DETERMINING SEDIMENT REMOVAL FREQUENCY}

Two methodologies were developed for determining the appropriate sediment removal frequency of a wet-detention stormwater management facility. The first method provides the required time for a single cleanout, while the second is more of a decision-making tool. Both are described in the following sections, along with how the cleanout costs were calculated.

\subsection{CLEANOUT COSTS}

While data about total cleanout costs and cost factors are available from a number of studies, data for cleanout costs based on the amount of sediment removed are lacking. This is because contractors are unwilling to release cost breakdowns to municipalities. Therefore, this model assumes that the total cleanout cost has two components: a fixed-cost, and a variable-cost based on how much sediment is removed. Equation 1 is used to calculate the cleanout cost $\boldsymbol{C}$, is shown below:

$$
\begin{array}{ll}
C=F+m v^{n} & \text { Equation } 1
\end{array}
$$

Where $\boldsymbol{F}$ is the fixed cost in dollars, $\boldsymbol{m}$ is the cost factor $\left(\$ / \mathrm{m}^{3}\right), \boldsymbol{V}$ is the volume of sediment removed, and $\boldsymbol{n}$ is a scaling factor. The cost factor depends heavily on the sediment removal technique used, due to equipment and dewatering costs, and the level of contamination present, which determines remediation and disposal fees. Studies have shown that the cost factor can vary between $\$ 14 / \mathrm{m}^{3}$ to $\$ 669 / \mathrm{m}^{3}$ in 1997 dollars (Greenland International Consulting Inc., 1999); therefore extra caution should be exercised when choosing an appropriate value. The 
scaling factor $\boldsymbol{n}$, is used to account for quantity-based discounting and takes on values between 0 and 1 , where 1 implies no discounting is used.

A cleanout cost that is incurred in year $y$ can be expressed as a capital cost in the first year of the pond's operation using Equation 2. This is useful if the municipality decides to set aside the money for sediment removal maintenance when the pond is constructed.

$$
P V=\frac{C}{(1+i)^{y}}
$$

Equation 2

Where $P V$ is the amount of money that needs to be set aside when the pond is built, $C$ is the cost of sediment cleanout in year $\boldsymbol{y}$ (from Equation 1), and $\boldsymbol{i}$ is the interest rate or construction cost index which can be chosen by the user. This model assumes a value of 5\%, as this is what is used by certain governmental agencies such as the Rideau Valley Conservation Authority (2011) to calculate project costs. The sediment removal cost can also be converted into an annuity $\boldsymbol{A}$, over the span of one cleanout cycle, using Equation 3.

$$
A=\frac{P V}{\frac{(1+i)^{y}-1}{i(1+i)^{y}}}
$$

Equation 3

This is useful if the municipality decides to set aside a certain portion of the annual maintenance budget for pond cleanouts. These calculations are performed by the Annual Cost Estimator tool which is used in both methodologies. 


\subsection{METHODOLOGY 1: REAL-TIME TOOL}

For this methodology, the objective function is to minimize cost, while the constraint is to have no violations. The decision variable is the cleanout frequency. A flowchart of the methodology is shown in Figure 20. The first step is the development of a sediment accumulation model, as described in Chapter 3. Ideally, the pond will have continuous, longterm monitoring of rainfall, TSS, and flows at the inlet and outlet, in place. Additionally, at least two sediment surveys of the facility are assumed between cleanouts in order to create a calibrated model.

The model can then be used to determine the annual sediment accumulation, the cumulative sediment accumulation and the annual removal efficiency of the facility. Performance regulations, like the 5\% maximum reduction in treatment efficiency due to sediment accumulation stated in the 2003 OMOE Stormwater Management Practices Planning and Design Manual, can be applied to ensure that the pond does not breach governmental regulations. The model iterates as long as the pond's removal efficiency is acceptable. However, as soon as the performance constraint is violated, the model stops iteration and indicates that a cleanout is required at the beginning of that year. Costs associated with cleanouts, including the construction cost index, fixed-cost and variable cost can be inputted into the Annual Cost Estimator tool, which can then be used to determine the cleanout costs, and the required year for

cleanout to occur, as shown in Figure 21. It does this by calculating the capital costs of cleanout in each year, converting the values into annual costs over the length of the cleanout cycle, and selecting the lowest annual cost as shown below. 


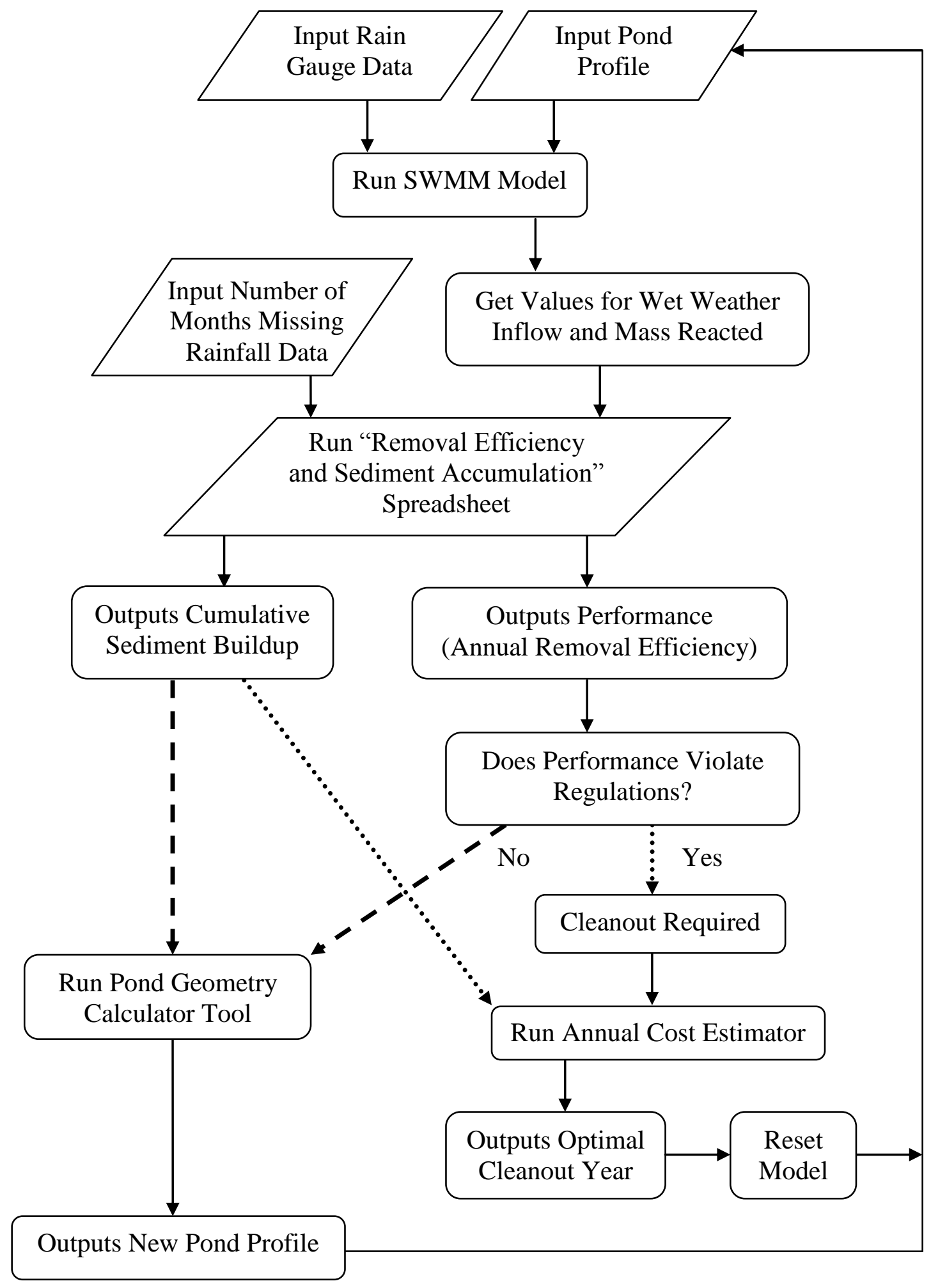

Figure 20 - Flowchart describing Methodology 1 


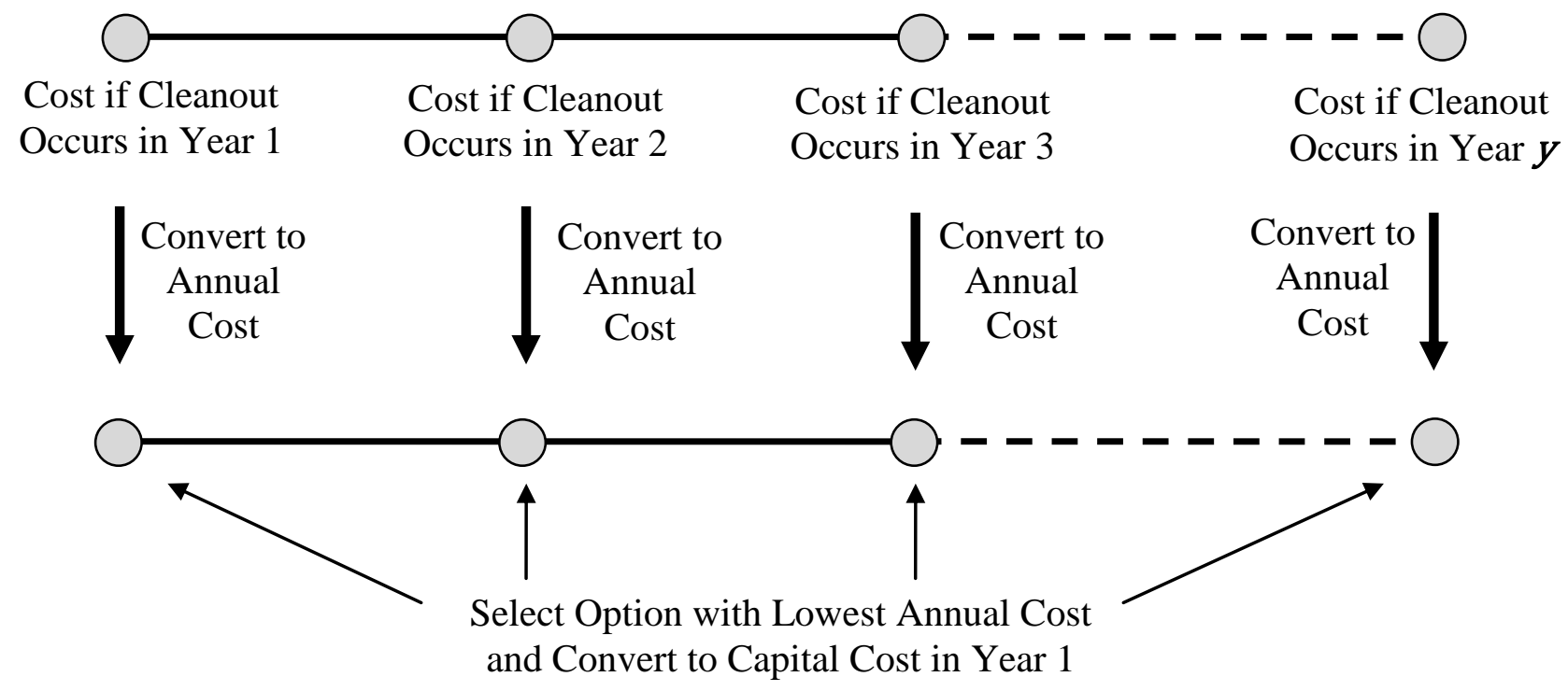

Figure 21 - Schematic showing how the Annual Cost Estimator tool selects the required year for cleanout

For real-time decision making, the model should be run at the beginning of the year. This allows the municipality to determine whether the pond's performance was adequate during the previous year, and make predictions of the performance for the current year. However, to make predictions, simulated rainfall for the upcoming year will be required. Average annual rainfall for the region can be used for this purpose. Deterministic, stochastic, conceptual and artificial neural network models can also be used (Vivekanandan, 2012) but are more labour-intensive.

\subsection{METHODOLOGY 2: ANALYSIS TOOL}

The use of this technique generates decision-making tools that relate cleanout frequency, annual cost, and violations, over a 50-year planning period. A flowchart of the methodology is shown in Figure 22. 
The first step is to run multiple sediment accumulation models for different cleanout frequencies, and enter the data into the Removal Efficiency vs Sediment Buildup tool. The cleanout frequencies can be chosen by the user. In this model, the following cleanout frequencies were modelled: 10, 20, 25, 30, 35, 40, 45 and 50 years. Two additional cases were tested, where the volume criteria was never violated (approximately every 5 years), and where the performance criterion of the pond was never violated (approximately every 16 years). The volume criteria comes from the widely used Storm Water Management Facility Sediment Maintenance Guide prepared by Greenland Consultants Inc. (1999), which recommends not letting the volume of the accumulated sediment exceed 5\% of the permanent pool volume. For this pond, the critical volume is $239.3 \mathrm{~m}^{3}$.

For each cleanout frequency, the total capital costs of cleanouts over the length of the planning period, are calculated as a capital cost in Year 1 by the Annual Cost Estimator 2 tool, as shown in Figure 23. This value is the amount of money that needs to be set aside by the municipality when the pond is built in order to be able to finance that particular maintenance frequency. This capital cost can also be converted an annual cost to finance this cleanout frequency. The Removal Efficiency and Sediment Buildup tool also outputs the number of years the facility's performance is in violation of OMOE regulations. All these data are compiled and summarized into three charts that compare: The cleanout frequency vs the number of years in violation; the cleanout frequency vs the annual cost; and the annual cost vs the number of years in violation. 
The charts display a feasible region which contains the recommended years for cleanout to -.•

occur. Any year within this region is acceptable: the exact year is left to the discretion of the user, and provides for a degree of flexibility when scheduling the next sediment removal maintenance. 


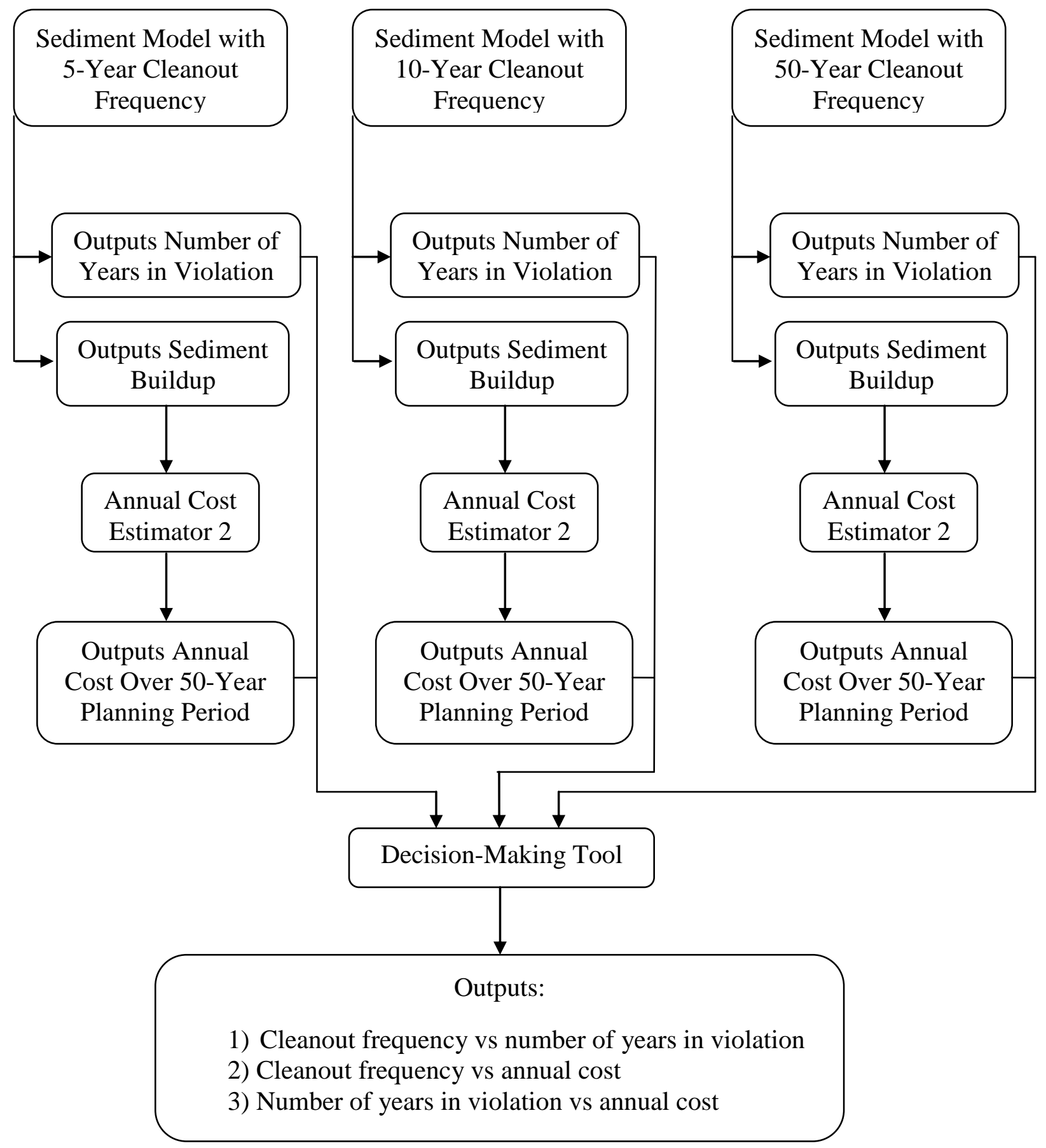

Figure 22 - Flowchart describing Methodology 2 


\section{0-Year Planning Period}

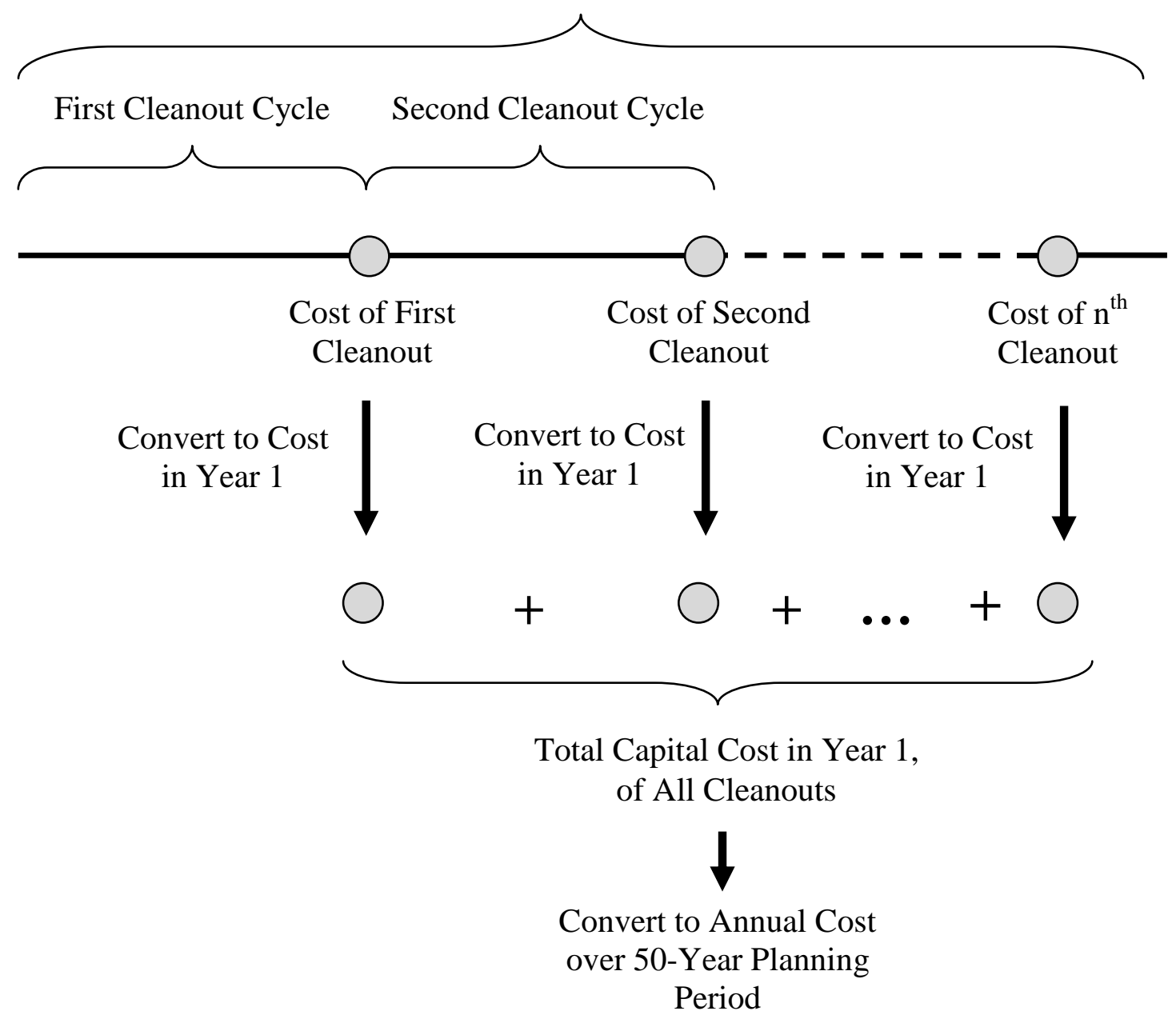

Figure 23 - Schematic showing how annual costs are calculated using Annual Cost Estimator 2 


\section{CHAPTER 5: RESULTS}

\subsection{APPLICATION OF METHODOLOGY 1}

The case study results of Methodology 1 indicate that the required cleanout frequency for this pond is 17 years, as shown in Figure 24. After the seventeenth year of operation, the simulated removal efficiency of the facility will drop below the OMOE Level 1 TSS removal rate of $75 \%$. The treatment efficiency of the pond decreases non-linearly, as seen below, with some years above average, and some below. The reasons for this are examined in Chapter 6.

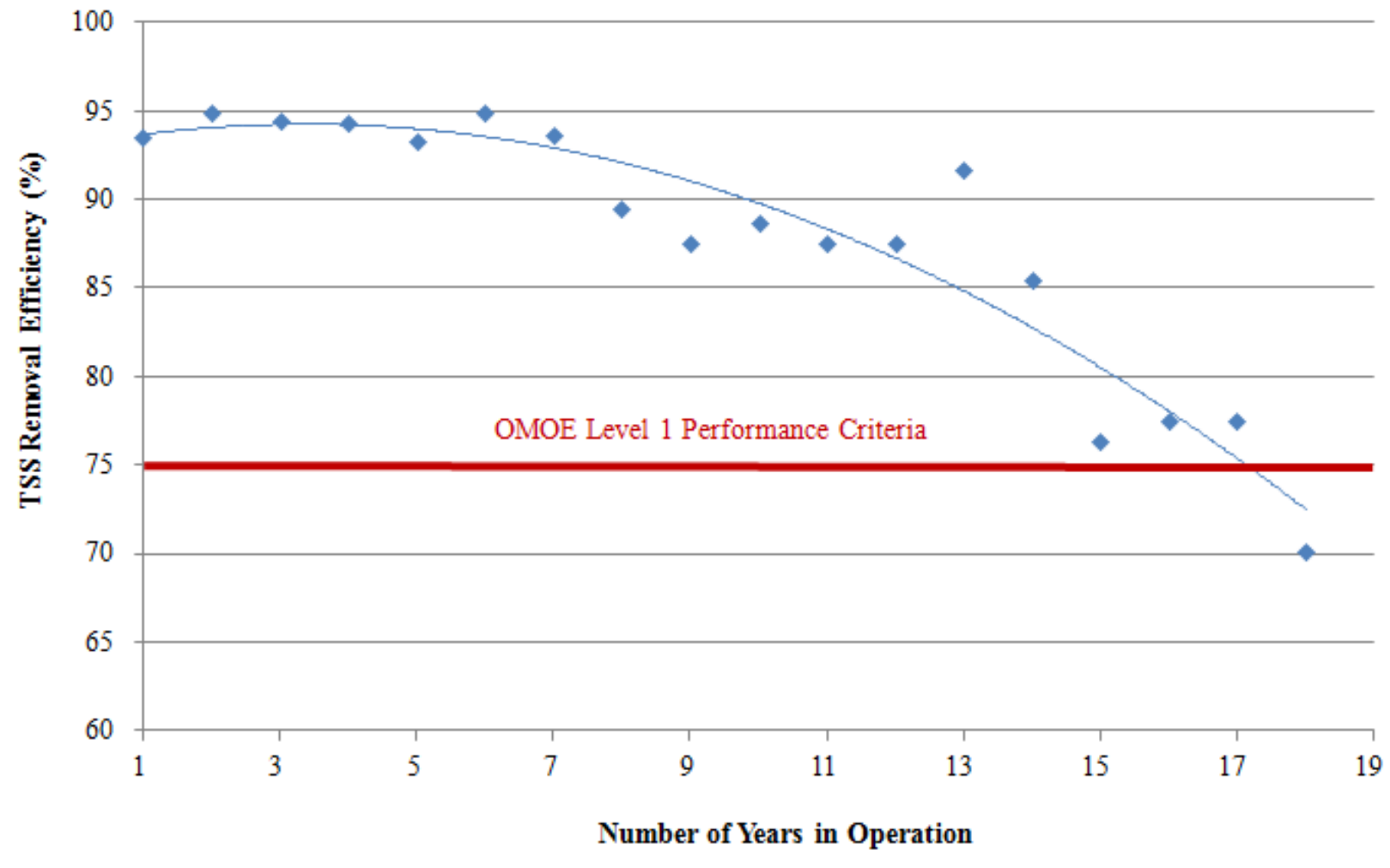

Figure 24 - Removal efficiency versus time for Facility 19-8 
Costs were calculated using the Annual Cost Estimator tool. The lowest annual cleanout cost for this particular facility is $\$ 2,150 / y r$, as shown in Figure 25, and corresponds to a capital cost of $\$ 24,236$ in the first year of the facility's operation. This is within the acceptable range of annual sediment removal costs of $\$ 250 / \mathrm{yr}$ to $\$ 4000 / \mathrm{yr}$, as found in literature (Erickson et al., 2010). Cleanout costs were calculated based on an assumed cost factor of $\$ 65 / \mathrm{m}^{3}$. The upper and lower envelopes use cost factors of $\$ 167 / \mathrm{m}^{3}$ and $\$ 19 / \mathrm{m}^{3}$, respectively. These values were taken from case studies that used mechanical dredging removal methods, and were converted to 2012 dollars (Greenland International Consulting Inc., 1999).

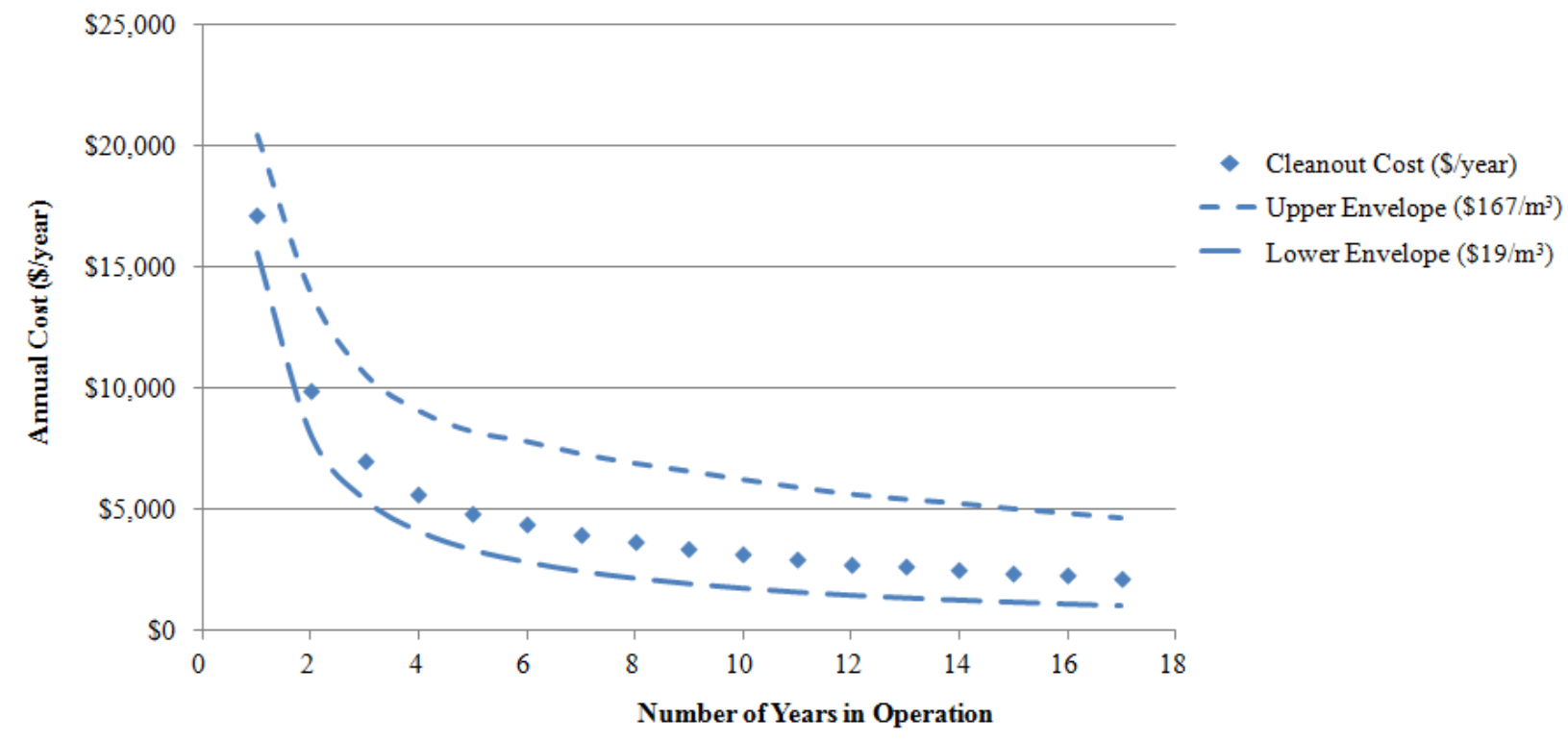

Figure 25 - Annual cleanout cost versus years in operation for Facility 19-8

Figure 26 displays the results, in a slightly different manner by plotting the annual cost versus the removal efficiency. A feasible region, bounded by the performance constraint, highlights the range of how much money a municipality needs to set aside annually to ensure ministry regulations are not violated. For this pond, this is any value above $\$ 2,150 / \mathrm{yr}$. 


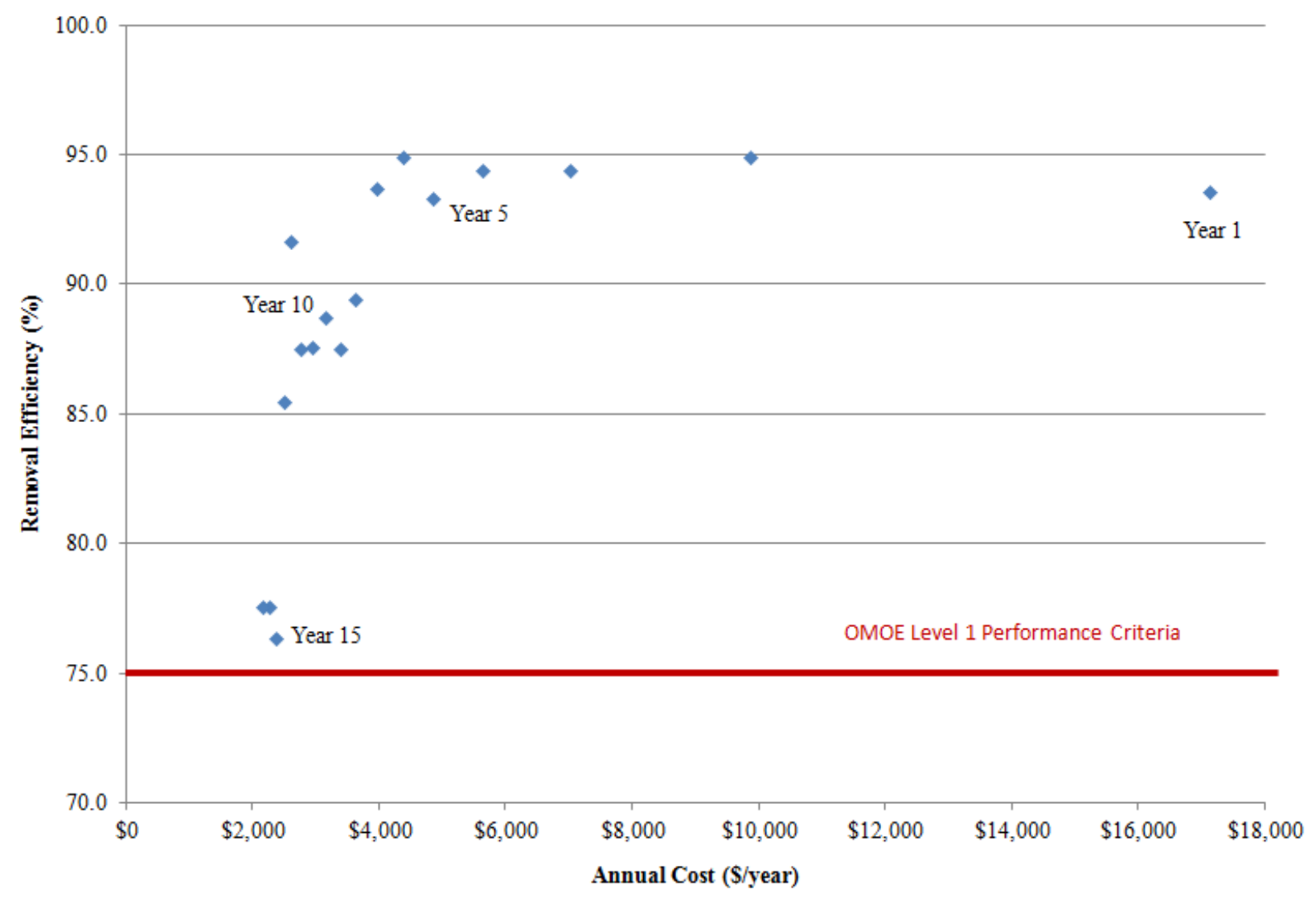

Figure 26 - Performance of Facility 19-8 versus annual sediment removal cost

\subsection{APPLICATION OF METHODOLOGY 2}

The second methodology provides a set of decision-making tools that display the cleanout frequency, the annual cost of sediment removal, and the number of years that the facility is in violation of OMOE performance standards, in the format of three graphs. The three graphs discussed below are compiled from the individual sediment accumulation models with varying cleanout frequencies; the graphs of which can be found in Appendix E. 
The first of the three graphs, Figure 27, displays the number of years in violation versus the cleanout frequency, over a planning period of 50 years. For this facility, if a cleanout occurs every 16 years, there will be no performance violations. However, for each additional year that sediment is not removed, the number of violations increases linearly.

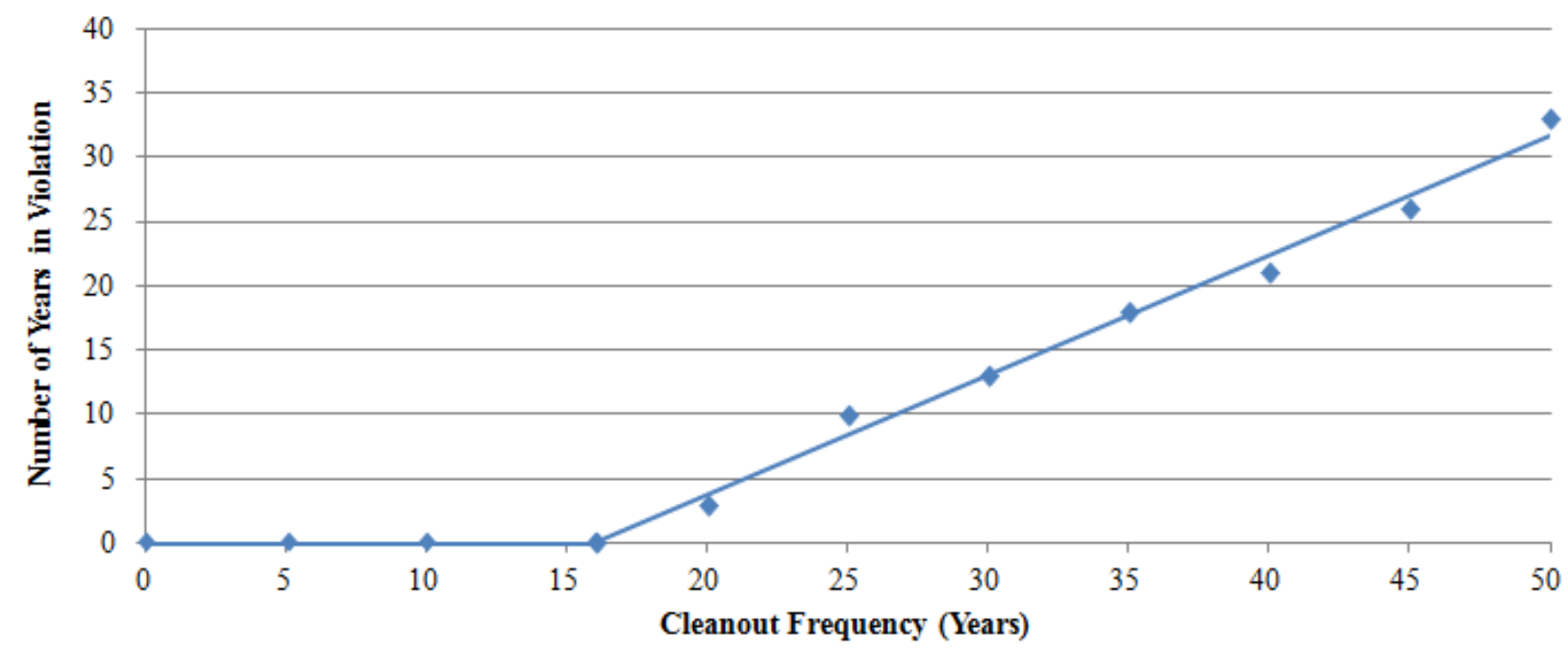

Figure 27 - Years in violation of performance regulations versus the sediment removal frequency for Facility $19-8$, over a 50-year planning period

Figure 28 displays the annual cost of sediment removal versus the number of years the facility is operating in violation of Ministry regulations. To have no violations over a 50 year planning period, the municipality needs to spend approximately $\$ 2,372$ per year, or $\$ 43,309$ in Year 1. Any less will not be enough to keep the facility from violating performance regulations. 


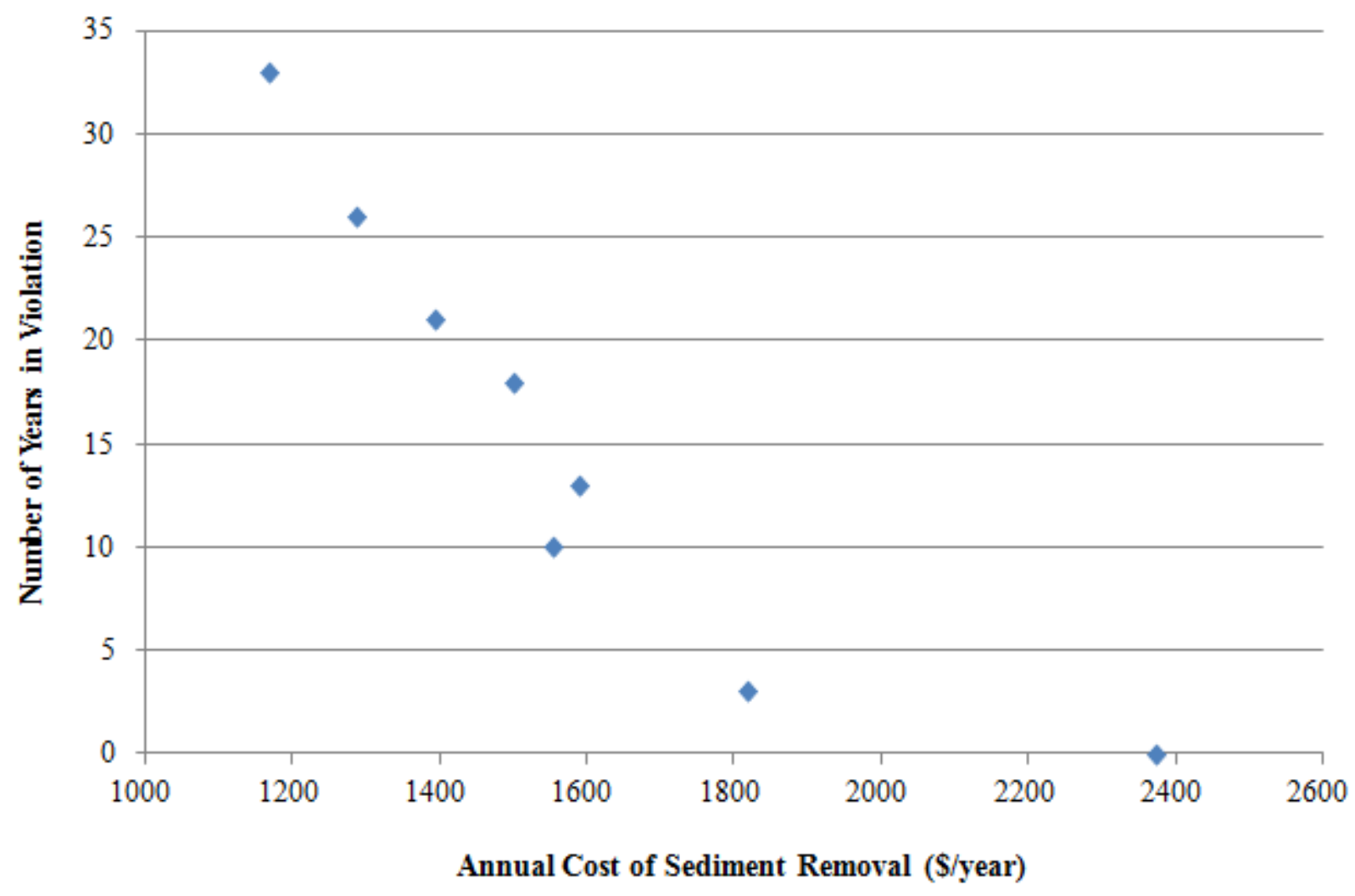

Figure 28 - Number of years the facility is in violation of OMOE performance regulations versus the annual cost of sediment removal maintenance 
The third graph, Figure 29, displays the annual cost versus the cleanout frequency. The non-linear curve shows how the annual cost drops significantly as the frequency increases from 5 to 20 years, but then decreases minimally between frequencies of 20 to 50 years.

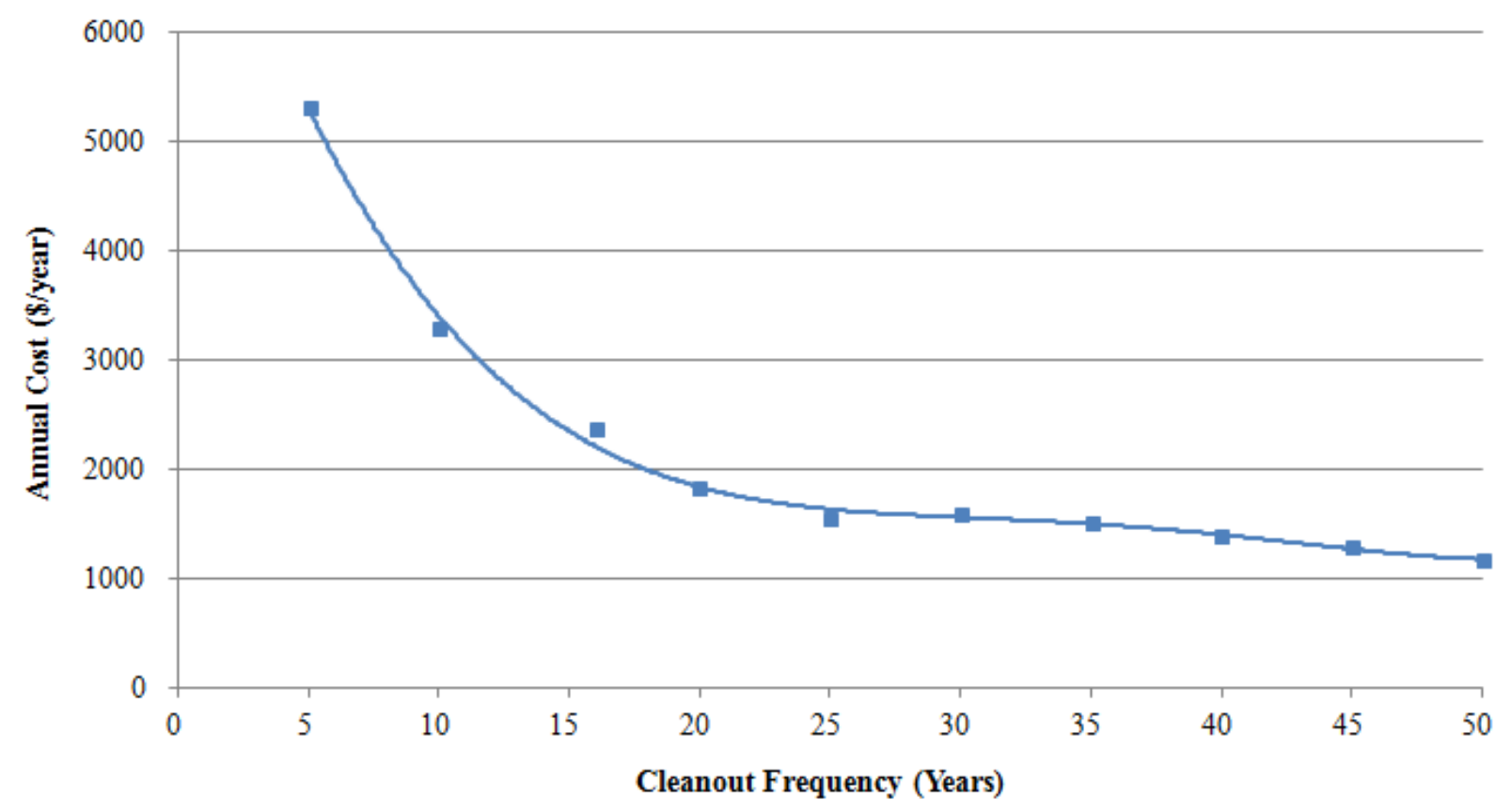

Figure 29 - Annual cost of sediment removal versus the cleanout frequency for Facility 19-8 


\section{CHAPTER 6: DISCUSSION}

The two methodologies developed in this thesis provide two different ways of solving the problem of when to clean out wet detention stormwater management facilities.

The first method uses the sediment accumulation model to determine sediment removal costs over one cleanout cycle, and then selects the cheapest option, without violating OMOE regulations. For Facility 19-8, the required cleanout frequency is 17 years, at an annual cost of $\$ 2,150$ or a capital cost of $\$ 24,236$ in the first year of the facility's operation. Methodology 1 is best suited to real-time decision making by running the model at the end of every year, using either historical annual rainfall or simulated annual rainfall to determine whether the facility needs maintenance during the upcoming year. The benefit of implementing this methodology is that it reduces the sediment survey frequency. Instead of conducting surveys every few years, a crew will only need to go to the pond when the model predicts that the facility is in danger of violating performance regulations. Given the number of ponds and the costs associated with performing sediment surveys, this methodology has the potential to save municipalities money.

The second methodology uses a number of sediment accumulation models, each with a different cleanout frequency over a 50-year planning period, to generate three decision making tools, in the form of graphs. The graphs display the cleanout frequency versus the annual cost versus the pond's TSS removal rate. For this pond, an annual budget of $\$ 2,372$ per year, or a capital cost $\$ 43,309$ in the first year of operation is required to ensure that the facility does not violate performance regulations. This corresponds to a cleanout frequency of approximately 16 years. This is in line with the OMOE's minimum design target of a 10-year sediment removal 
frequency for stormwater management facilities (OMOE, 1994). Methodology 2 provides flexibility by examining longer cleanout frequencies where performance regulations might be violated under an assumed rainfall period. This can be used in the planning phase to determine a window when a facility might be in danger of violating performance regulations. Sediment surveys and sediment removal can then be scheduled accordingly. Applying this methodology to all ponds in a municipality will save time and money by greatly simplifying maintenance schedules.

The difference in cost between the two methodologies is due to the length of the planning period, and therefore, the number of cleanout cycles. The first methodology only examines one cleanout cycle, while the second methodology includes more than three. The cleanout frequencies of the three cycles are not identical either: the first two cleanouts occur after 16 years while the third occurs after 14 years. This is because the cycles are dependent upon the sediment accumulation rate, which in turn, is related to the amount of sediment entering the facility. Figure 30 shows the linear relationship between the total annual precipitation and the annual amount of sediment entering the pond.

The variation in annual removal efficiency, as seen in Figures E1 to E10 in Appendix E, is also related to rainfall. The efficiency drops or increases from year-to-year due in part to the intensity, duration and inter-event time of rainfall events. High intensity events, for example, might cause some of the runoff to bypass treatment by overflowing through the weir. Similarly, if the inter-event time is less than the pond's drawdown time of 95 hours, much of the runoff 
might leave the facility untreated. Additionally, rainfall can vary in an urban subcatchment increasing the uncertainty in stormwater models.

In the methodologies presented, historical rainfall data was used to simulate future rainfall events. As the exact nature of future rainfall events cannot be accurately predicted, using a long historical record suffices. A record that is as long as the planning period is recommended. Otherwise, stochastic rainfall models may be used to generate future rainfall over the planning horizon.

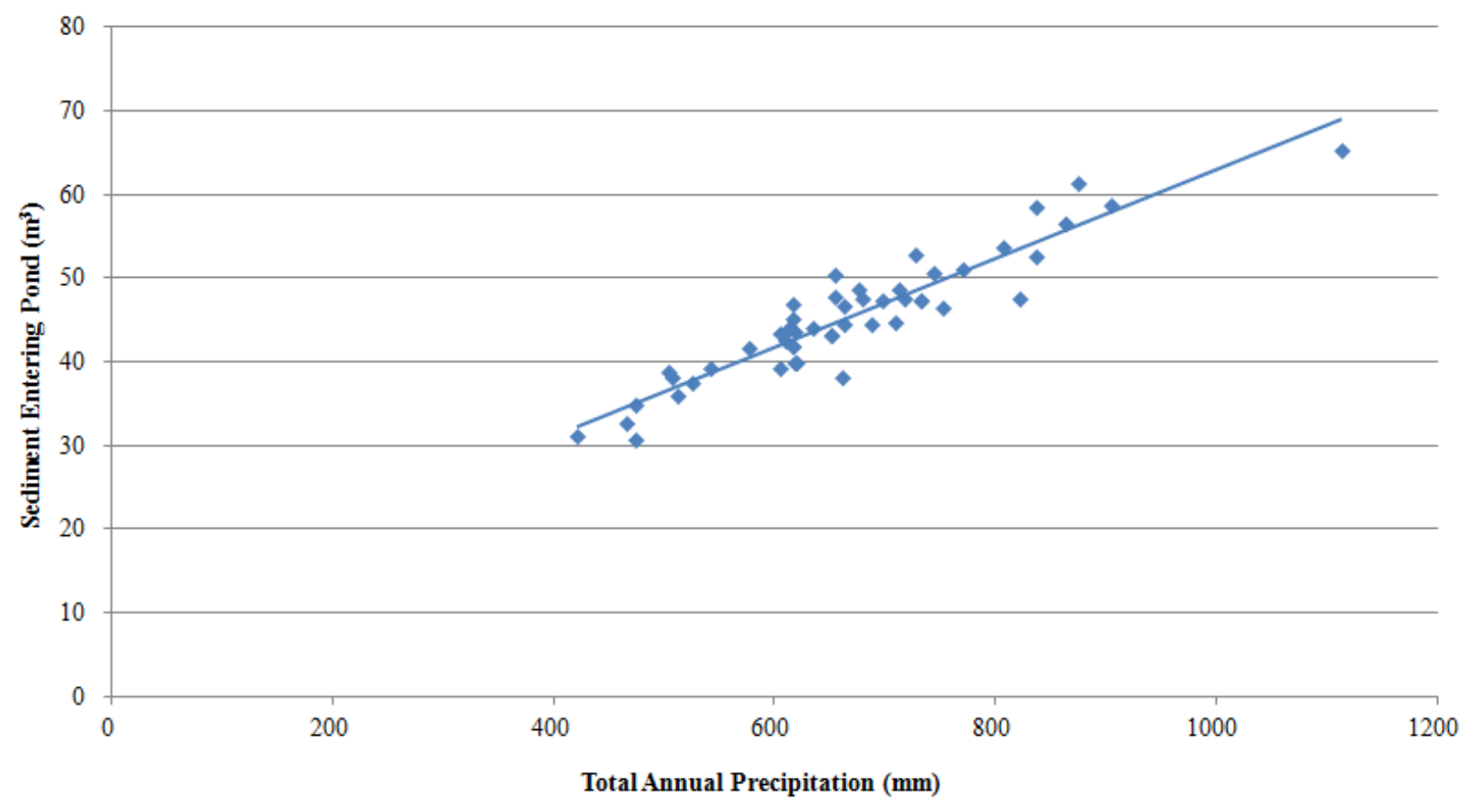

Figure 30 - Annual sediment entering Facility 19-8 versus annual rainfall over 50 years

Nevertheless, the process of developing a sediment accumulation model and the two methodologies can be applied to any wet detention facility to determine both the required sediment removal time for one cycle, and the appropriate removal time over a fixed planning period. 
Difficulties emerged when developing the sediment accumulation model. Determination of the actual values of certain parameters, as opposed to theoretical values, such as the percent imperviousness, the suction head and conductivity of the soil, was fairly time-consuming, as was the sensitivity analysis and calibration process. The previous version of SWMM had automated sensitivity analysis and calibration functionality built in, but these features were missing in the latest version. The inability of SWMM to allow for the dynamic updating of parameters was an issue and required the development of external tools. The maximum pond depth and the profile of the pond had to be changed manually and was time consuming.

A number of uncertainties exist within the two methodologies. The few missing years of rainfall data were one of the sources of uncertainties. As the rain gauges were both temporally and spatially separated, it was difficult to quantify whether there was any variation between the rainfall characteristics of different stations. Another issue was the lack of rainfall data in the winter, as it is standard practice to remove rain gauges between November and April. Further uncertainties arose from the manner in which the sediment surveys were undertaken. Although the depth to the sediment was measured in a grid, the depth to the pond bottom was only measured at the midpoint of each transect. Because the cleanout altered the very profile of the pond itself, the complete pond profile, and therefore volume, could not be determined as accurately as desired. Additionally, upon inspection of the facility, overgrown vegetation was found in the pond, as shown in Figure 31. Quantifying how much this reduced the pond's capacity or how it affected sedimentation processes is difficult. In fact, Persson and Pettersson (2009) concluded that vegetation is one of the factors that need to be accounted for in the design of stormwater ponds. Furthermore, because the contamination level of the sediment in the pond 
was unknown, it was difficult to use a precise cost factor, hence the envelope provided in Figure 25. The overall accuracy of stormwater models will improve as the quality and quantity of data increases.

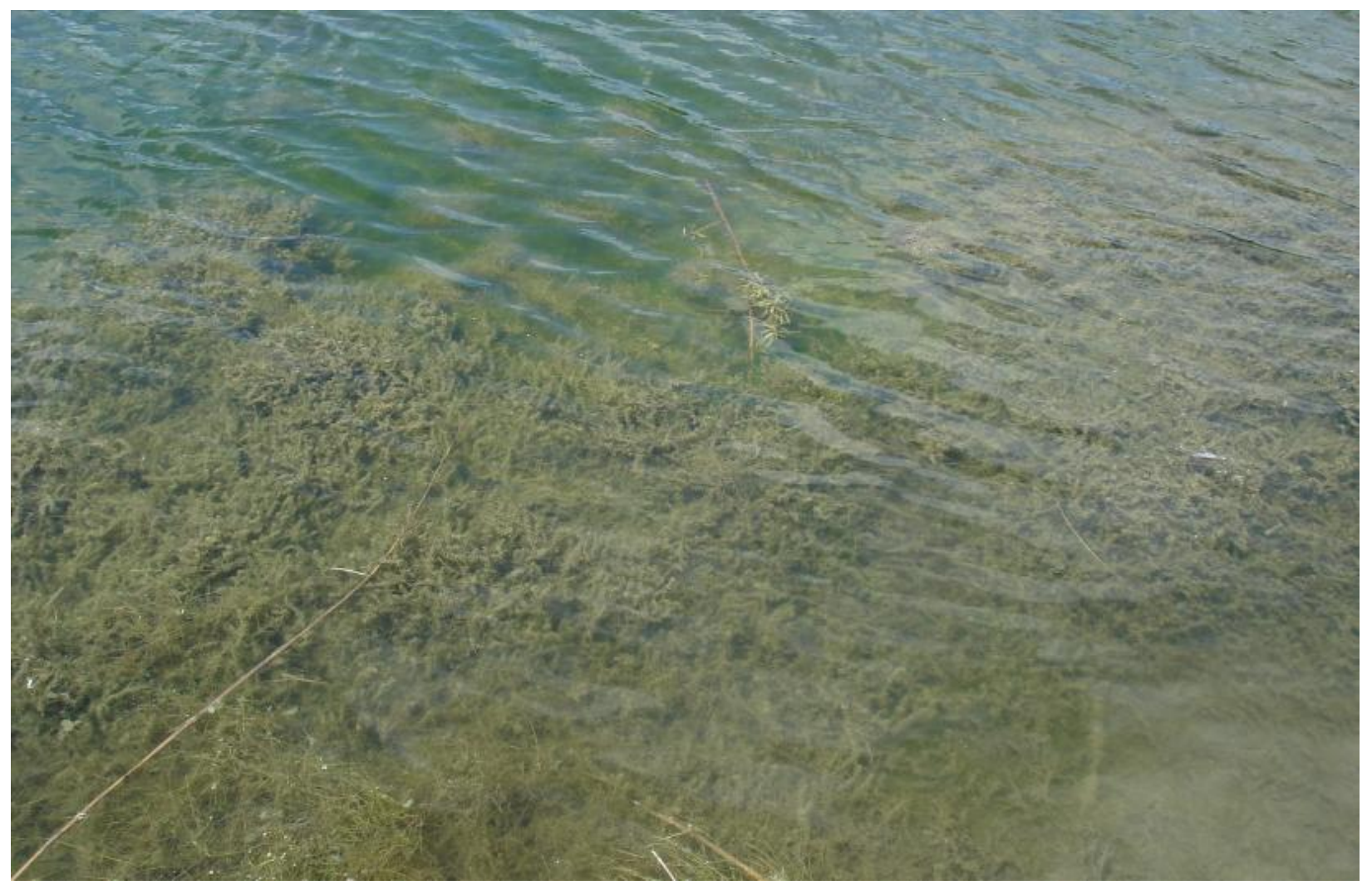

Figure 31 - Excessive and uncontrolled growth of vegetation in Facility 19-8 


\section{CHAPTER 7: CONCLUSIONS}

The purpose of this study was to develop a methodology for determining the appropriate sediment removal frequency from wet-detention stormwater management facilities. Using data from a wet pond in the Town of Richmond Hill, a sediment accumulation model was built primarily using SWMM 5. The model generated an accumulation rate of $4.52 \mathrm{~m}^{3} / \mathrm{ha} /$ year which is in good agreement with field measurements, and well within the accumulation rates of 0.2

$\mathrm{m}^{3} / \mathrm{ha} /$ year and $5.8 \mathrm{~m}^{3} / \mathrm{ha} /$ year found in literature (Greenland International Consulting Inc., 1999).

Two different cleanout methodologies were then developed and applied to the facility. The results show that the appropriate time for sediment removal, and the annual costs differ slightly based on the methodology used. Application of the first methodology to this particular facility suggests a recommended cleanout frequency of 17 years, with an annual cost of $\$ 2,150$ to fund sediment removal. Use of the second methodology indicates a cleanout frequency of 16 years, with $\$ 2,372$ set aside annually, is sufficient to keep the facility from violating performance regulations. The difference in recommended values between the two methodologies is due to the effects of the planning period on the model.

The primary issues faced in developing an accurate sedimentation model were lack of water quality data, rainfall records and detailed cleanout information. The inability of SWMM 5 to model sediment accumulation and update parameters dynamically and were also major issues, which were tackled by developing a set of tools that performed these functions. It is also unclear how to quantify the effects the overgrown vegetation on sedimentation processes and pond 
capacity, and then simulate this in a stormwater model. Future studies examining this issue are suggested.

A number of additional important findings were made by this study. Analysis of the water level data highlighted the importance of frequent inspections of the pond's outlet structure, to ensure that debris does not prevent proper drainage. It was also found that the removal efficiency of the pond stays relatively stable during the first five years following a cleanout, and then decreases rapidly in a non-linear fashion after this period. This phenomenon might occur due to increased flooding from a loss in storage capacity. Another key finding showed a linear relationship between rainfall and the amount of sediment entering the facility.

This study recommends increasing continuous monitoring of water quality and quantity parameters at both the inlet and outlet of wet detention stormwater management facilities. Appropriate sediment surveys should also be performed, along with collection of continuous precipitation data at the pond location, even through the winter months if possible. Records of sediment removal, including costs, quantity, and quality of sediment removed should be kept by the municipality. This will facilitate the development of more comprehensive and accurate sediment accumulation models. It is recommended that the two methodologies developed by this study be implemented during both the planning and operation phase of stormwater ponds in order to minimize sediment cleanout costs. 


\section{CHAPTER 8: RECOMMENDATIONS}

This section proposes a number of suggestions that would be beneficial to the advancement of stormwater pond maintenance research. Future research may be focused on optimizing the total cost of pond cleanup and survey as well as downstream receiving water rehabilitation; and / or automating the two analysis methodologies. Improvements to facility monitoring techniques are recommended along with ideas on how to improve the functionality of SWMM. It is also suggested that future research be focused on the fate of other pollutants in stormwater ponds, along with the effects of climate change on these facilities.

\subsection{OPTIMIZATION OF POND MAINTENANCE BY INCORPORATING OTHER COSTS}

Introducing downstream environmental/rehabilitation and inspection costs to this research, will create a new optimization model. The downstream cost represents the expenses incurred to remediate receiving waterways and waterbodies from the detrimental effects of the facility's discharge. The inspection cost includes the expenses incurred from sending maintenance crews to the facility and downstream locations, and the cost of performing sediment surveys. The optimization problem can be formulated by minimizing the total cost of clean out, inspections, and downstream rehabilitation. The decision variables would be the cleanout frequency, the remediation frequency, and the inspection frequency, with the number of sediment accumulation violations being the primary constraint Percent of degraded downstream receiving streams, and maximum inspection frequency within the planning horizon can be implemented as secondary constraints. 


\subsection{AUTOMATION OF PROCEDURES}

Automation of the methodologies presented in this report is highly recommended so that users do not manually have to transfer data between the individual tools developed. This will speed up analysis times and make the procedure more accessible to casual users. With a minimal amount of programming, Methodology 1 can be further developed into a real-time tool for municipalities to use for any wet-detention stormwater pond, and Methodology 2 can be used to assist in the development of maintenance plans, potentially saving municipalities and therefore taxpayers, significant amounts of money.

\subsection{DEVELOPMENT OF INTEGRATED REAL-TIME, MONITORING SYSTEMS}

The development of intelligent systems and software that can autonomously determine when sediment removal is required would be of great use to practitioners in this field. A computer connected to monitoring devices could continuously store rainfall, pollution, sediment depth, water level, and flow data. If the system was built with the ability to remotely send status updates to the maintenance department, it would reduce the number of maintenance inspections and sediment surveys required. The data gathered could also be used for further studies.

In the absence of intelligent monitoring systems, it is recommended that manual sediment surveys be taken prior to cleanout, after cleanout and every few years. It would also be highly beneficial if measurements of the pond depth were taken at every point.

\subsection{INCLUSION OF LIDs AND BMP DEVELOPMENT}

The sediment accumulation model developed can be further refined by including the effects of Low Impact Developments (LIDs) such as grass swales, rain gardens, green roofs, 69 
infiltration trenches and porous pavement. It is possible to use SWMM and a sediment accumulation model similar to the one developed to determine which LIDs have the greatest effect on sedimentation rates within a single subcatchment. This may eventually be incorporated into local guidelines for pond maintenance, or it may be formalized into the design of best management practices.

Modelling of other hydrogeologic processes like ground-water inflows, snow-melt and evaporation will also increase the accuracy of the models. It is highly unlikely that one facility will have continuous, long-term monitoring of all these processes; however, it would be beneficial for researchers to take these factors into consideration for future studies.

\subsection{IMPROVING THE FUNCTIONALITY OF SWMM}

Modelling a system with parameters that change over time using continuous simulation is difficult using SWMM. Because the SWMM user community is relatively large, comments sent to the moderator about program functionality are seriously considered for inclusion in the next iterations of the program. Recommendations for the next iteration of program development include the ability to change parameters during simulation and a built-in sensitivity analysis tool (e.g., the functionality provided by other programs like PC-SWMM or previous versions like SWMM 4). Additionally, the ability to run multiple models simultaneously would be of great benefit to users.

\subsection{DETERMINING THE BUILDUP AND TRANSPORT OF OTHER POLLUTANTS}

The loading of particulate-bound contaminants other than total suspended solids, can also be examined by using the pollutant editor in SWMM. These include heavy metals, organic 
contaminants and certain polycyclic aromatic hydrocarbons (PAHs). The relationship between dry and wet weather patterns and the loading of seasonal pollutants like road salts can also be examined. The challenge is data limitation; however, a long-term study can be undertaken where monitoring equipment is provided by the research team. This will contribute to a better understanding of pollutant fate and transport within urban water systems.

\subsection{MODELLING THE IMPACTS OF CLIMATE CHANGE}

The impacts of climate change on detention ponds can be simulated using predicted high-intensity rainfall events. The rate of sediment accumulation and removal efficiency can be compared to lower-intensity events, and if computational fluid mechanic simulation software is utilized, differences in the sediment distribution within the pond can be determined. The effect of higher intensity storms on stormwater ponds is currently unknown, due to the increased likelihood of runoff overflowing through the weir. This stormwater is not treated by the pond and the resulting sediment behaviour is not clearly defined in literature. 


\section{Appendix A - Parameters Used in SWMM Model}

Table A1 - Subcatchment properties

\begin{tabular}{|c|c|c|}
\hline Parameter & Calibrated Value & Notes \\
\hline Area & 10.45 ha & \\
\hline Width & $300 \mathrm{~m}$ & \\
\hline$\%$ Slope & $2.0 \%$ & From satellite image \\
\hline$\%$ Imperv & $48.9 \%$ & Corresponds to "dense grass" \\
\hline N-Imperv & 0.013 & \\
\hline N-Perv & 0.24 & From satellite image \\
\hline Dstore-Imperv & $0.8 \mathrm{~mm}$ & \\
\hline Dstore-Perv & $1.5 \mathrm{~mm}$ & \\
\hline \%Zero-Imperv & $22.4 \%$ & \\
\hline Subarea Routing & OUTLET & \\
\hline Percent Routed & 100 & \\
\hline Groundwater & NO & \\
\hline LID Controls & 0 & \\
\hline Land Uses & 1 & \\
\hline Initial Buildup & 1600 & \\
\hline Curb Length & & \\
\hline
\end{tabular}


Table A2 - Infiltration editor

\begin{tabular}{|c|c|c|}
\hline Parameter & Calibrated Value & Notes \\
\hline Method & GREEN_AMPT & \\
\hline Suction Head & $109.2 \mathrm{~mm}$ & \\
\hline Conductivity & $10.92 \mathrm{~mm}$ & \\
\hline Initial Deficit & 0.263 & See calculations below \\
\hline
\end{tabular}

The initial deficit is defined as the difference between the soil porosity $\boldsymbol{\Phi}$, and the initial moisture content or field capacity, FC.

Initial Deficit $=\boldsymbol{\Phi}-\mathbf{F C}=0.453-0.19=0.263$

Table A3 - Storage unit properties

\begin{tabular}{|c|c|c|}
\hline Parameter & Calibrated Value & Notes \\
\hline Invert Elevation & $211.5 \mathrm{~m}$ & \\
\hline Max Depth & $3.0 \mathrm{~m}$ & $\begin{array}{c}\text { Not used due to level of } \\
\text { complexity required }\end{array}$ \\
\hline Initial Depth & $1.98 \mathrm{~m}$ & $\begin{array}{c}\text { Not used since climatology } \\
\text { data required }\end{array}$ \\
\hline Ponded Area & 0 & YES \\
\hline Evap. Factor & TABULAR & $\begin{array}{c}\text { Name varies based on model } \\
\text { and year }\end{array}$ \\
\hline Infiltration & PondCurve19XX-MMy & \\
\hline Storage Curve & &
\end{tabular}


Table A4 - Nodes/links

\begin{tabular}{|c|c|c|}
\hline Parameter & Calibrated Value & Notes \\
\hline Node Invert & 0 & \\
\hline Node Max Depth & 4 & $\mathrm{~m}$ \\
\hline Node Ponded Area & 0 & \\
\hline Conduit Length & 1 & \\
\hline Barrels & CIRCULAR & \\
\hline Shape & 2.0 & \\
\hline Max. Depth & 0.01 & \\
\hline Conduit Roughness & CFS & \\
\hline Flow Units & DEPTH & \\
\hline Link Offsets & KINEMATIC WAVE & \\
\hline Routing Model & & \\
\hline
\end{tabular}


Table A5 - Weir properties

\begin{tabular}{|c|c|c|}
\hline Parameter & Calibrated Value & Notes \\
\hline Inlet Node & POND1 & \\
\hline Outlet Node & J1 & \\
\hline Type & TRAPEZOIDAL & \\
\hline Height & $20.08 \mathrm{~m}$ & Horizontal:Vertical \\
\hline Length & $3: 1$ & \\
\hline Side Slope & 214.5 & \\
\hline Inlet Offset & $1.52 \mathrm{~m}^{3} / \mathrm{s}$ & \\
\hline Discharge Coeff. & $\mathrm{NO}$ & $\begin{array}{c}\text { Length of weir is greater than } \\
\text { the width of the channel }\end{array}$ \\
\hline Flap Gate & $1.52 \mathrm{~m} 3 / \mathrm{s}$ & \\
\hline End Coeff. & 0 & \\
\hline End Contractions & &
\end{tabular}


Table A6 - Permanent pool storage characteristics

\begin{tabular}{|c|c|}
\hline Depth $(\mathrm{m})$ & Area $\left(\mathrm{m}^{2}\right)$ \\
\hline 0 & 12.5 \\
\hline 0.25 & 339 \\
\hline 0.50 & 666 \\
\hline 0.75 & 796 \\
\hline 1.00 & 925 \\
\hline 1.25 & 1139 \\
\hline 1.50 & 1353 \\
\hline 1.75 & 1834 \\
\hline 2.00 & 2314 \\
\hline 2.25 & 2650 \\
\hline 2.50 & 2986 \\
\hline 2.75 & 3710 \\
\hline 3.00 & 4434 \\
\hline
\end{tabular}




\section{Appendix B - Water Quantity Model: Sensitivity Analysis Charts}

\section{Subcatchment Properties}

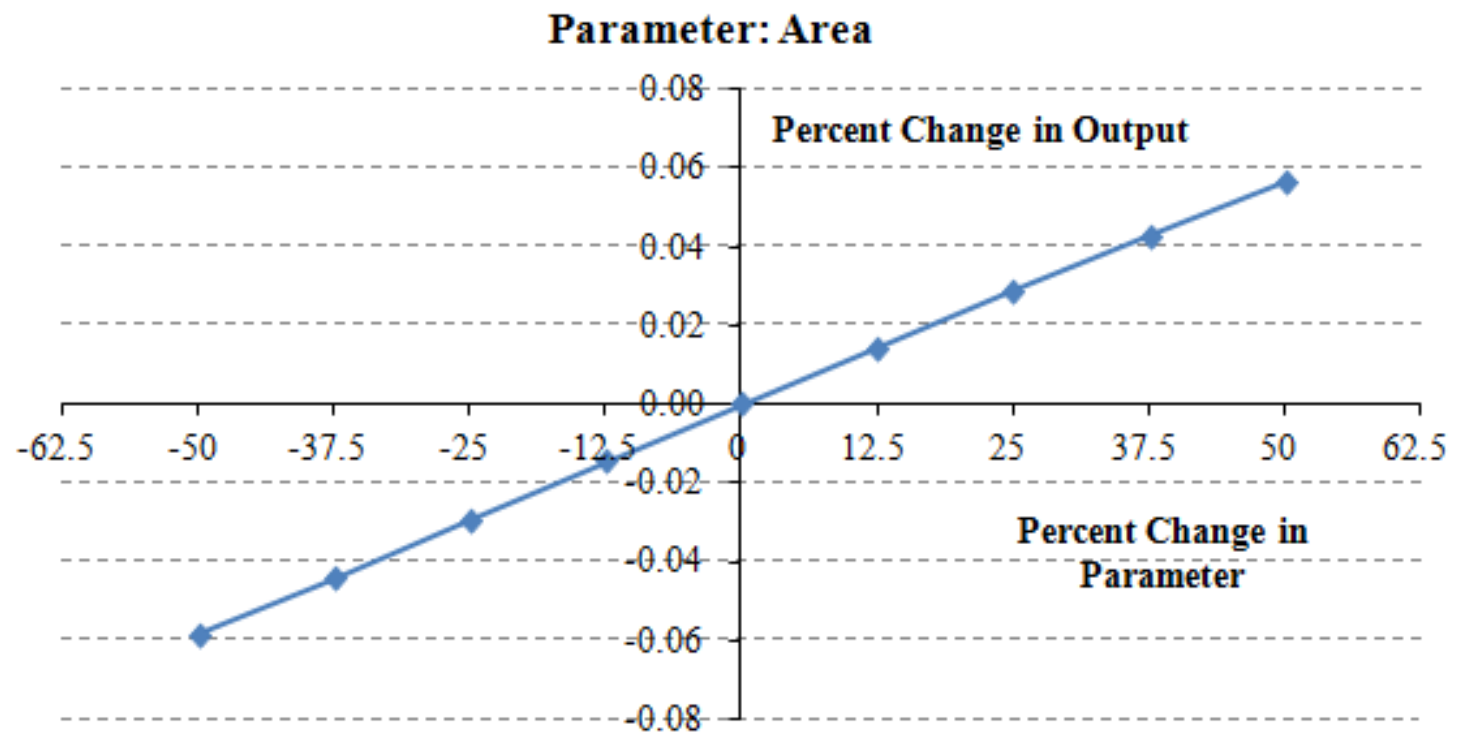

Figure B1 - Sensitivity analysis chart of area parameter

\section{Parameter: Width}

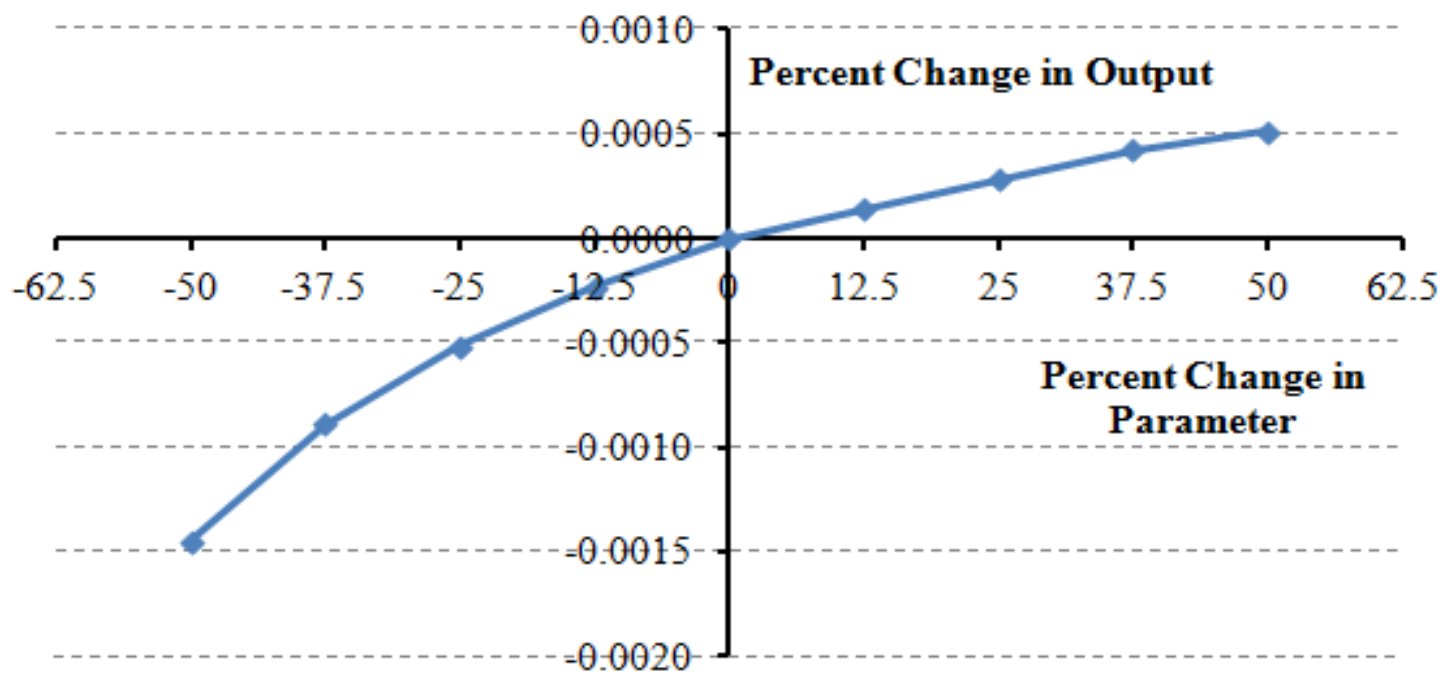

Figure B2 - Sensitivity analysis chart of width parameter 


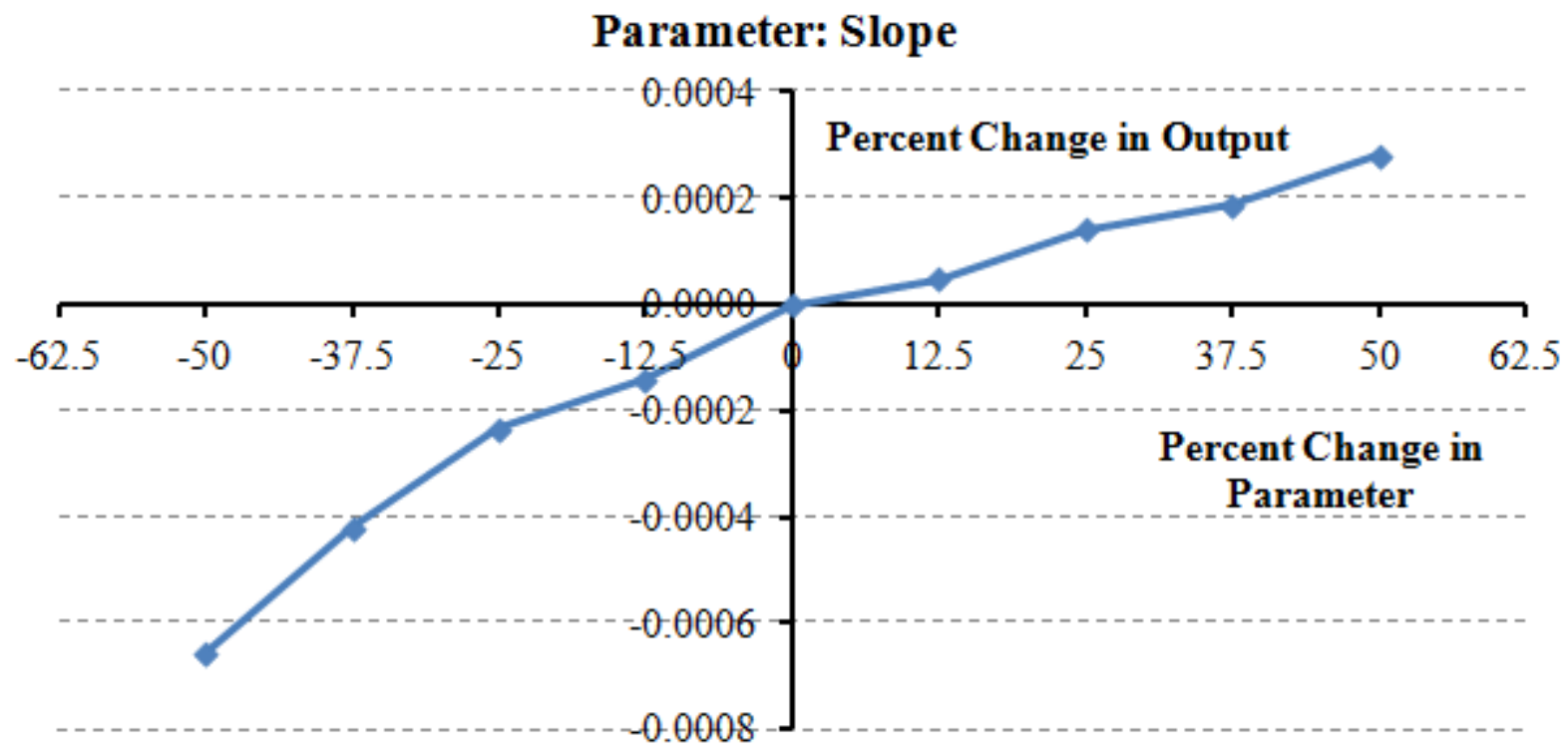

Figure B3 - Sensitivity analysis chart for slope parameter

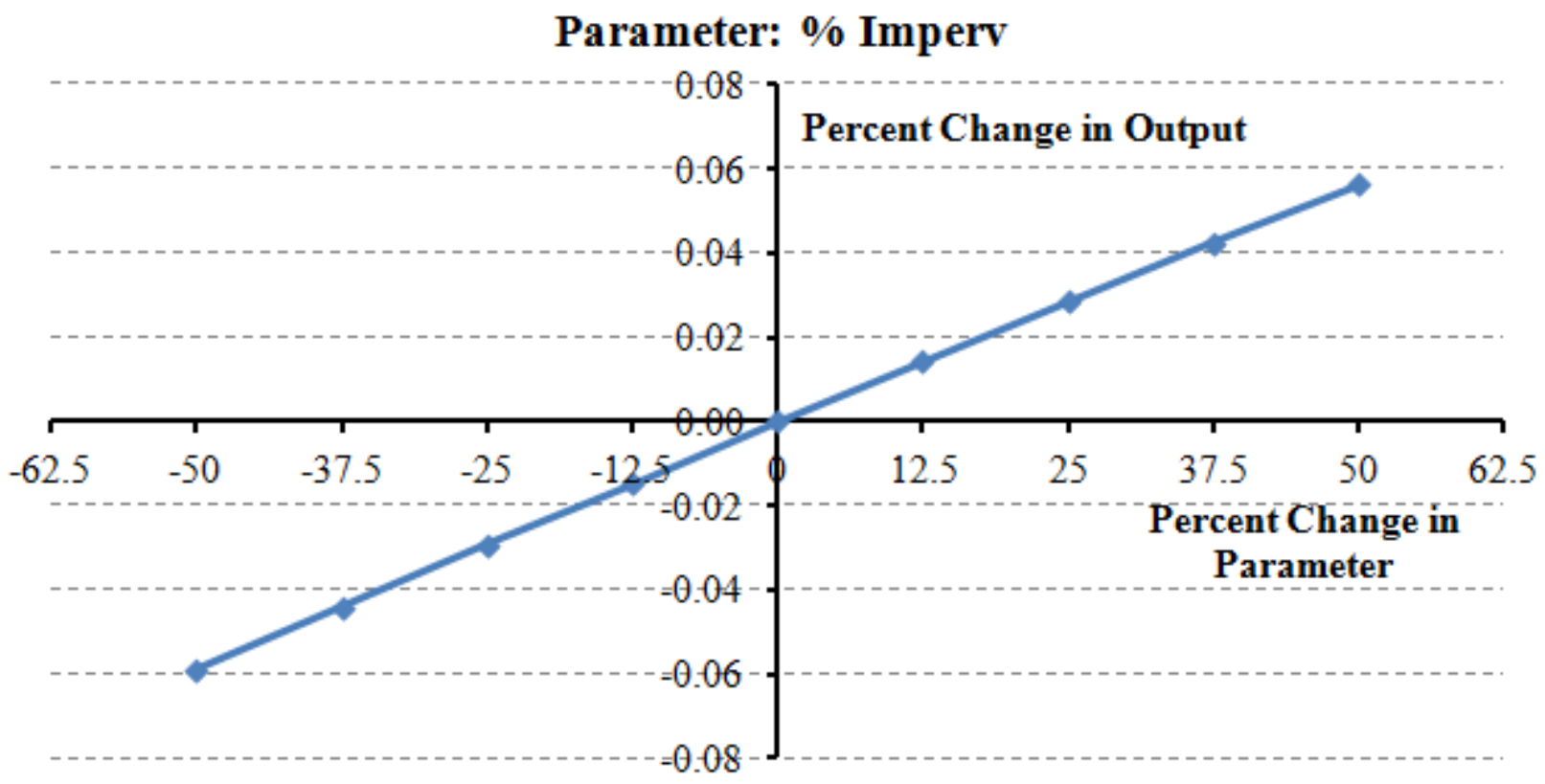

Figure B4 - Sensitivity analysis chart for \% Imperv parameter 


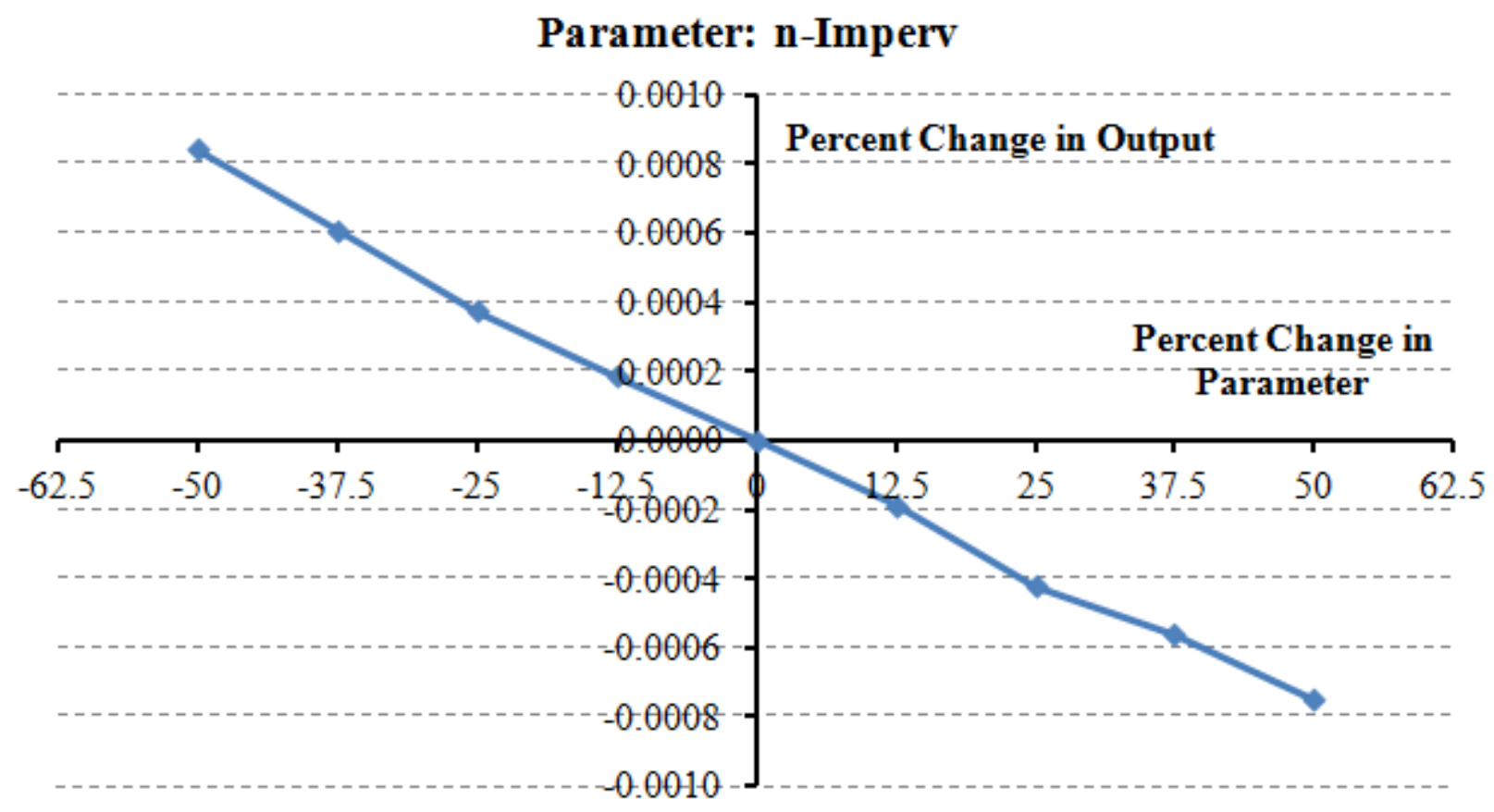

Figure B5 - Sensitivity analysis chart for n-Imperv parameter

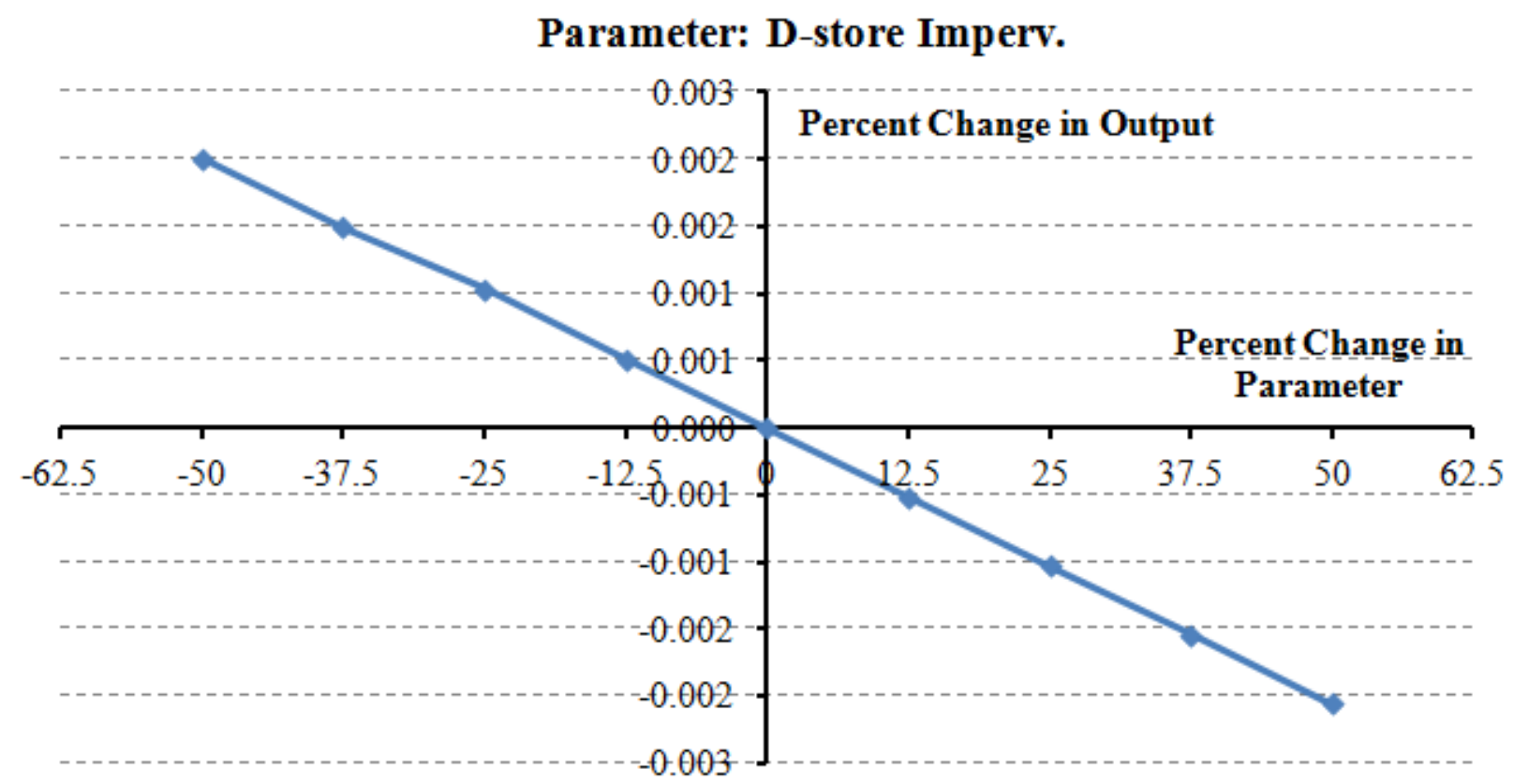

Figure B6 - Sensitivity analysis chart for D-store Imperv parameter 


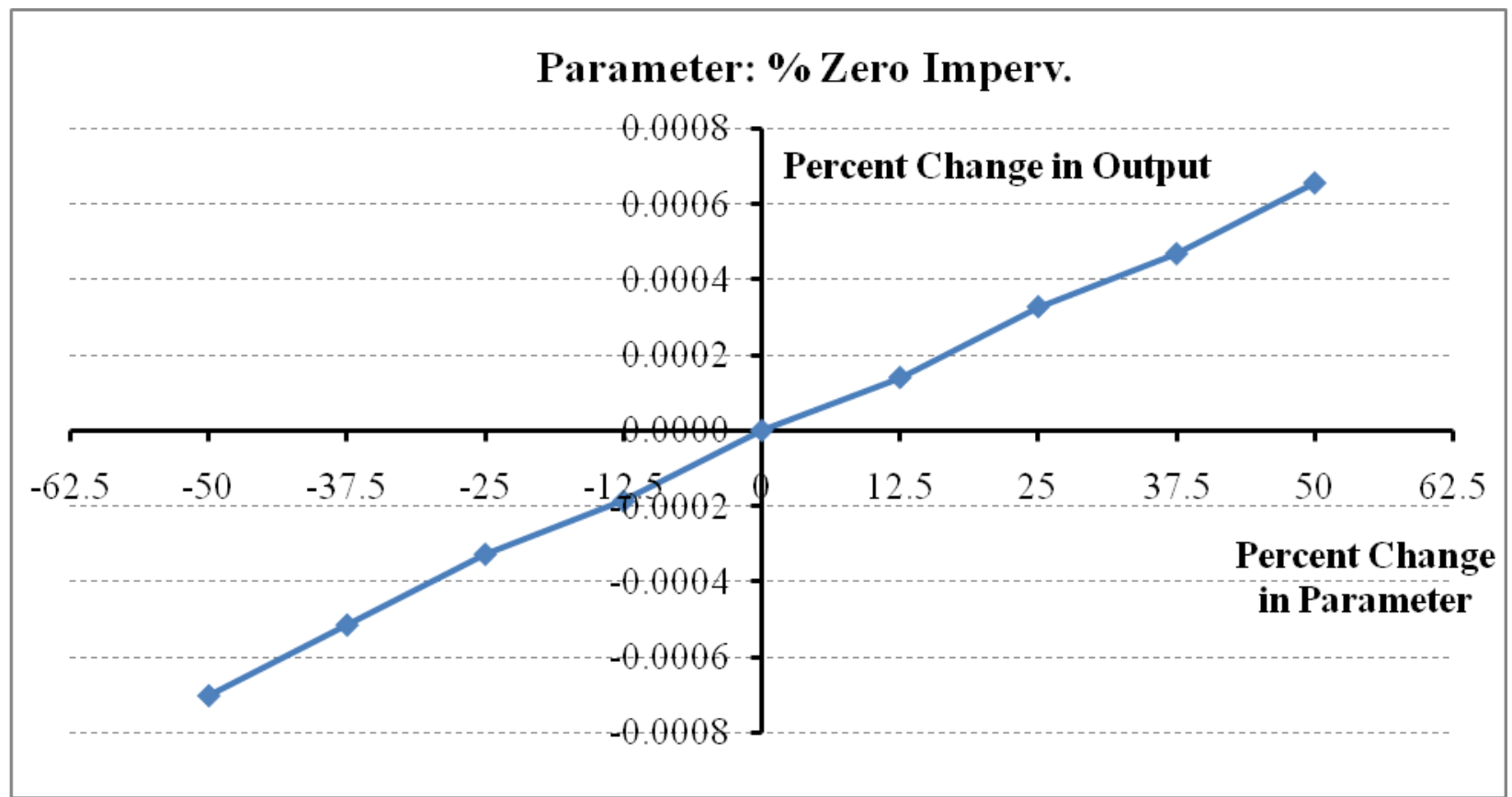

Figure B7 - Sensitivity analysis chart for \% Zero Imperv parameter

\section{Storage Unit Properties}

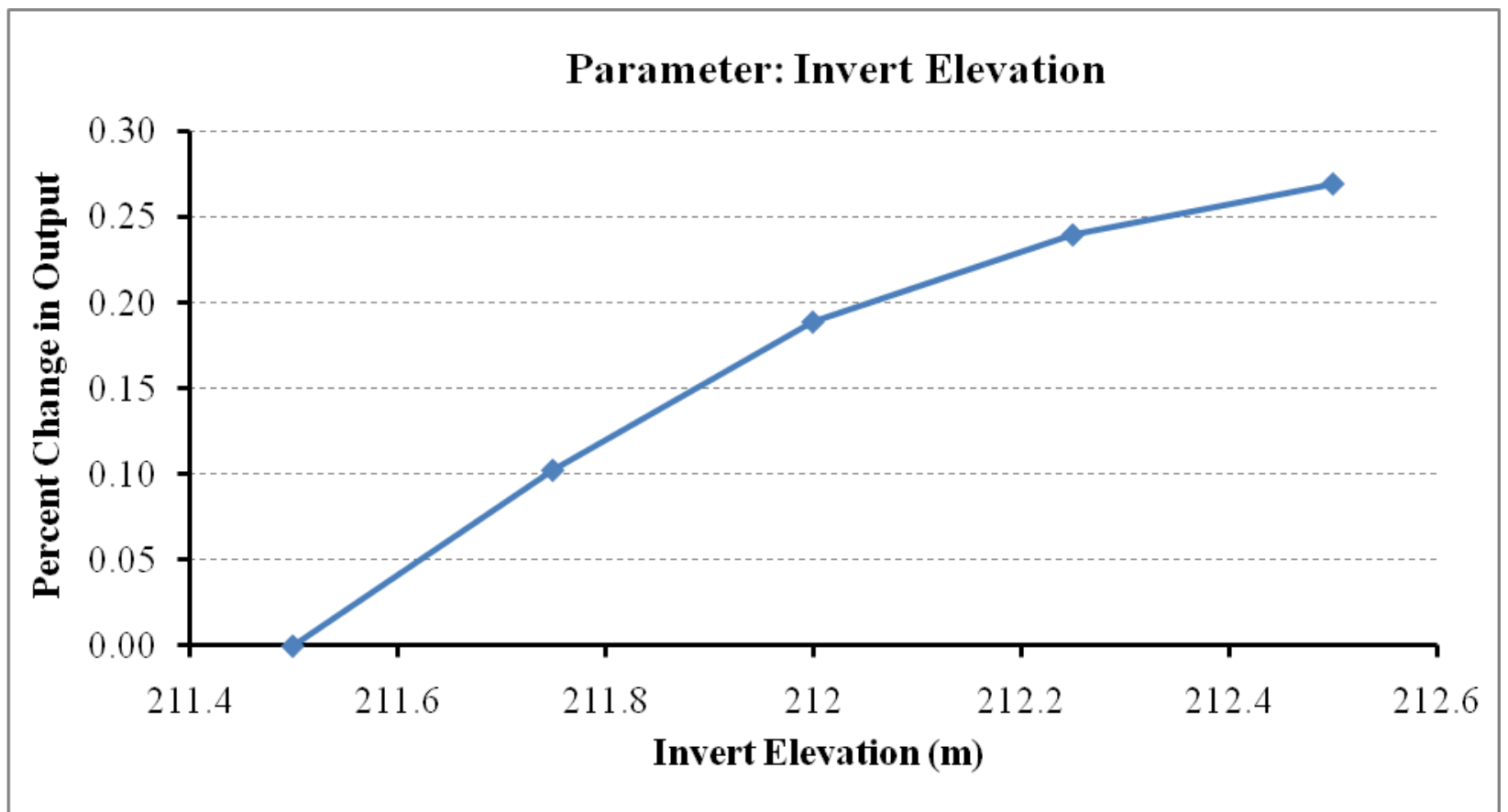

Figure B8 - Sensitivity analysis chart for invert elevation parameter 


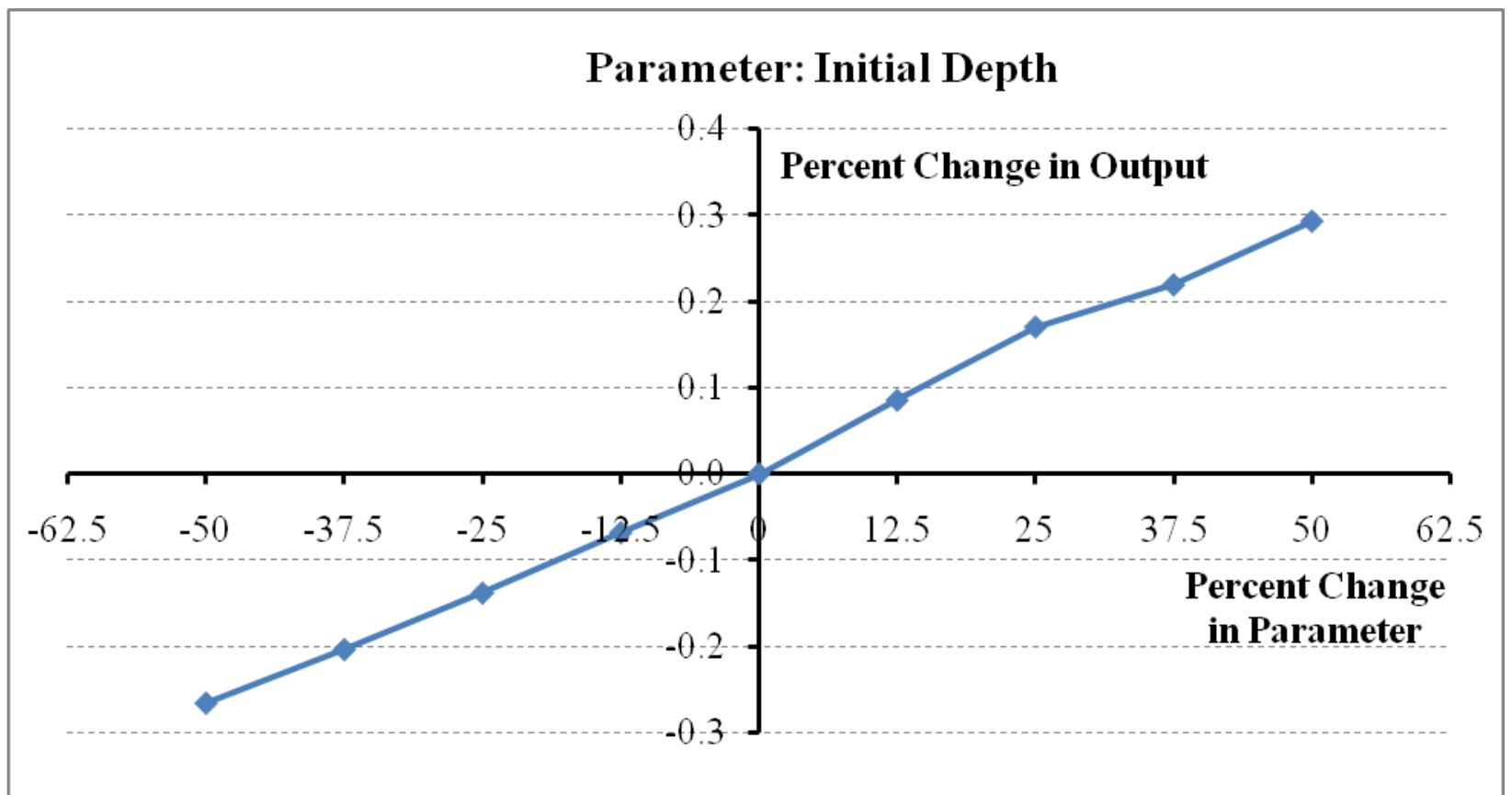

Figure B9 - Sensitivity analysis chart for initial depth parameter

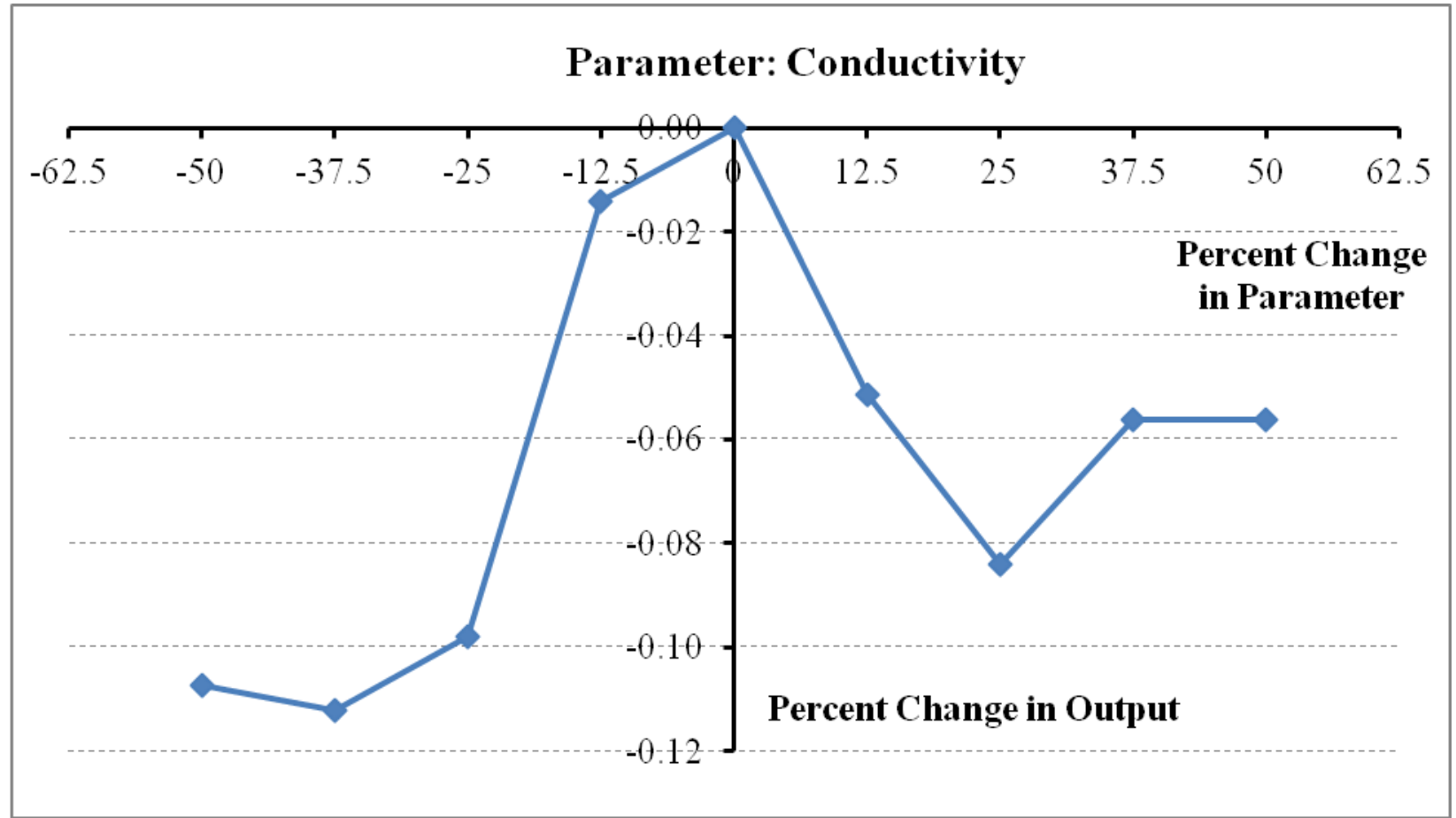

Figure B10 - Sensitivity analysis chart for conductivity parameter 


\section{Orifice Properties}

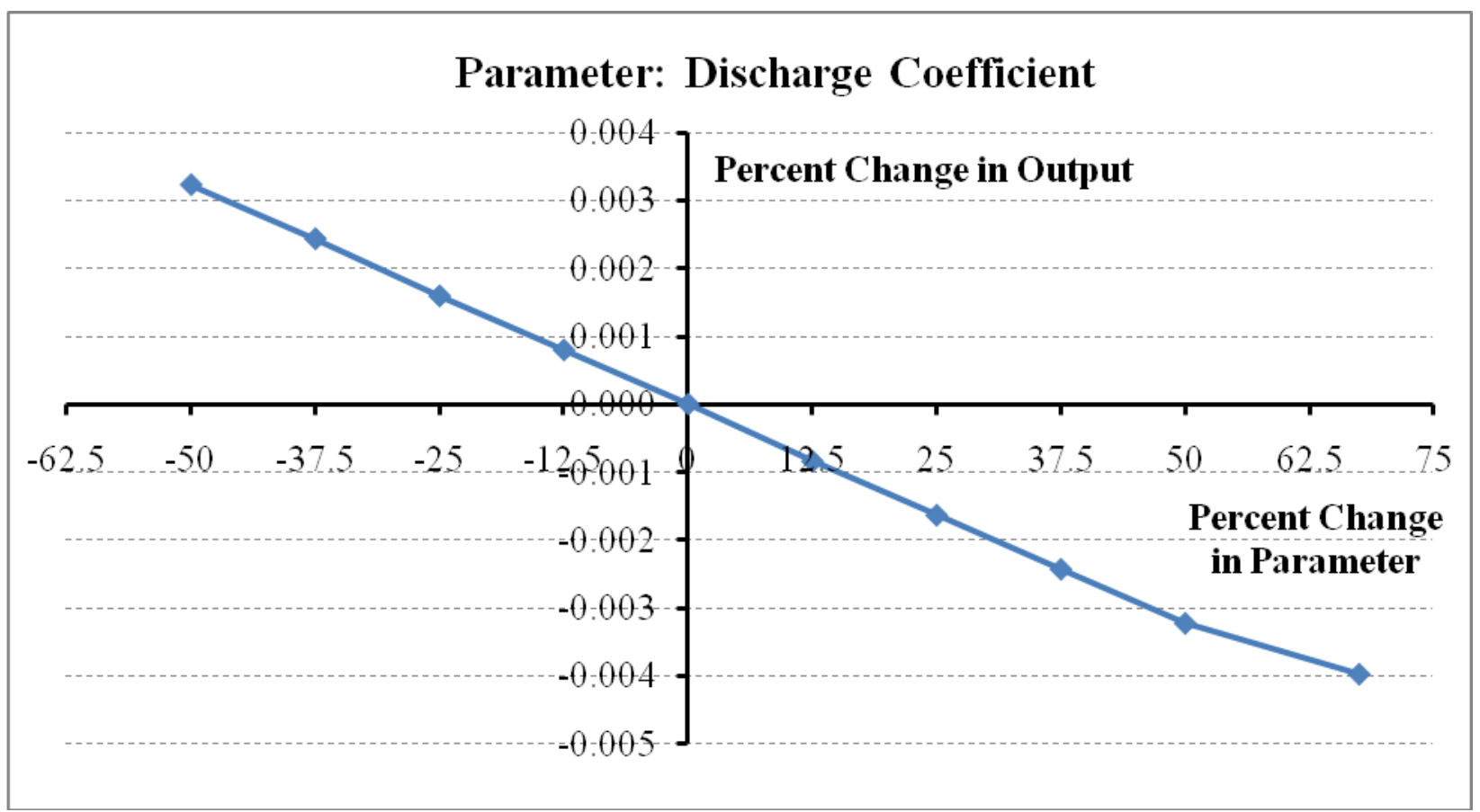

Figure B11 - Sensitivity analysis chart for discharge coefficient parameter 


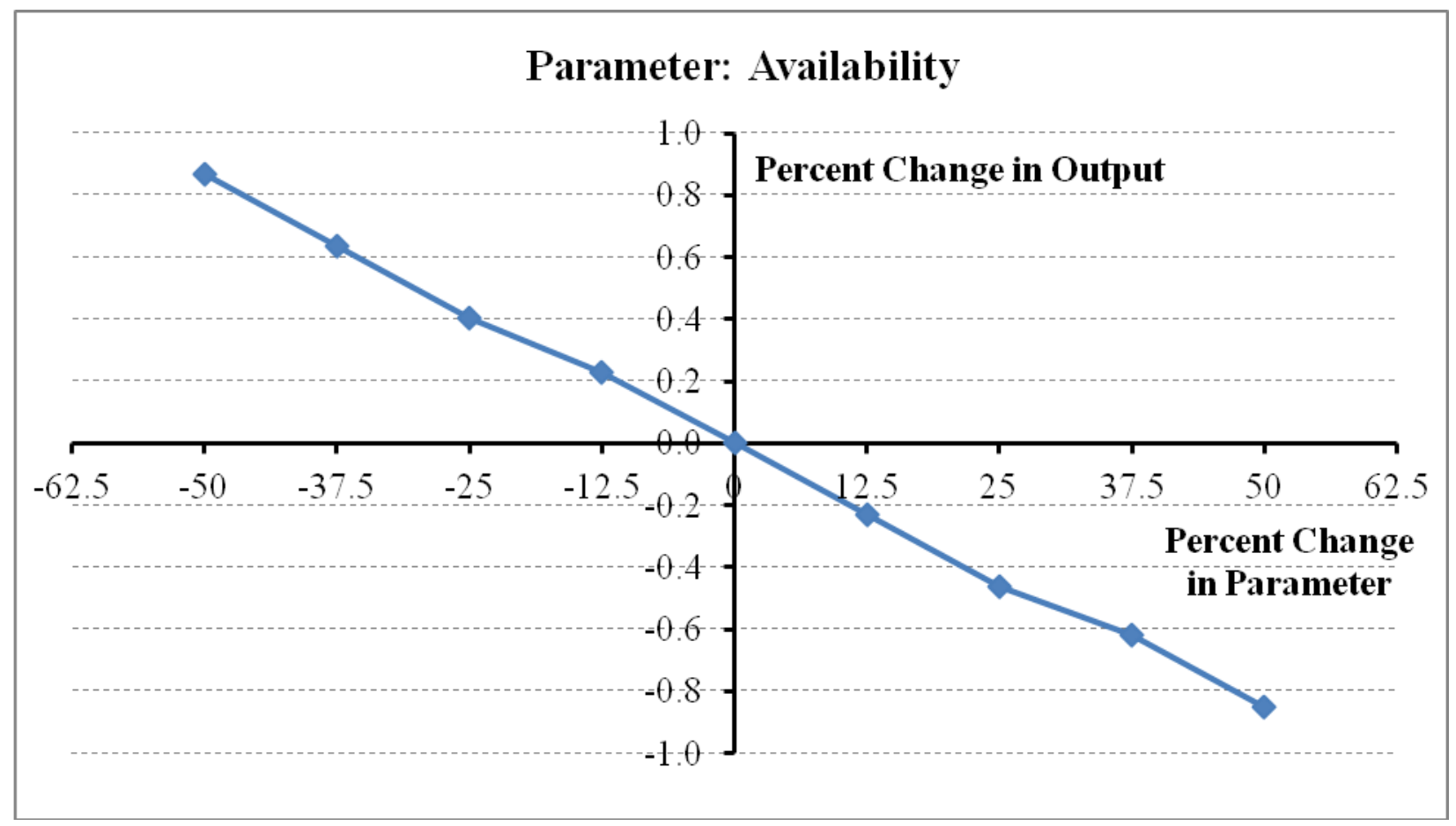

Figure $\mathrm{C} 1$ - Sensitivity analysis chart for availability parameter

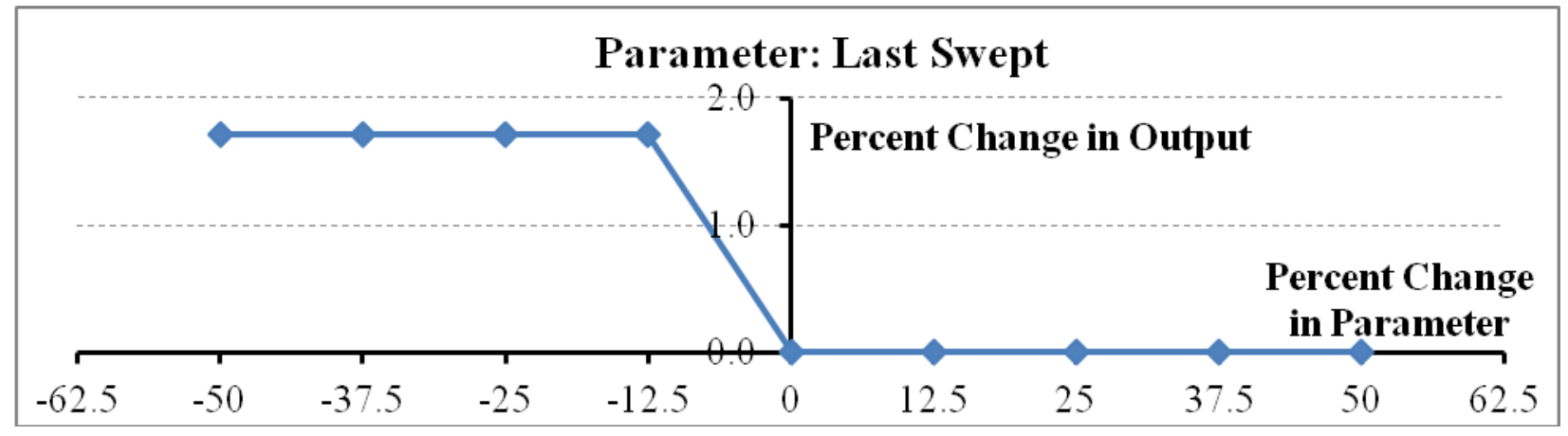

Figure C2 - Sensitivity analysis chart for last swept parameter 


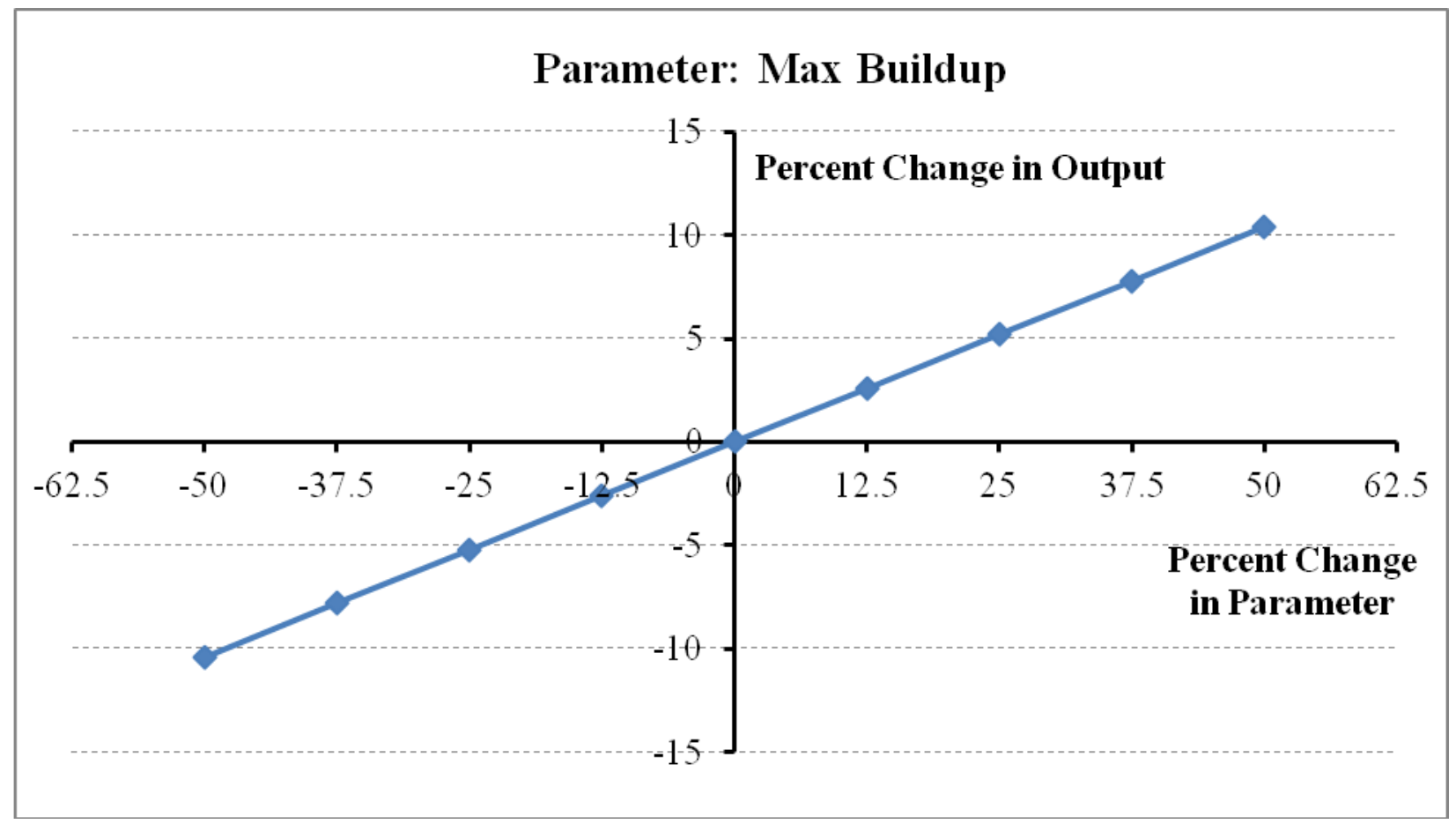

Figure C3 - Sensitivity analysis chart for max buildup parameter

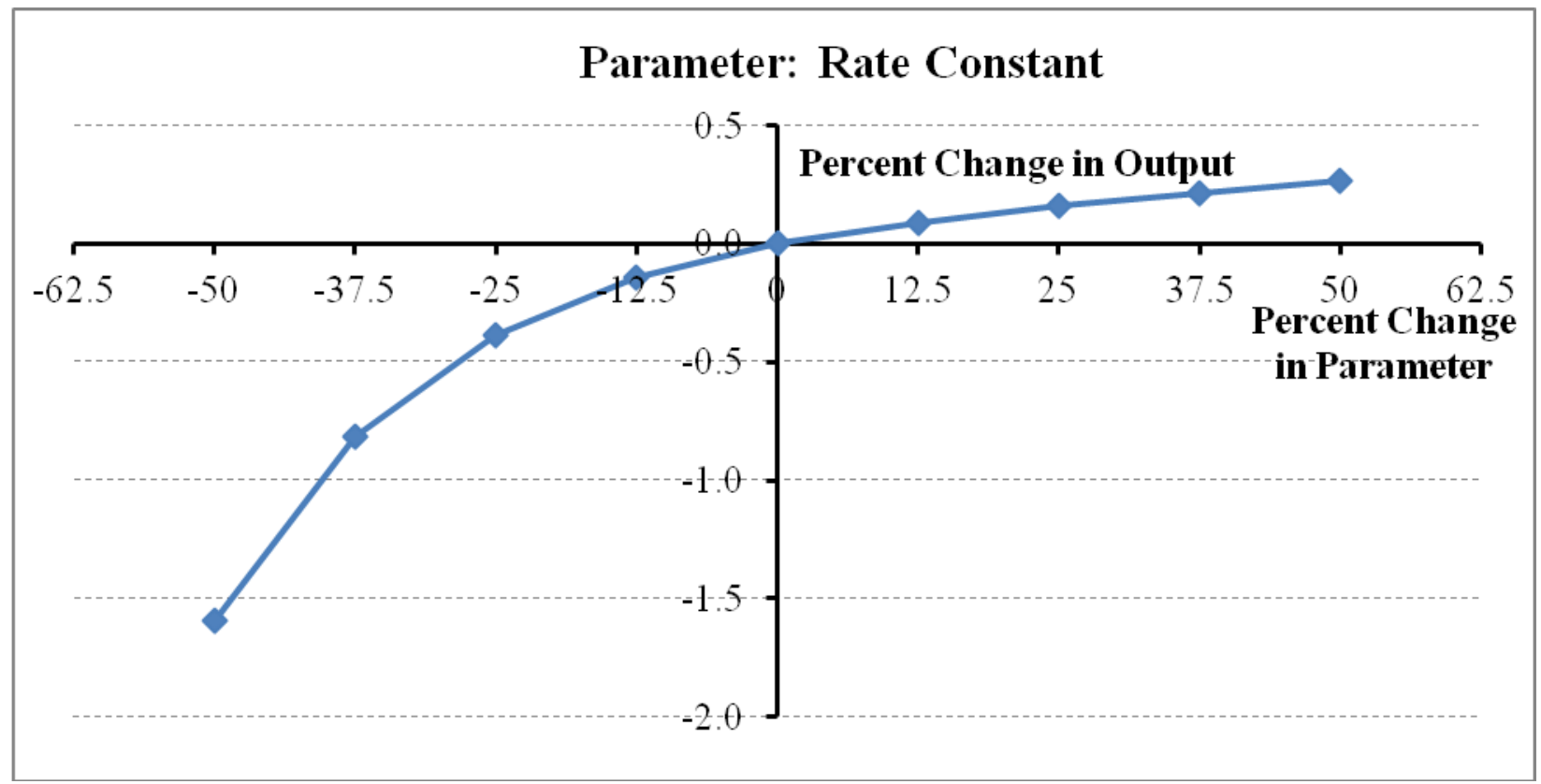

Figure C4 - Sensitivity analysis chart for rate constant parameter 


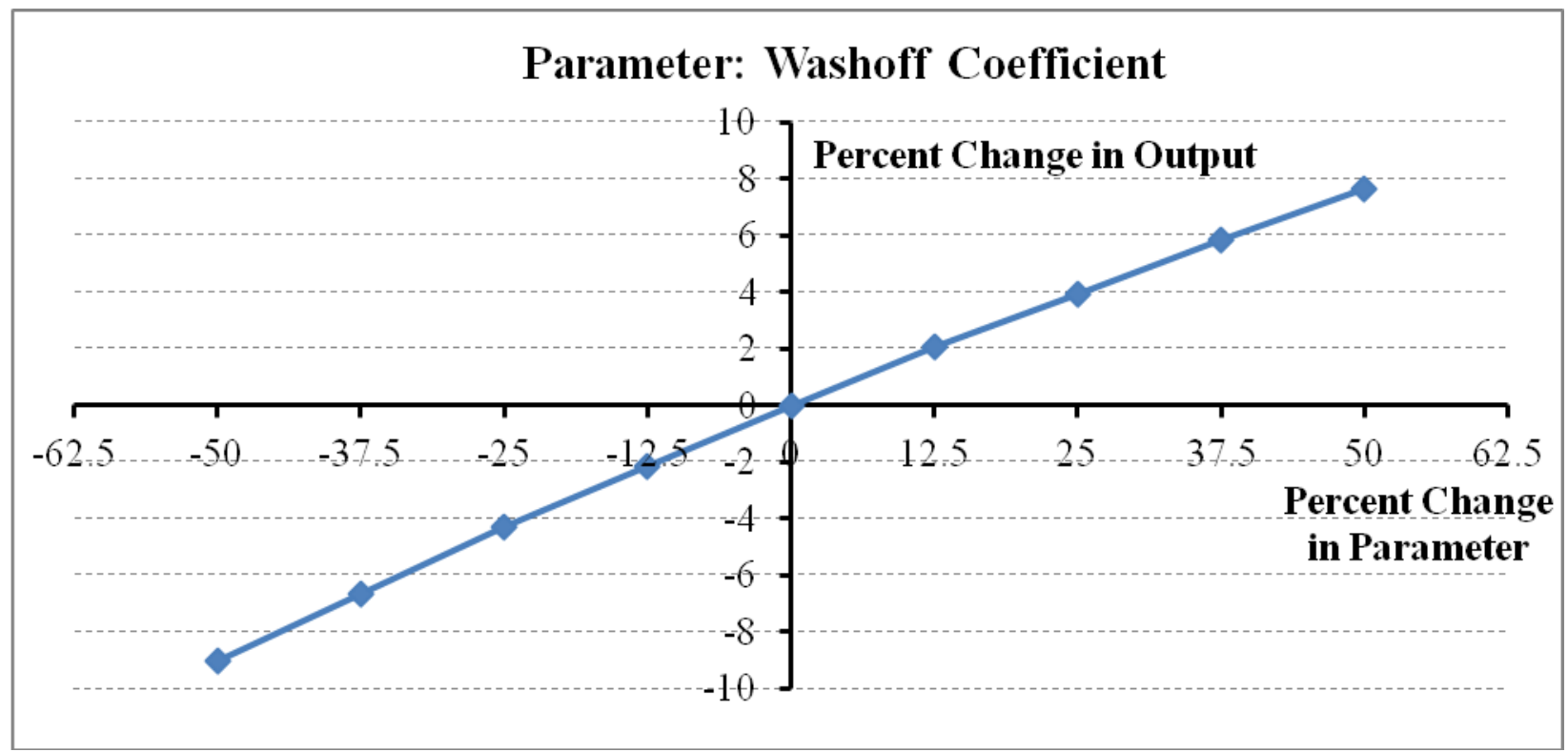

Figure C5 - Sensitivity analysis chart for washoff coefficient parameter

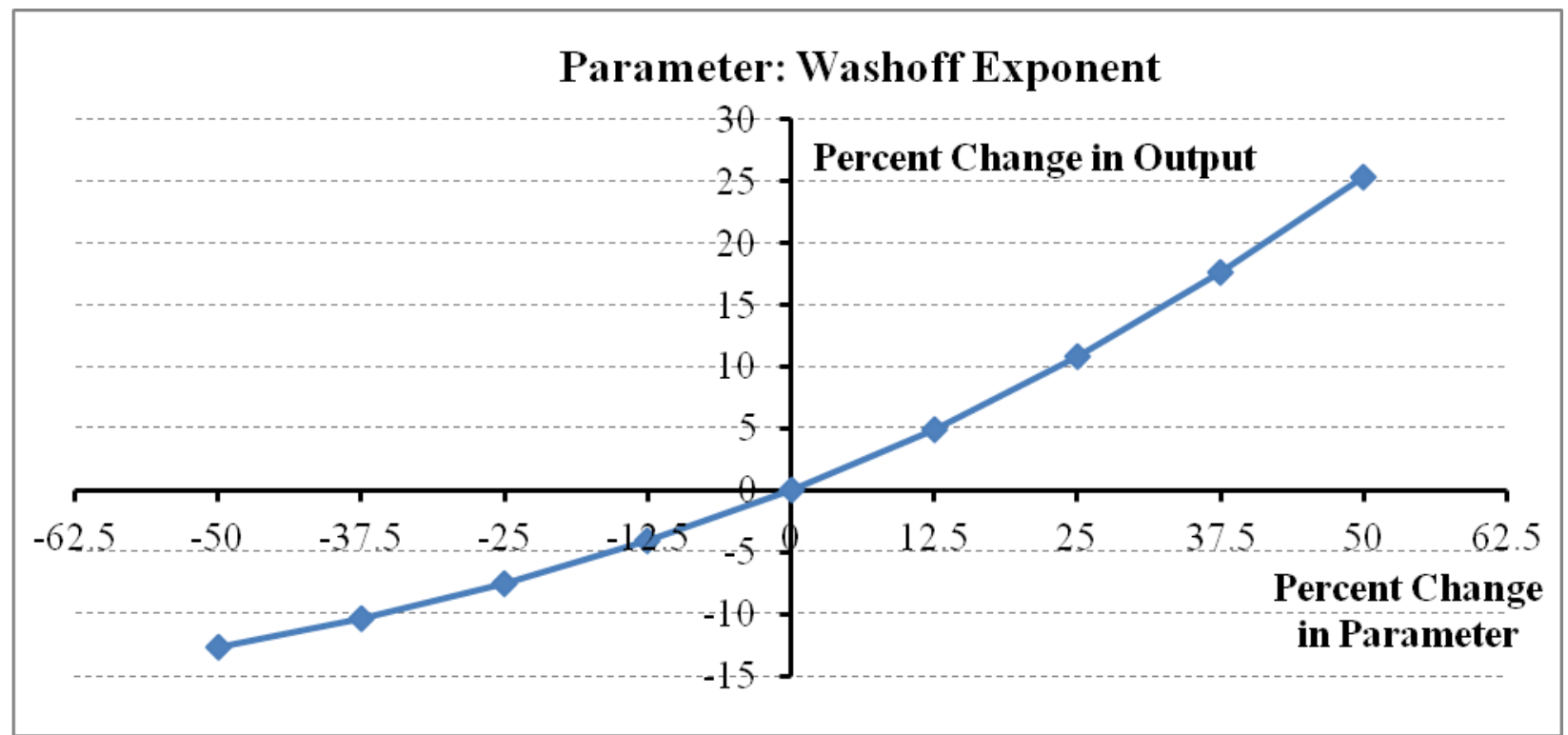

Figure C6 - Sensitivity analysis chart for washoff coefficient parameter 


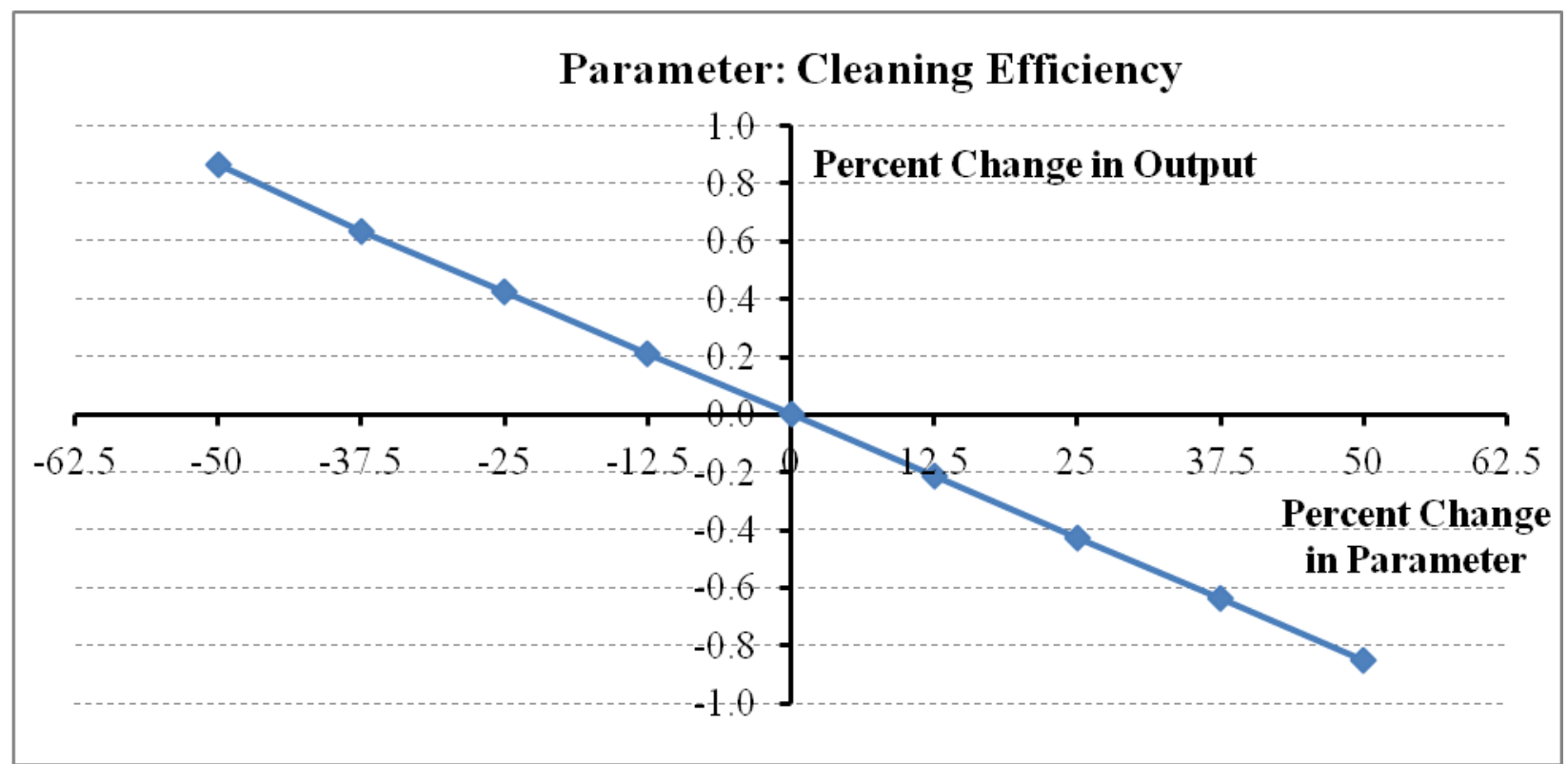

Figure C7 - Sensitivity analysis chart for cleaning efficiency parameter 


\section{Appendix D - Water Quantity Model: Calibration Charts}

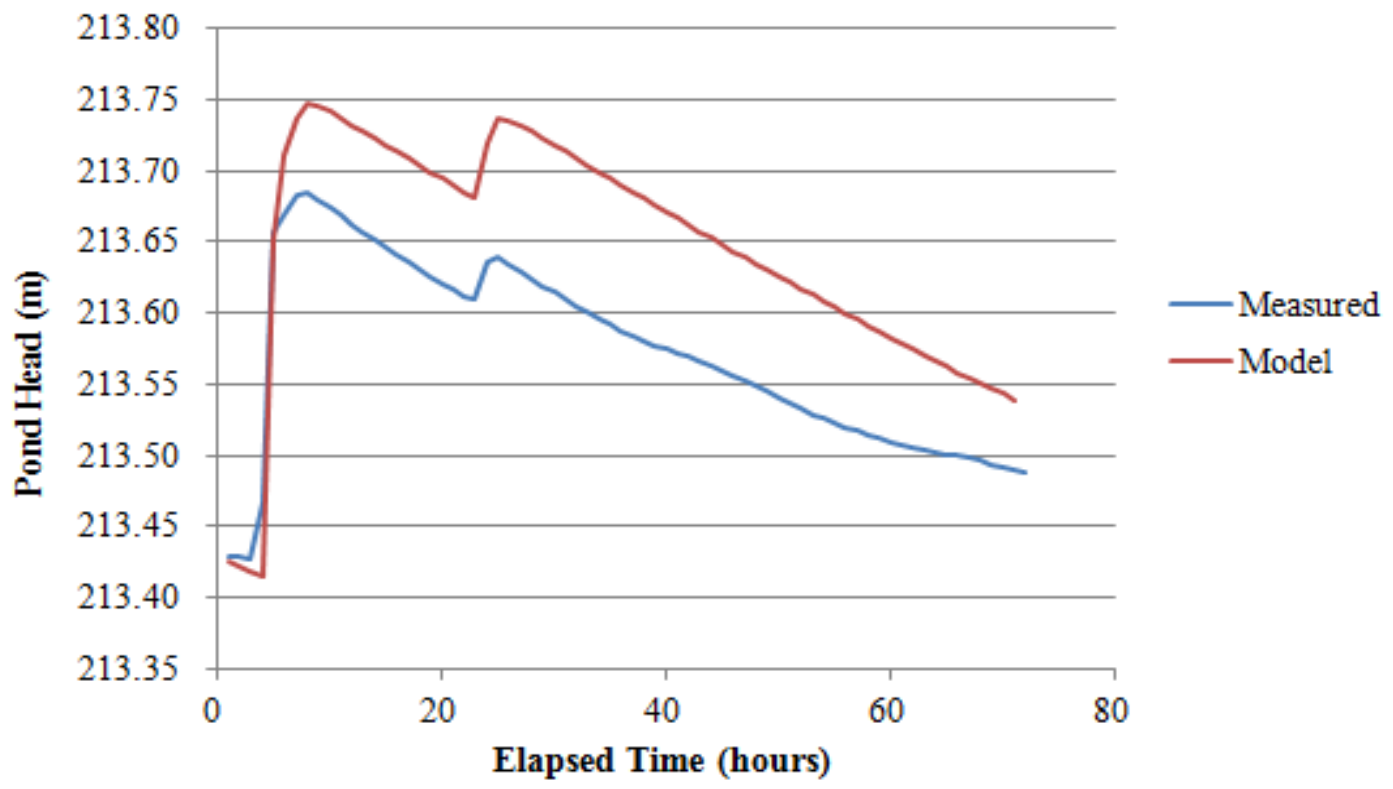

Figure D1 - Pond head comparison for August 24-27, 2007 rainfall event

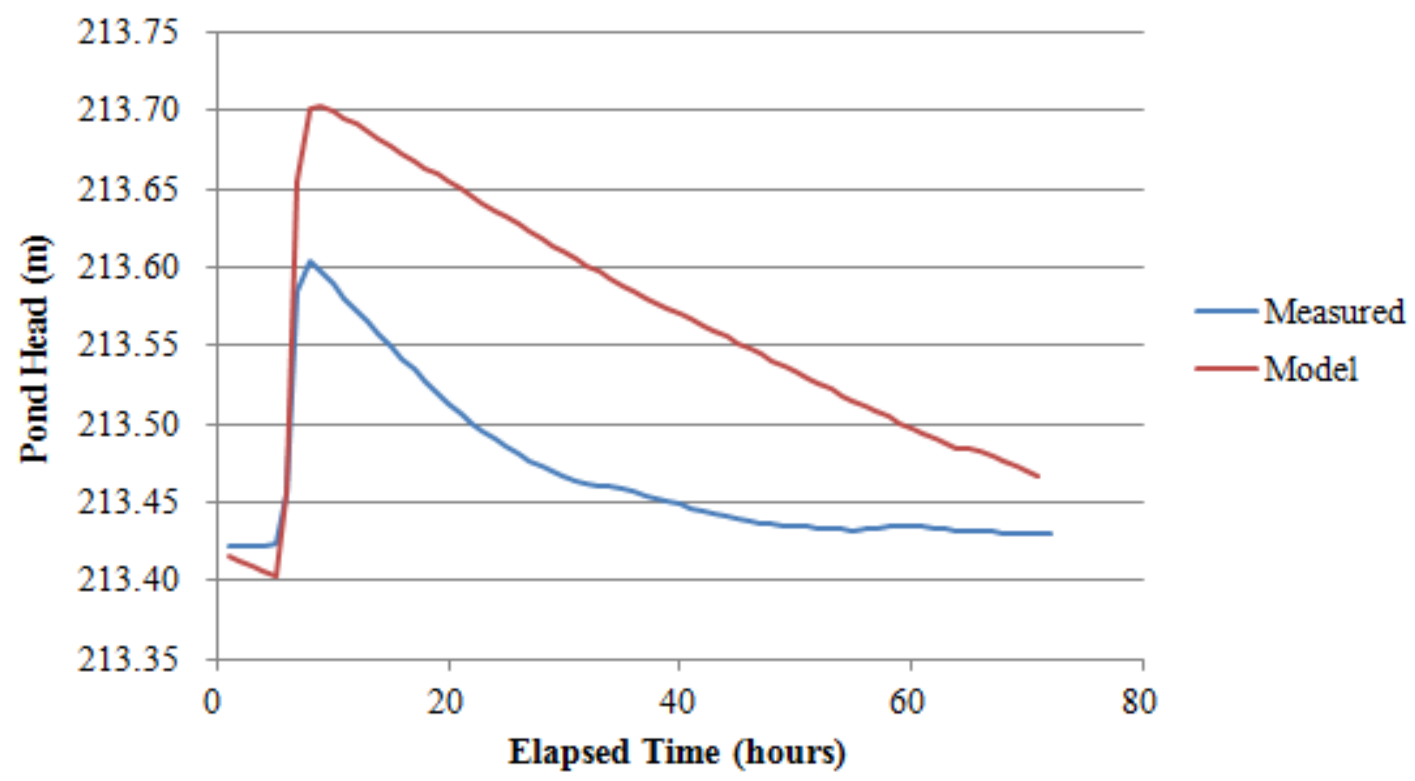

Figure D2 - Pond head comparison for September 5-7, 2007 rainfall event 


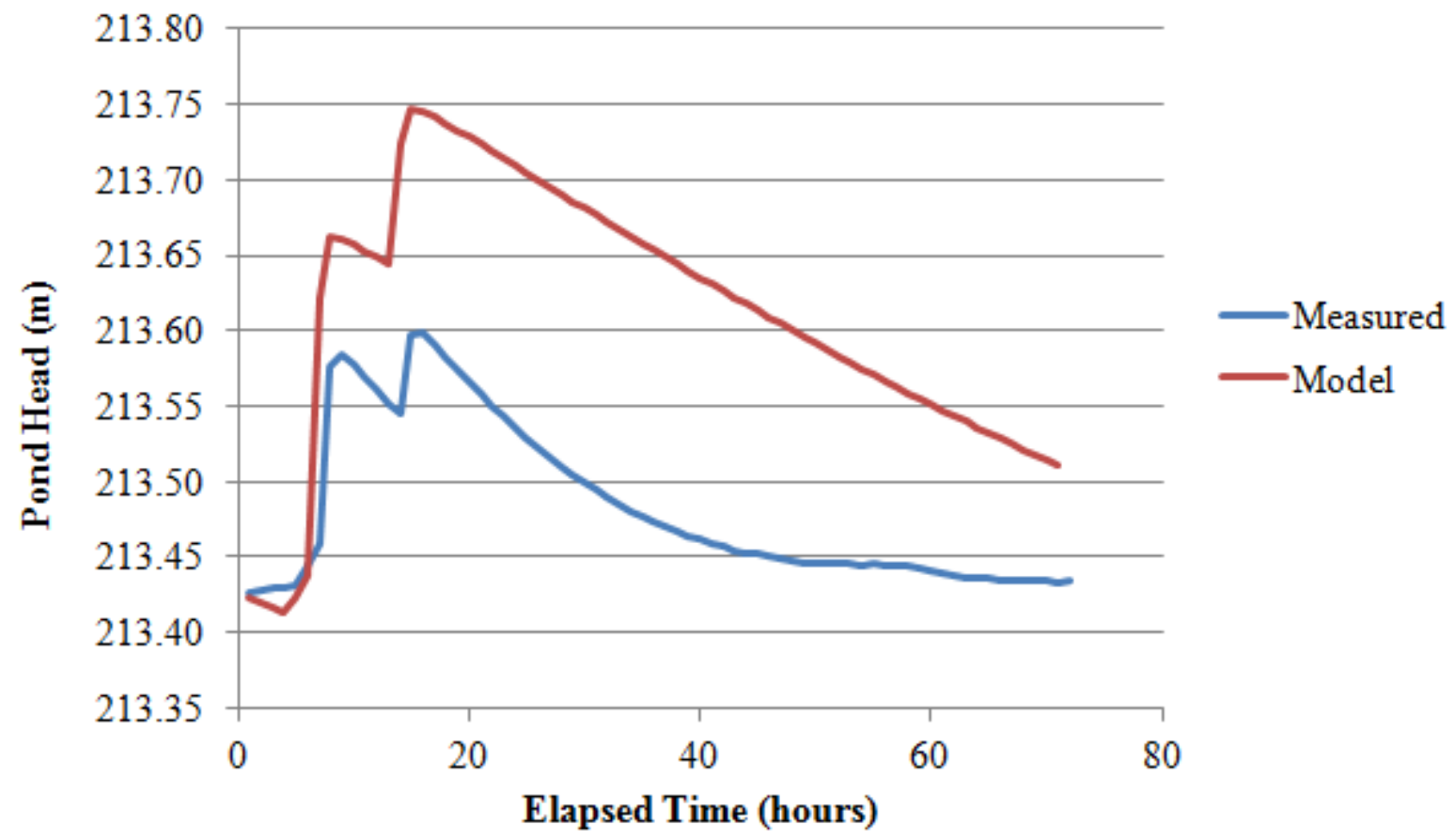

Figure D3 - Pond head comparison for October 6-9, 2007 rainfall event

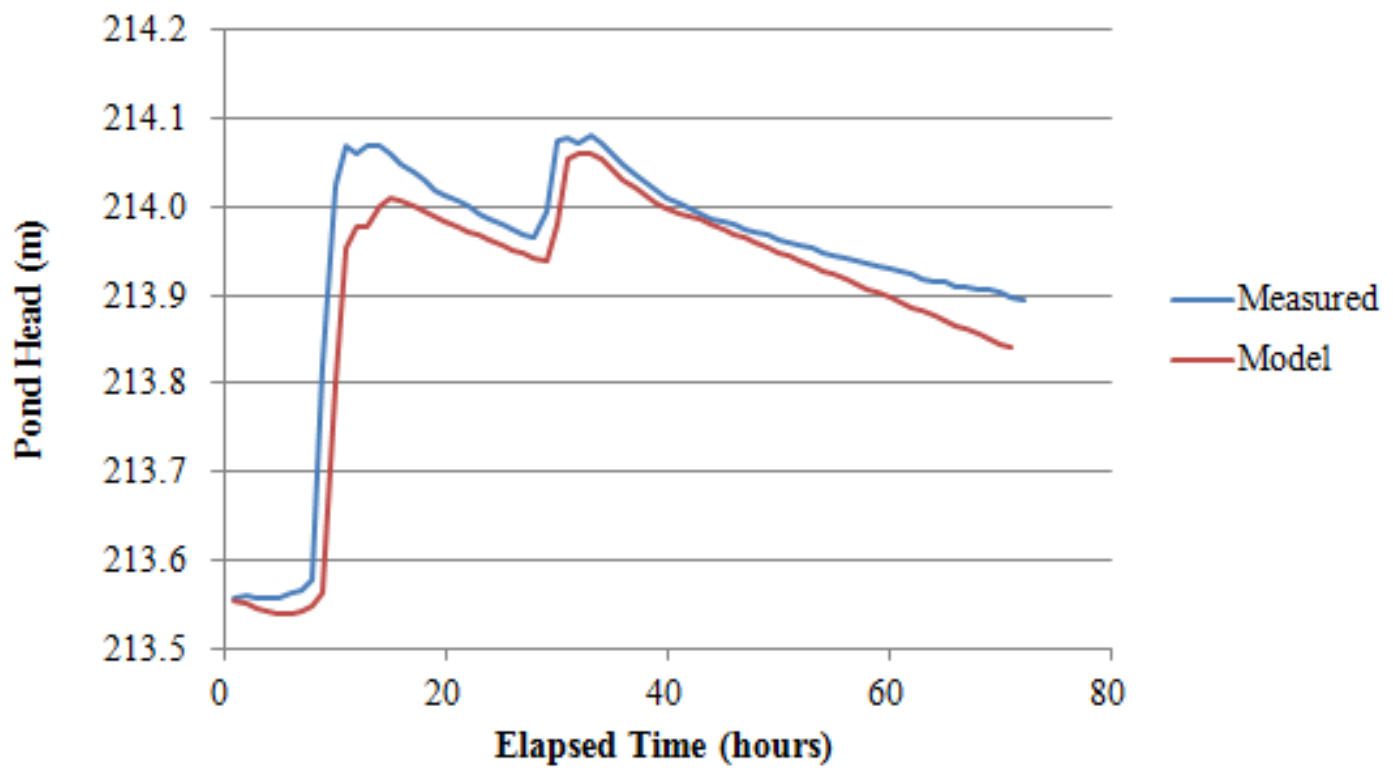

Figure D4 - Pond head comparison for September 13-16, 2007 rainfall event 


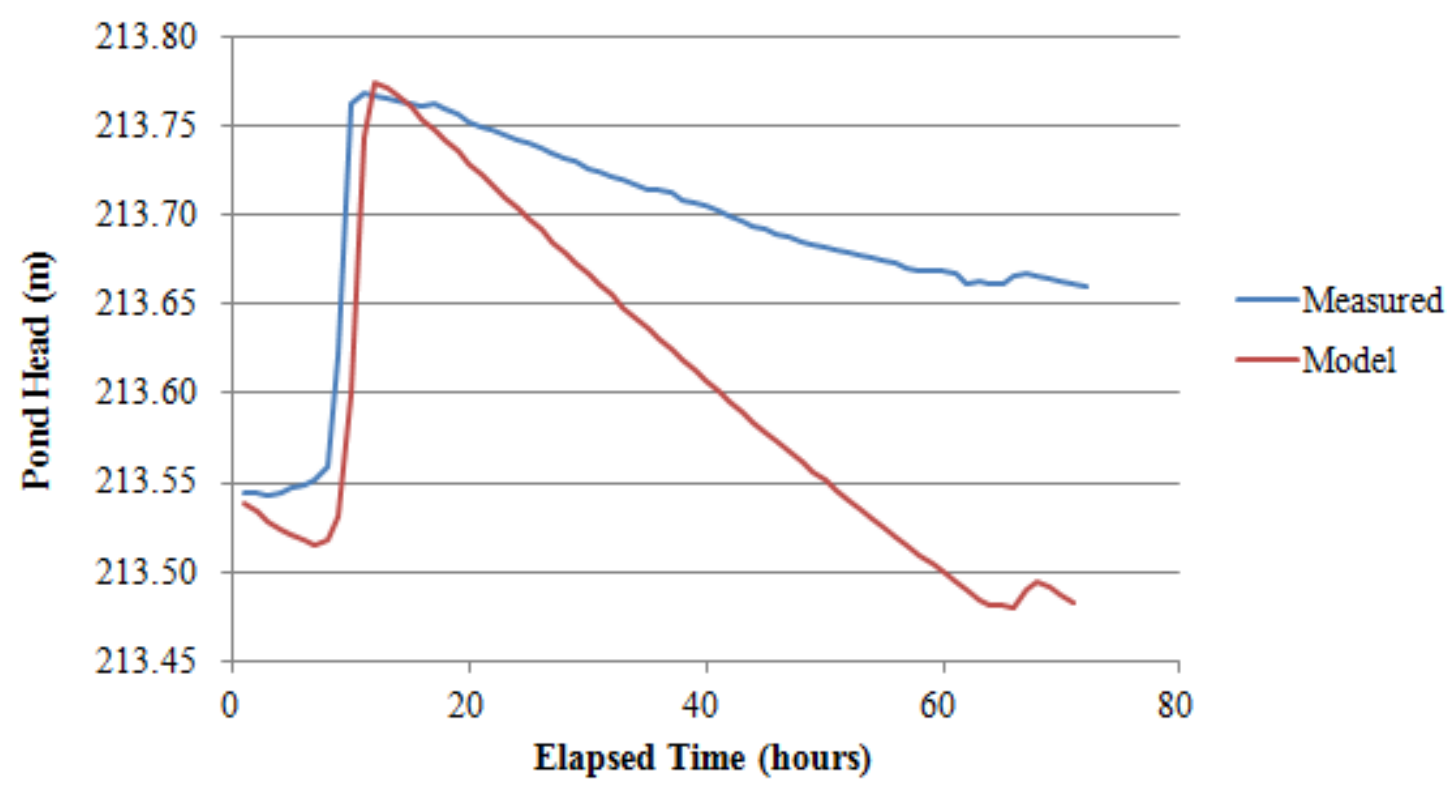

Figure D5 - Pond head comparison for September 30 - October 2, 2008 rainfall event

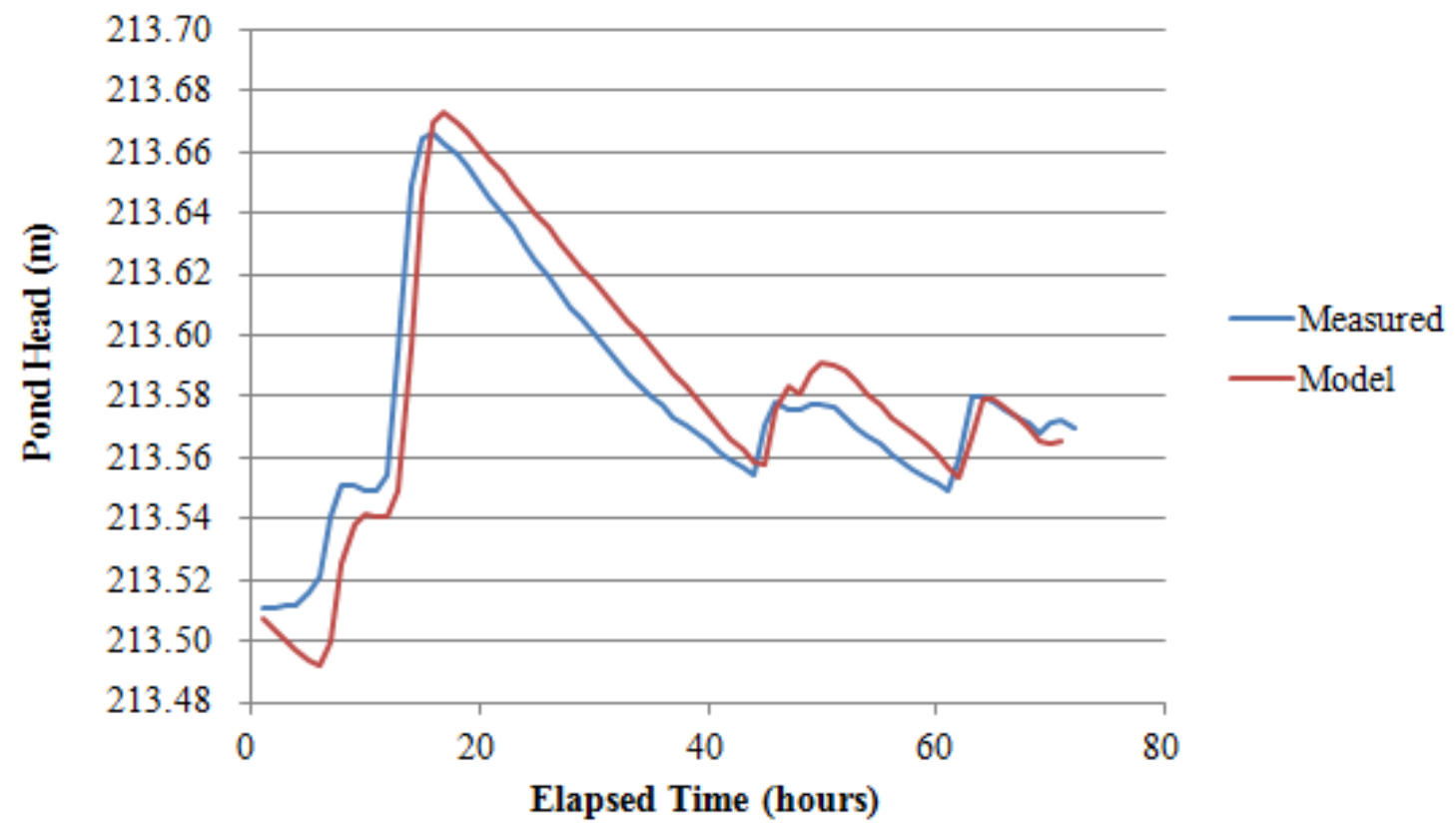

Figure D6 - Pond head comparison for October 24-27, 2008 rainfall event 


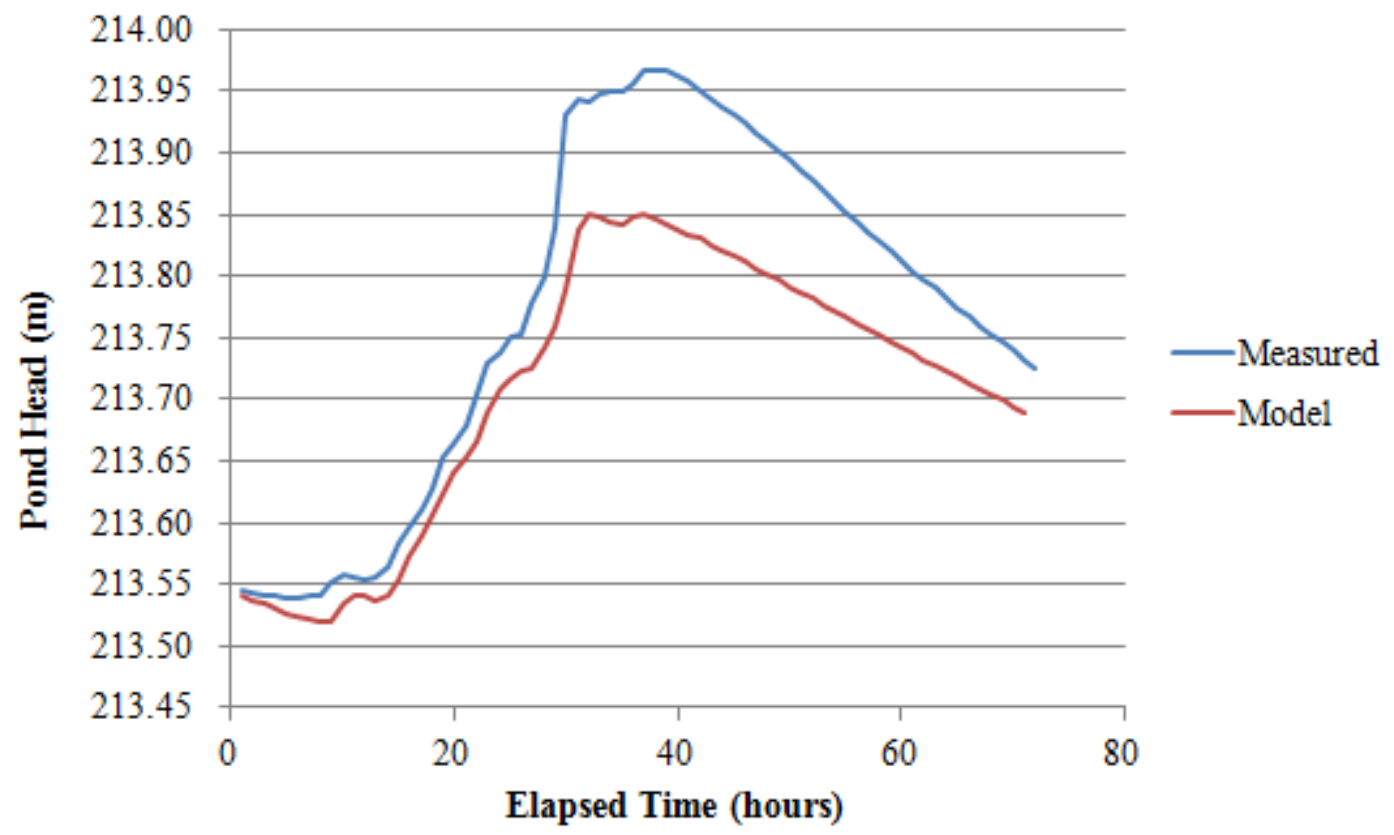

Figure D7 - Pond head comparison for November 14-17, 2008 rainfall event

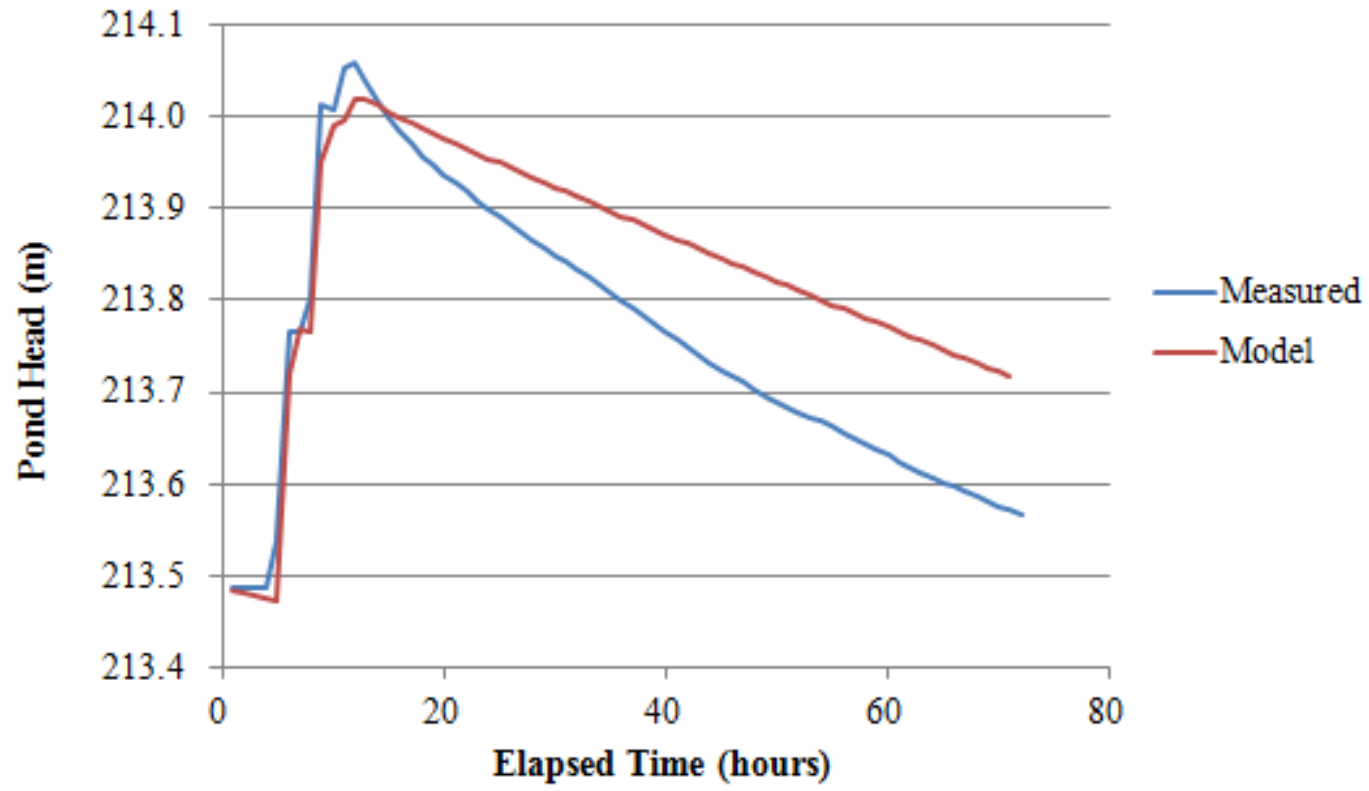

Figure D8 - Pond head comparison for May 9-12, 2009 rainfall event 


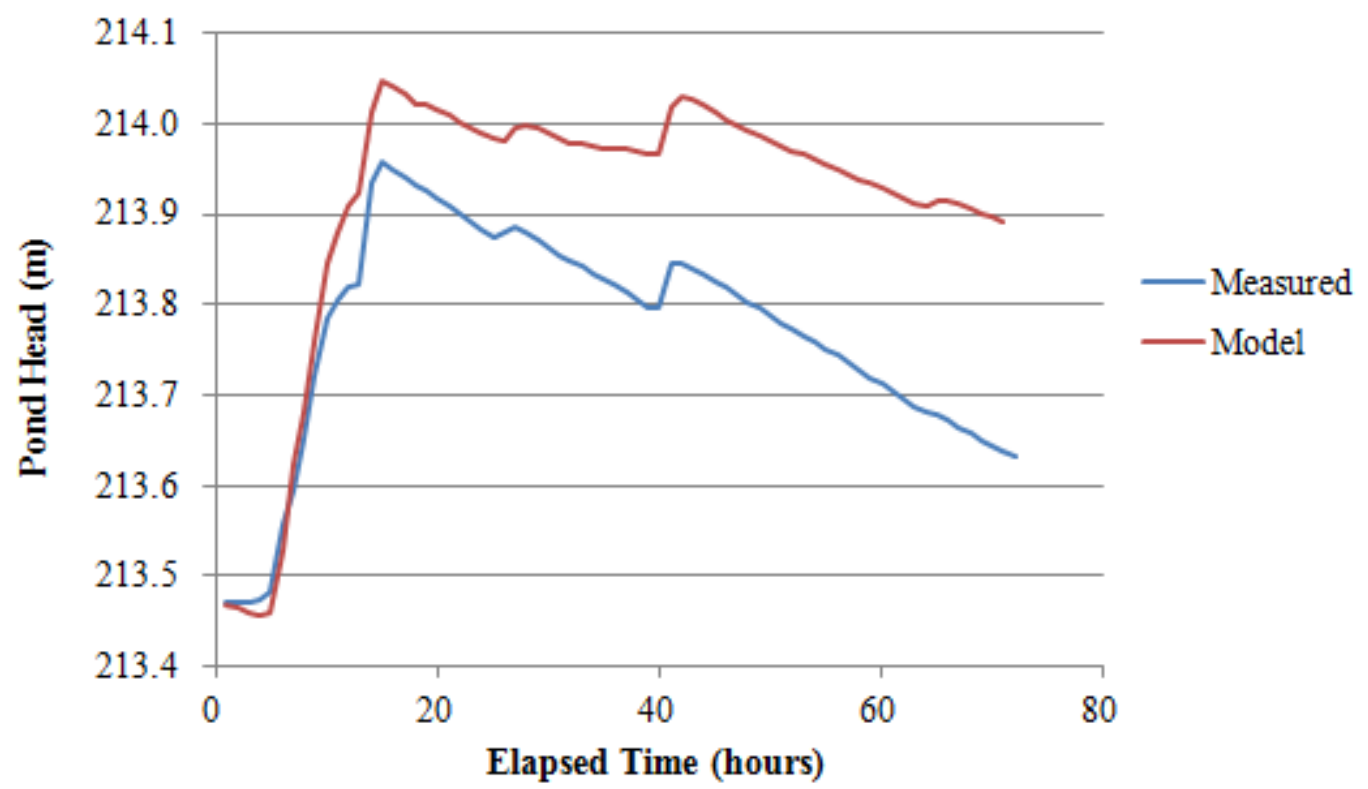

Figure D9 - Pond head comparison for May 27-30, 2009 rainfall event 


\section{Appendix E - Cleanout Frequency Charts}

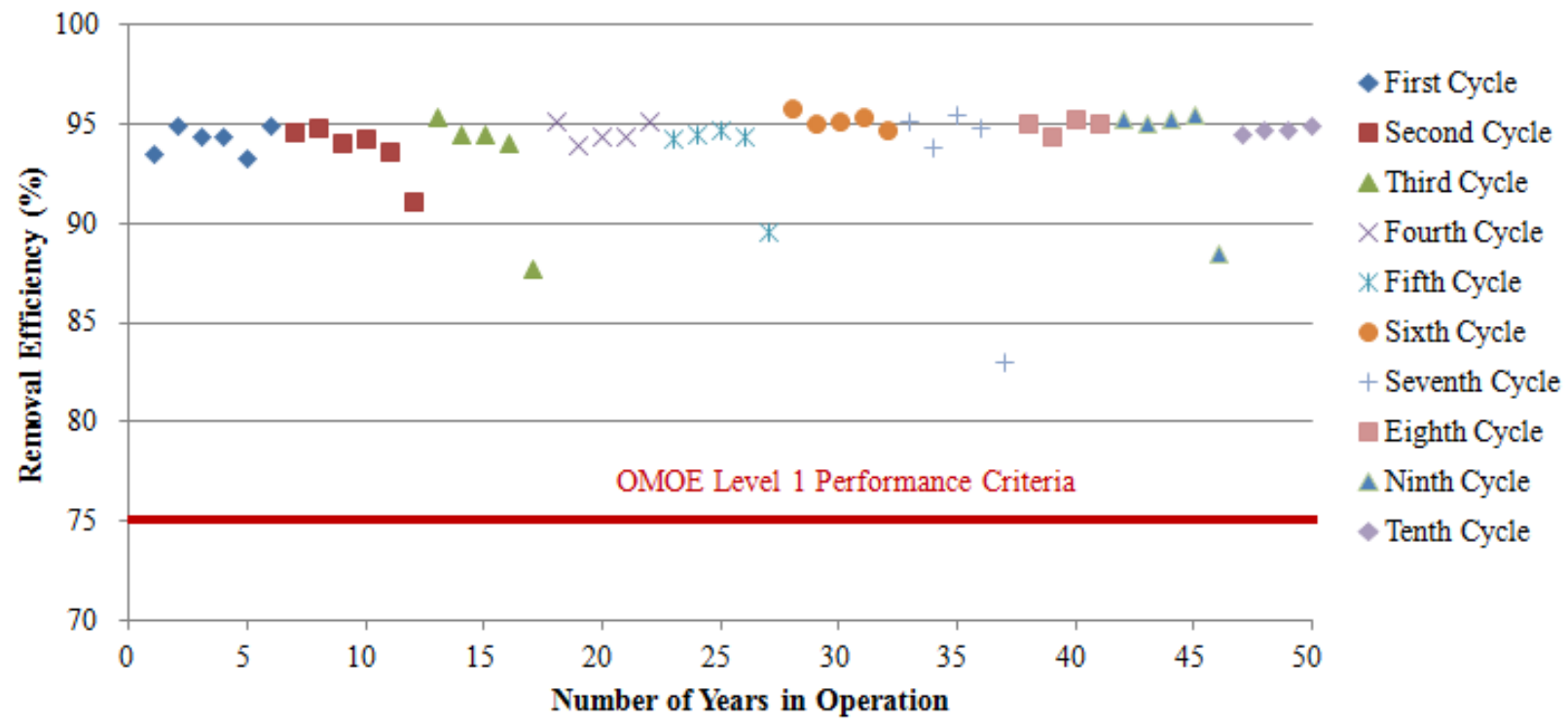

Figure E1 - Removal efficiency versus time using a 5\% loss of volume criteria

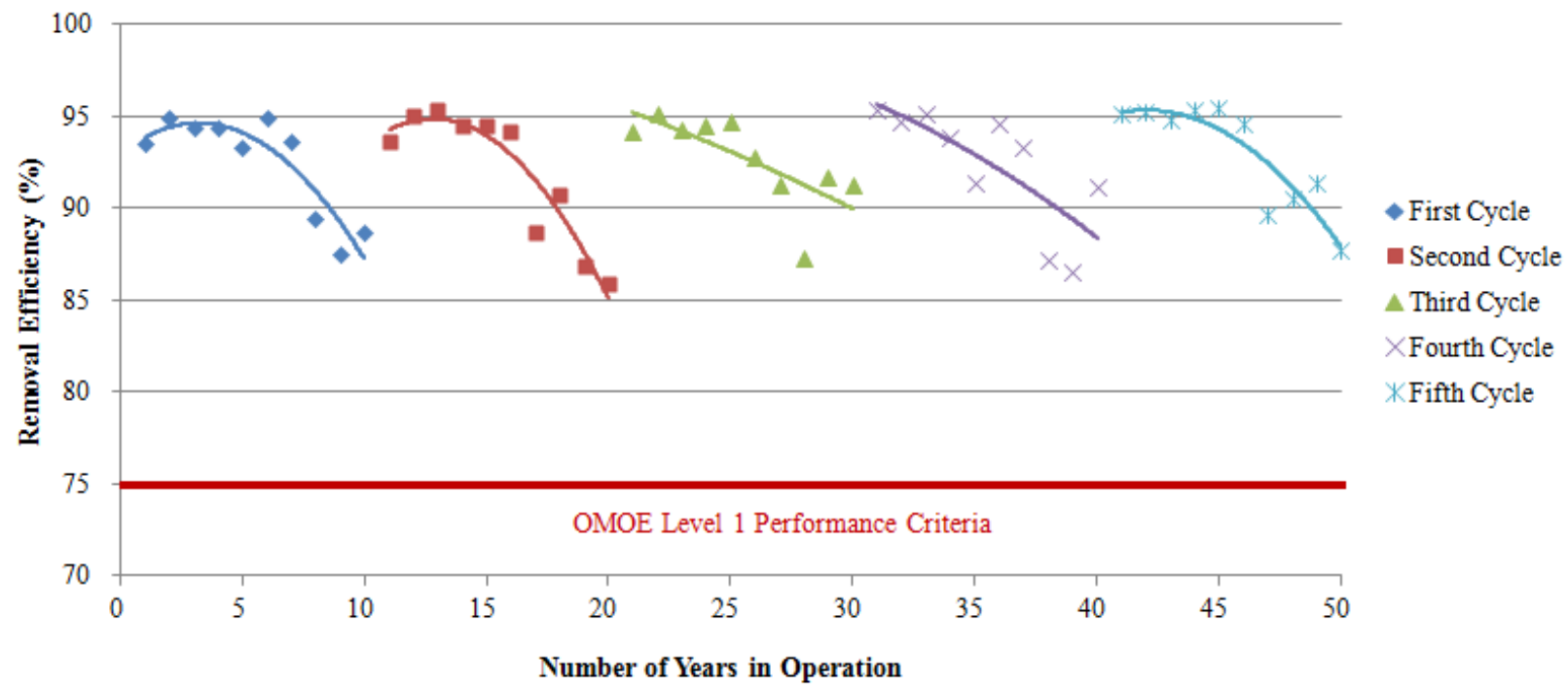

Figure E2 - Removal efficiency versus time for a cleanout frequency of 10 years 


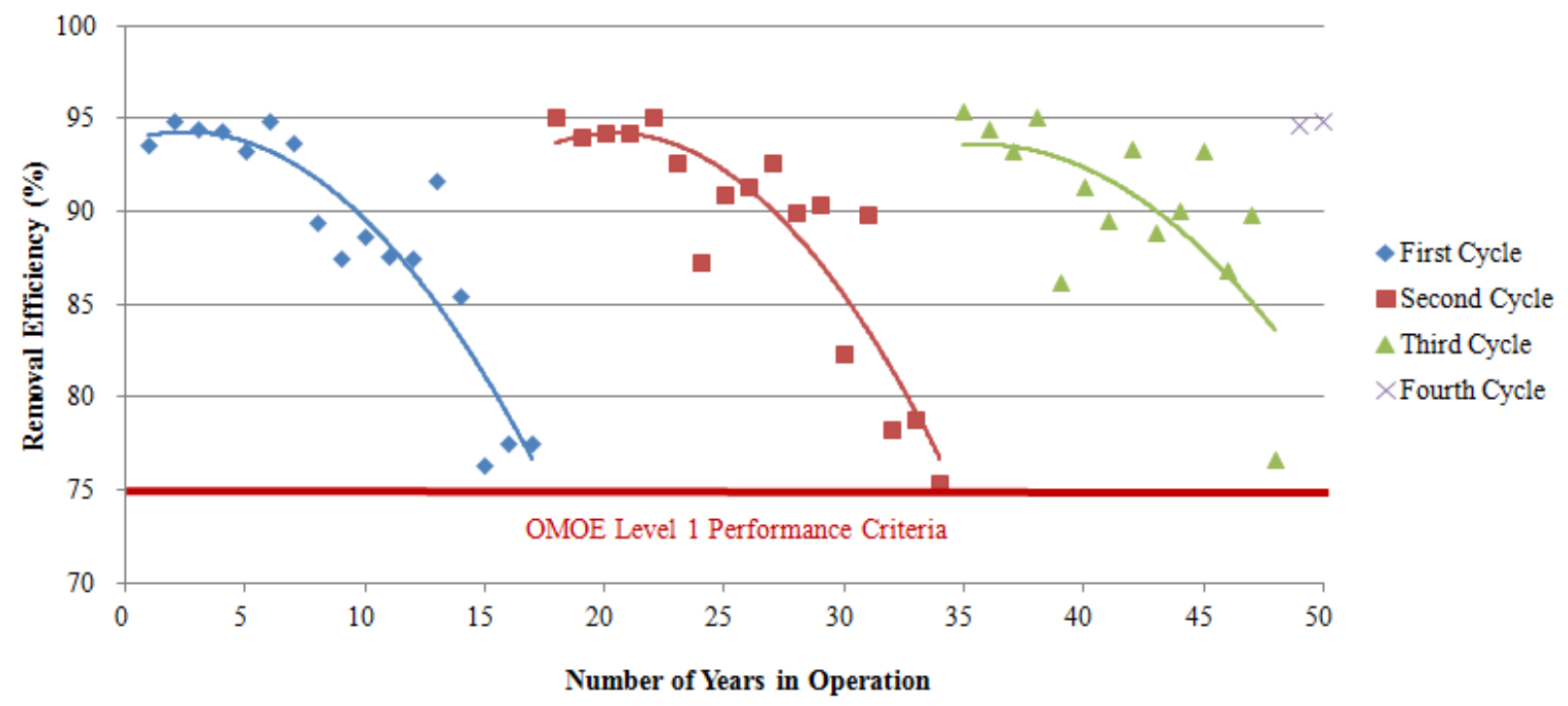

Figure E3 - Removal efficiency versus time using a 5\% loss of performance criteria

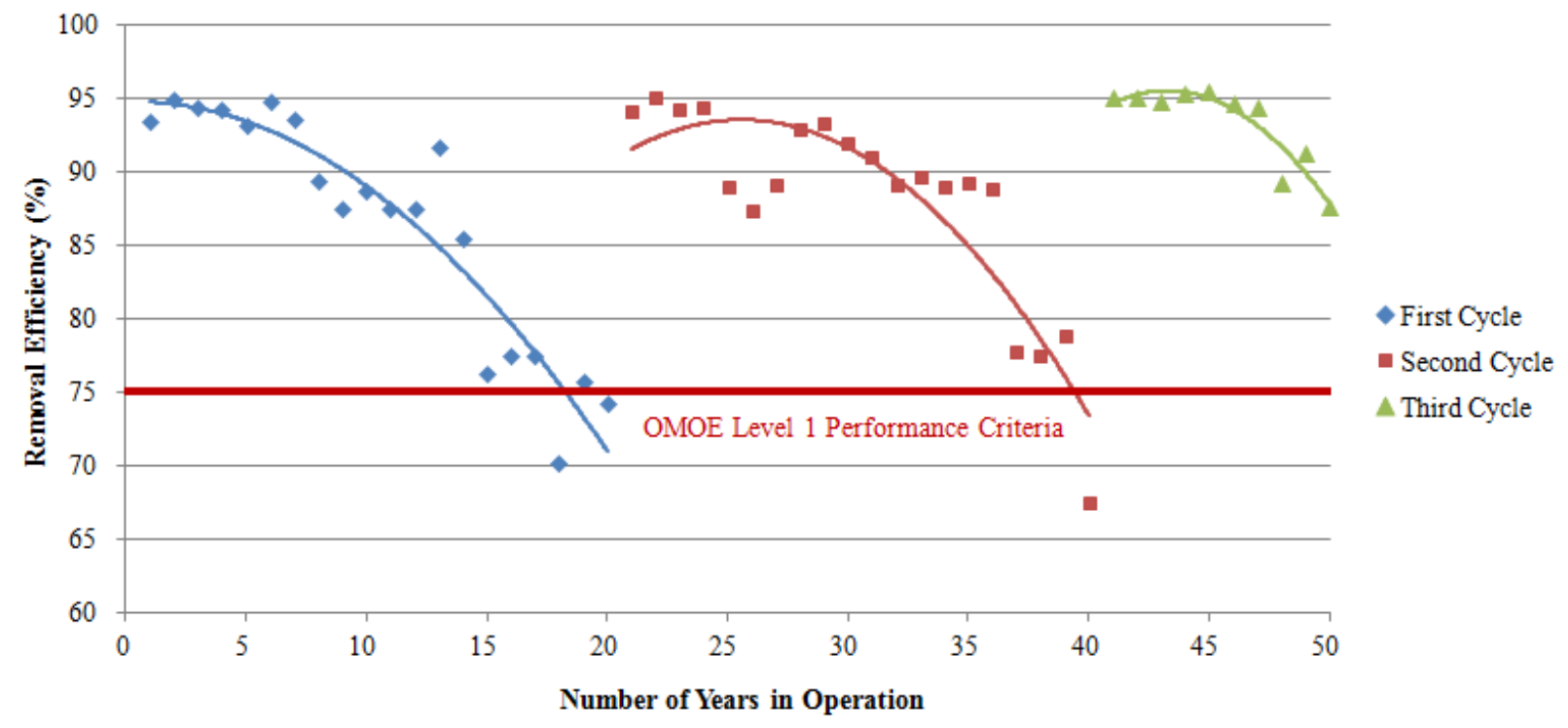

Figure E4 - Removal efficiency versus time for a cleanout frequency of 20 years 


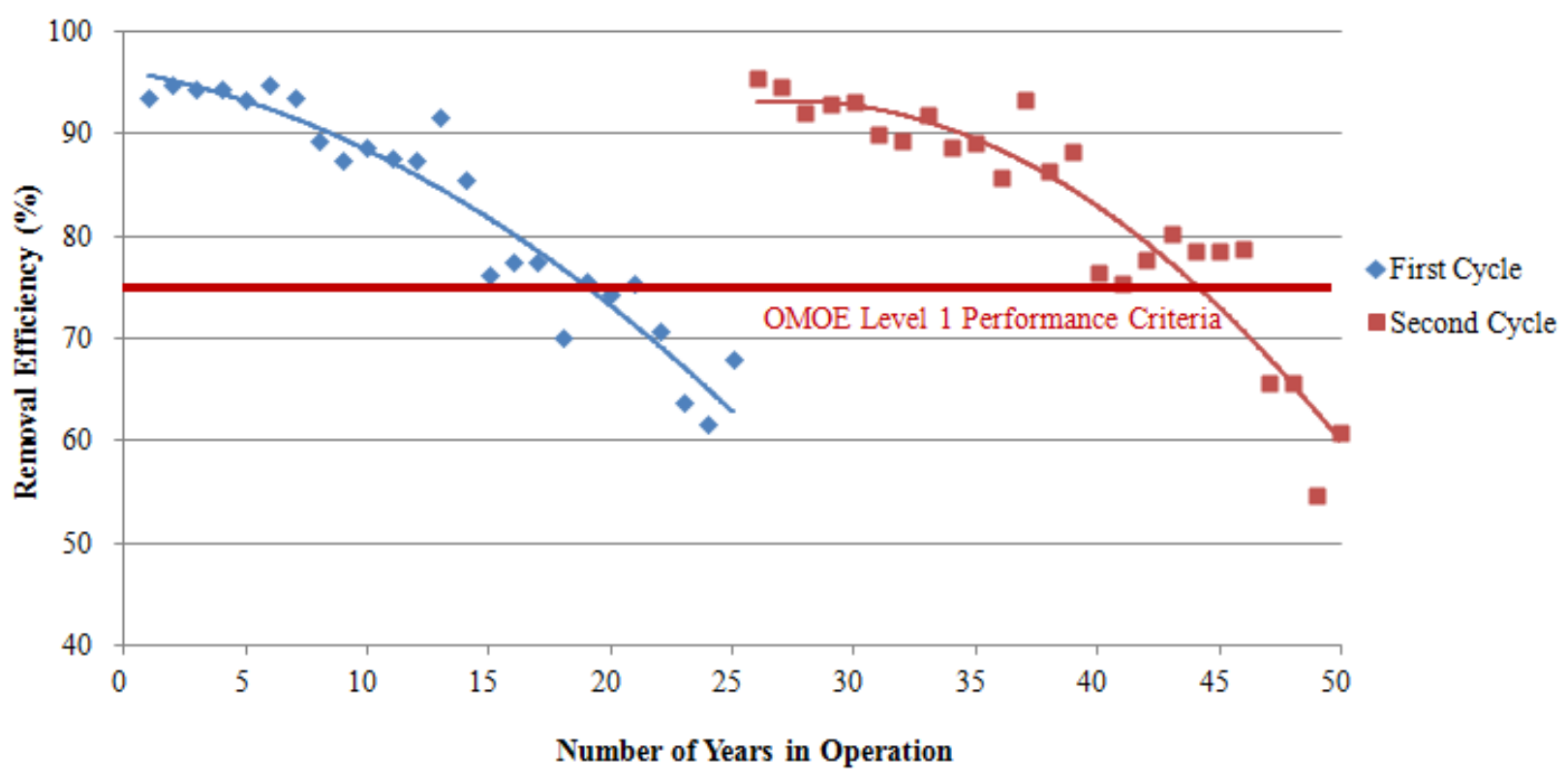

Figure E5 - Removal efficiency versus time for a cleanout frequency of 25 years

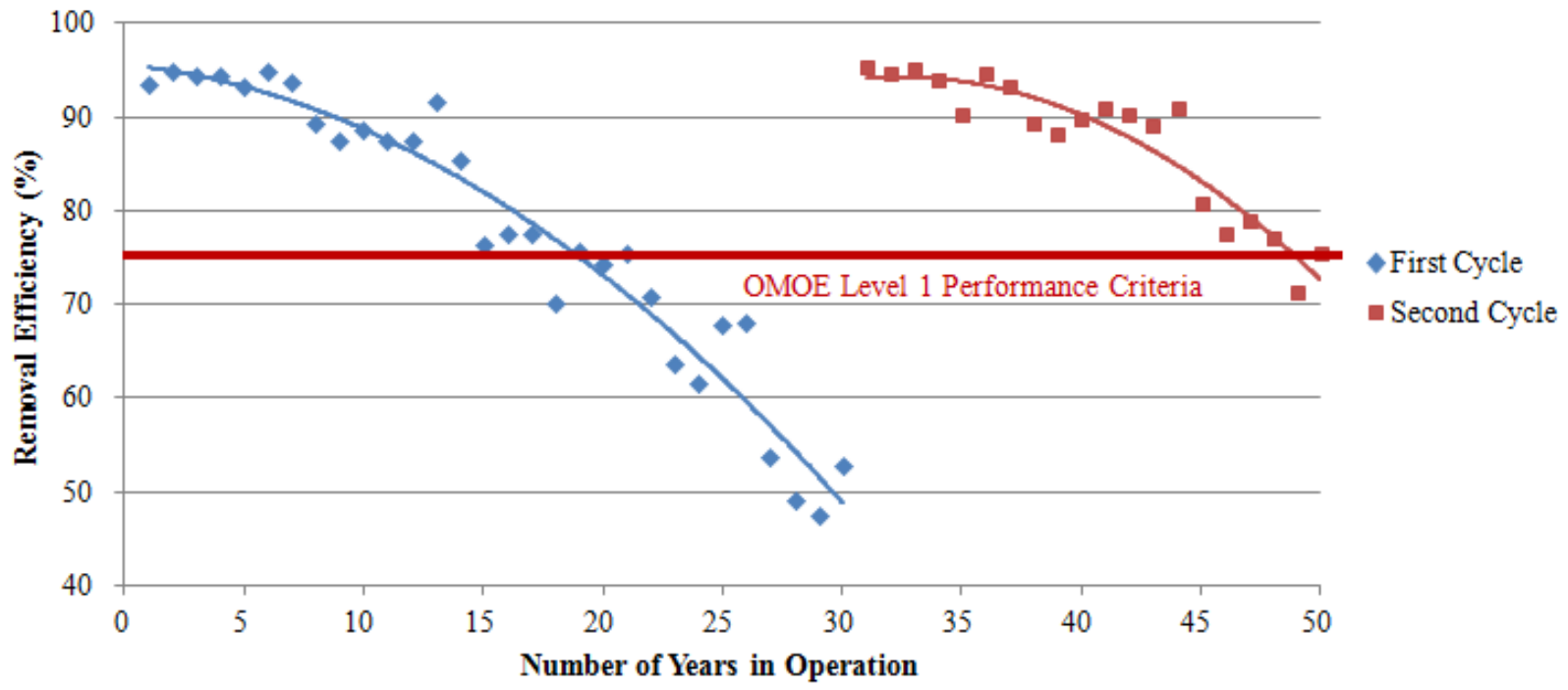

Figure E6 - Removal efficiency versus time for a cleanout frequency of 30 years 


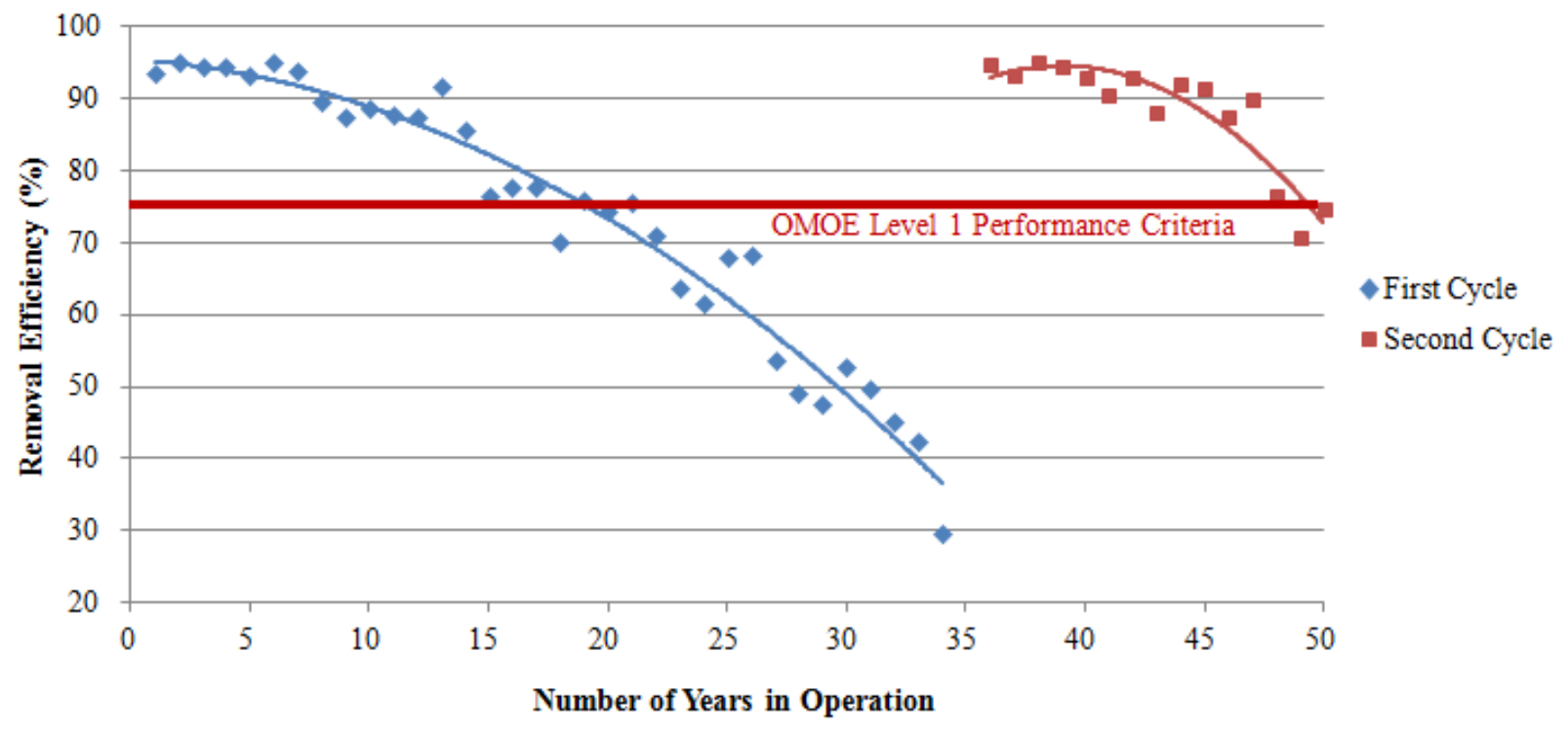

Figure E7 - Removal efficiency versus time for a cleanout frequency of 35 years

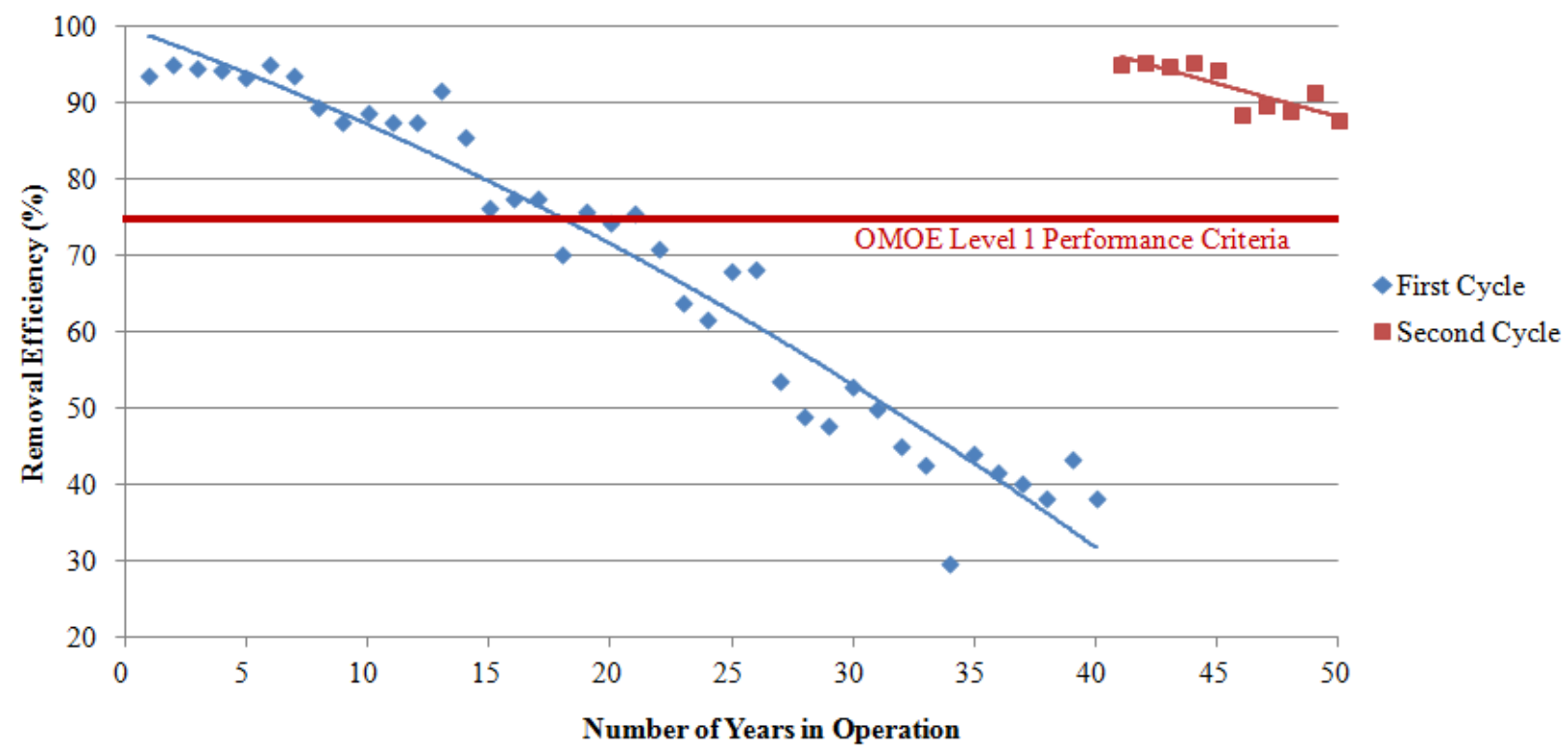

Figure E8 - Removal efficiency versus time for a cleanout frequency of 40 years 


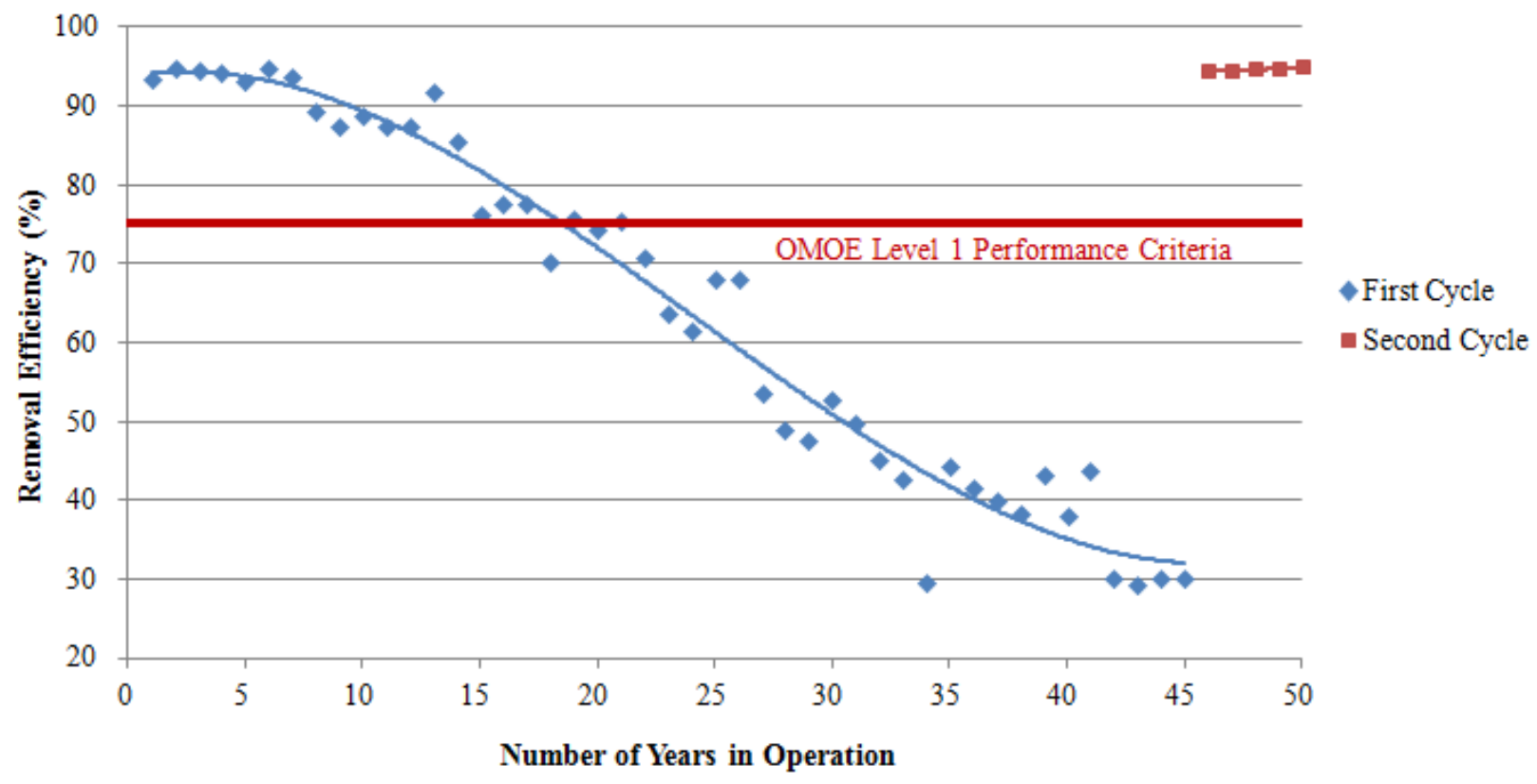

Figure E9 - Removal efficiency versus time for a cleanout frequency of 45 years

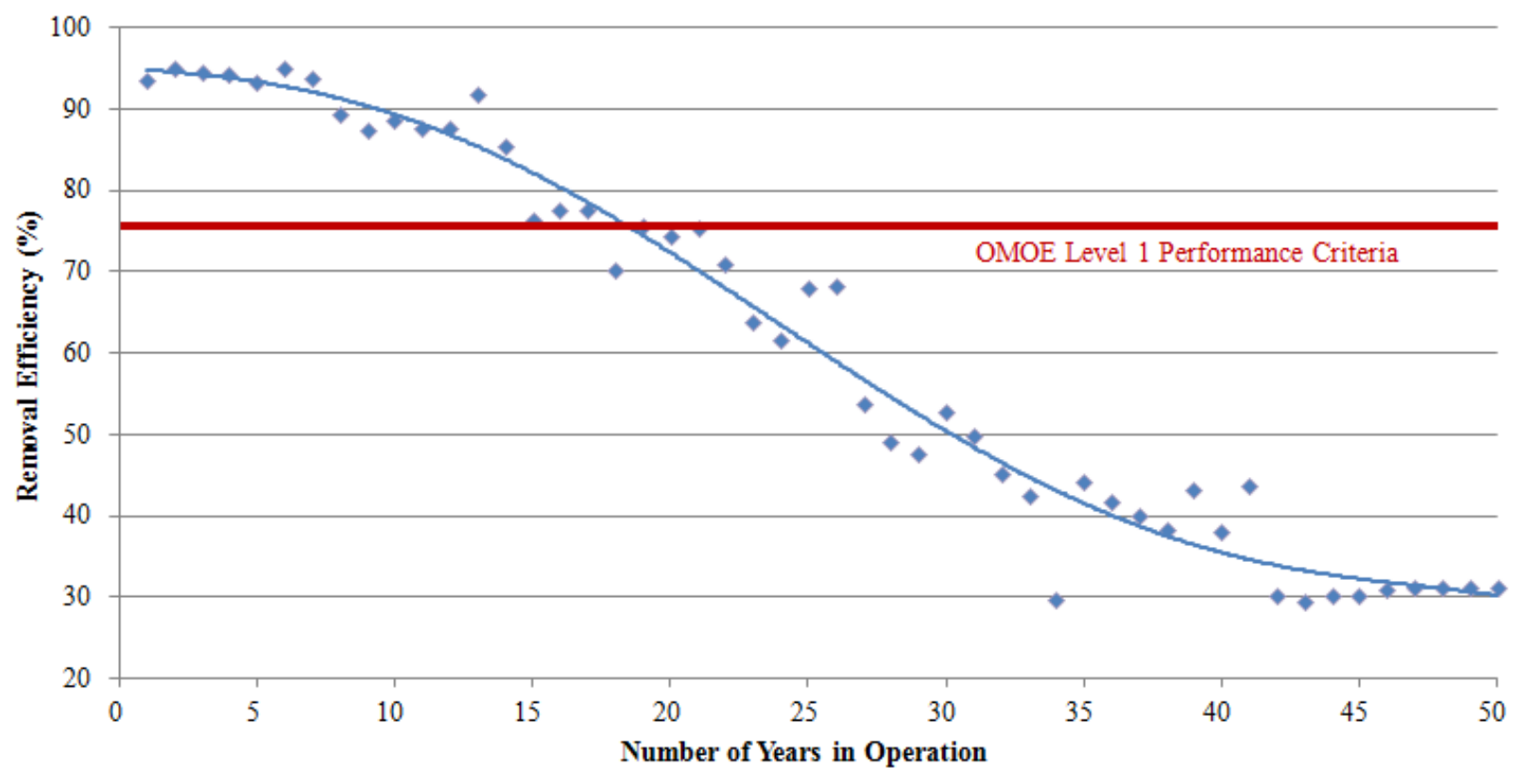

Figure E10 - Removal efficiency versus time for a cleanout frequency of 50 years 


\section{Appendix F - Description of Tools Developed}

Tool Name: $\quad$ Transposed Matrix to Vector Converter

Program Used: $\quad$ Microsoft Excel

Inputs: $\quad$ A square array of hourly rain gauge data over 1 month.

Calculations: $\quad$ Pressing the command button converts the hourly data for 1 month to a vector. The user is required to copy and paste the output into the following sheet, where hours and days are converted to cumulative hours in a year. The user is required to repeat this process for all 12 months. If data for a month is missing, the user can skip that month, as the default value is 0 . Data is copied to a third sheet where non-zero values are kept while the rest are deleted. The data is copied to a fourth sheet where tips (in $0.1 \mathrm{~mm}$ ) are converted to $\mathrm{mm}$.

Outputs: Annual hours versus rainfall in $\mathrm{mm}$. 
Tool Name: $\quad$ Graph Shape and Max Checker

Program Used: $\quad$ Microsoft Excel

Inputs: $\quad$ Historical facility elevation data and facility elevation data from model.

Calculations: $\quad$ The user is required to paste the historical and model data into the appropriate columns. The tool then automatically graphs the two sets of values and superimposes them. The tool calculates the peak head in meters and the percent difference.

Outputs: $\quad$ Peak head difference in meters and percent difference between model and measurements. 
Tool Name: $\quad$ Pond Geometry Calculator Tool

Program Used: $\quad$ Microsoft Excel

Inputs: $\quad$ Cumulative sediment accumulation in cubic meters.

Calculations: $\quad$ Uses volume of frustums to approximate pond volume and calculates new pond profile.

Outputs: $\quad$ Pond profile as depth in meters versus area in square meters. 
Tool Name: $\quad$ Removal Efficiency Versus Sediment Buildup Tool

Program Used: $\quad$ Microsoft Excel

Inputs: $\quad$ Mass into the facility and mass reacted in kilograms from the model. Number of months of missing rainfall data.

Calculations: $\quad$ Calculates mass out in kilograms, sediment buildup in cubic meters, and buildup during months without rainfall data. Buildup during missing months is calculated by taking the known buildup, dividing by the number of months for which rainfall data is available and multiplying by the number of missing months of data. Adds buildup during missing months with modelled sediment buildup to calculate annual sediment buildup. Uses annual sediment buildup to calculate cumulative sediment buildup in cubic meters, and calculates the annual removal efficiency as a percentage.

Outputs: Annual and cumulative sediment buildup in cubic meters and the annual removal efficiency as a percentage. 
Tool Name: $\quad$ Annual Cost Estimator for Methodology 1

Program Used: $\quad$ Microsoft Excel

Inputs: Cumulative sediment buildup from model in cubic meters, fixed cost in dollars, cost factor from table in dollars per cubic meter and quantity-based discounting factor, the annual performance (removal efficiency) and the annual budget constraint.

Calculations: This tool calculates the cleanout cost, the equivalent cost in the first year of operation of the facility, the equivalent annual cost over the cleanout cycle and selects the year with the lowest annual cost for cleanout.

Outputs: Year with lowest annual cost for cleanout, chart displaying annual cost versus time, and chart displaying annual cost versus performance. The second chart includes a 'feasible region' of removal times. 
Tool Name: $\quad$ Annual Cost Estimator for Methodology 2

Program Used: $\quad$ Microsoft Excel

Inputs:

The volume of sediment removed per cleanout per cleanout frequency model in cubic meters, the year in which the cleanout occurs, the fixed cost in dollars, the cost factor from the table provided in dollars per cubic meter and the quantity-based discounting factor, the annual performance (removal efficiency) as a percentage and the annual budget constraint in dollars per year.

Calculations: The tool calculates the cost per cleanout in dollars, the cost per cleanout in the first year of the facility's operation in dollars, the total cost of all cleanouts in the first year of the facility's operation in dollars, and the equivalent annual cost over 50 years in dollars per year.

Outputs: $\quad$ The tool outputs three charts:

1) Displaying the cleanout frequency in years versus the number of years in violation of government performance regulations,

2) Displaying annual cost in dollars per year versus the number of years in violation of government performance regulations,

3) Displaying the cleanout frequency in years versus the annual cost in dollars per year. 


\section{REFERENCES}

Aryal, R. K., \& Lee, B.-K. (2009). Characteristics of suspended solids and micropollutants in first-flush highway runoff. Water Air Soil Pollution: Focus, 9, 339-346.

Alley, W. M., \& Veenhuis, J. E. (1983). Effective impervious area in urban runoff modeling. Journal of Hydraulic Engineering, 109(2), 313-319.

Bannerman, R. (2007). Reducing the uncertainty in the calculations of street cleaner performance for Wisconsin municipalities. Retrieved from http://www.cws.msu.edu/documents/ BannermanR133BMPStormCon082107.pdf

Barbé, D. E., Cruise, J. F., \& Mo, X. (1996). Modeling the buildup and washoff of pollutants on urban watersheds. Water Resources Bulletin, 32(3), 511-519.

Behera, P. K., Papa, F., \& Adams, B. J. (1999). Optimization of regional storm-water management. Journal of Water Resources Planning and Management, 125(2), 107-114.

Drake, J., \& Guo, Y. (2008). Maintenance of wet stormwater ponds in Ontario. Canadian Water Resources Journal, 33(4), 351-368.

Ecojustice. (2004). The national sewage report card: Grading the sewage treatment of 22 Canadian cities. Retrieved from http://www.ecojustice.ca/publications/reports/nationalsewage-report-card-iii/attachment

Environment Canada. (2002). Interprovincial movement of hazardous waste and hazardous recyclable material regulations. Retrieved from http://www.ec.gc.ca/lcpecepa/default.asp?lang=En\&n=2058D801-1\&offset=7\&toc=show\#anchor1.1 
Erickson, A. J., Gulliver, J. S., Kang, J.-H., Weiss, P. T., \& Wilson, C. B. (2010). Maintenance for stormwater treatment practices. Journal of Contemporary Water Research \& Education, 146, 75-82.

Fleming, H., \& Slack, D. (2001). Trends in sewer overflow management. Water Engineering \& Management, 148(2), 21-24.

Gabric, A. J., \& Bell, P. R. F. (1993). Review of the effects of non-point nutrient loading on coastal ecosystems. Australian Journal of Marine and Freshwater Research, 44(2), 261283.

Graham, E. J., \& Lei, J. H. (2000). Stormwater management ponds and wetlands sediment maintenance. Water Quality Resources Journal of Canada, 35(3), 525-539.

Greenland International Consulting Inc. (1999). Storm water management facility sediment maintenance guide. Concord, ON.

Hogan, D. M., \& Walbridge, M. R. (2007). Best management practices for nutrient and sediment retention stormwater runoff. Journal of Environmental Quality, 36(2), 386-395.

James, W. (2005). Rules for responsible modeling: $4^{\text {th }}$ edition. Guelph, ON: CHI.

Krasnova, R. (2004). Hydrologic modelling of construction site sediment control pond using SWMM (Master's thesis). Ryerson University, Toronto, ON.

Lee, J. H., \& Bang, K. W. (2000). Characterization of urban stormwater runoff. Water Research, 34(6), 1773-1780. 
Line, D. E., \& White, N. M. (2007). Effects of development on runoff and pollutant export. Water Environment Research, 79(2), 185-190.

May, D., \& Sivakumar, M. (2009). Prediction of nutrient concentrations in urban storm water. Journal of Environmental Engineering, 135(8), 586-594.

Mulroy, K. (2010). Assessing the performance of two stormwater management ponds in Waterloo, Ontario (Master's thesis). Retrieved from University of Waterloo Library, UWSpace.

Murty, K. G. (2003). Optimization models for decision making: Volume 1. Ann Arbor, MI: University of Michigan.

Narayanan, A., \& Pitt, R. (2006). Costs of urban stormwater control practices. Tuscaloosa, AL: The University of Alabama.

Nie, F., Li, T., Yao, H., Feng, M, \& Zhang, G. (2008). Characterization of suspended solids and particle-bound heavy metals in a first flush of highway runoff. Journal of Zhejiang University - Science A, 9(11), 1567-1575.

Obropta, C. C., \& Kardos, J. S. (2007). Review of urban stormwater quality models: Deterministic, stochastic, and hybrid approaches. Journal of the American Water Resources Association, 43(6), 1508-1523.

Ogunfowokan, A. O., Asubiojo, O. I., \& Fatoki, O. S. (2003). Isolation and determination of polycyclic aromatic hydrocarbons in surface runoff and sediments. Water, Air, and Soil Pollution, 147, 245-261. 
Ontario Ministry of the Environment. (1993). Subwatershed planning. Toronto, ON: Queen's Printer for Ontario.

Ontario Ministry of the Environment. (1994). Stormwater management practices planning and design manual. Toronto, ON: Queen's Printer for Ontario.

Ontario Ministry of the Environment. (2003). Stormwater management planning and design manual. Toronto, ON: Queen's Printer for Ontario.

Persson, J., \& Pettersson, T. J. R. (2009). Monitoring, sizing and removal efficiency in stormwater ponds. E-Water, 4. Retrieved from http://www.ewaonline.de/

Pyatt, L. (2003). Performance evaluation of a sediment control pond (Master's thesis). Toronto, ON: Ryerson University.

Randolph, J. (2004). Environmental land use planning and management. Washington, DC: Island Press.

Rathnam, E. V., Cheeralaiah, N., \& Jayakumar, K. V. (2004). Dynamic programming model for optimisation of stormwater retention ponds in multiple catchment system. Hydrology: Science \& Practice for the $21^{\text {st }}$ Century. 2, 326-330.

Rideau Valley Conservation Authority. (2011). Britannia village flood control project. Retrieved from http://www.rvca.ca/britannia/files/Britannia_\%20Summary_14_04_11.pdf

Sartor, J. D., Boyd, G. B., \& Agardy, F. J. (1974). Water pollution aspects of street surface contaminants. Water Pollution Control Federation, 46(3), 458-467. 
Schoellhamer, D. H., Mumley, T. E., \& Leatherbarrow, J. E. (2007). Suspended sediment and sediment-associated contaminants in San Francisco Bay. Environmental Research, 105, 119-131.

Schueler, W. (1994). Pollutant dynamics of pond muck. Watershed Protection Techniques, 1(2), 39-46.

Toronto and Region Conservation Authority. (2010). Low impact development stormwater management planning and design guide. Toronto, ON: TRCA. Retrieved from http://www.sustainabletechnologies.ca/Portals/_Rainbow/Documents/LID\%20SWM\%20G uide\%20-\%20v1.0_2010_1_no\%20appendices.pdf

Town of Richmond Hill. (1997). Stormwater management facilities design brief: Leslie Heights Development Limited: OPA 121 \& 135. Pickering, ON: Sabourin Kimble \& Associates Ltd.

Triboit, F., Laffont-Schwob, I., Demory, F., Soulié-Märsche, I., Rabier, J., Despréaux, M., \& Thiéry, A. (2010). Heavy metal lability in porewater of highway detention pond sediments in south-eastern France in relation to submerged vegetation. Water Air Soil Pollution, 209, 229-240.

United States Environmental Protection Agency. (2009). Storm water management model applications manual. Cincinnati, OH: US EPA. Retrieved from http://www.epa.gov/nrmrl/wswrd/wq/models/swmm/ epaswmm5_apps_manual.zip 
United States Environmental Protection Agency. (2010). Storm water management model user's manual version 5.0. Cincinnati, OH: US EPA. Retrieved from http://nepis.epa.gov/Exe/ZyPURL.cgi?Dockey= P100ERK4.txt

Van Vliet, T. (2003). The use of geographic information systems in the development of a userpay stormwater utility in the Mimico Creek Watershed. Retrieved from Digital Commons @ Ryerson.

Vivekanandan, V. (2012). Proceedings from India Water Week 2012: Water, Energy and Food Security: Call for Solutions. New Delhi, DL.

Wahlberg, E. J., \& Tarpey, T. (2003). Primary clarifier optimization study methodology. Retrieved from http://www.tappi.org/Downloads/unsorted/UNTITLED---env0327pdf.aspx

Wanielista, M. P., \& Yousef, Y. A. (1993). Stormwater management. New York, NY: John Wiley \& Sons, Inc.

Westerbeek-Vopicka, K. (2009). Sediment assessment of stormwater retention ponds within the urban environment of Calgary, Canada. Water Quality Resources Journal of Canada, 44(1), 81-91.

Westerlund, C., \& Viklander, M. (2006). Particles and associated metals in road runoff during snowmelt and rainfall. Science of the Total Environment, 323, 143-156.

Wilson, B. N., \& Barfield, B. J. (2009). Proceedings from $33^{\text {rd }}$ IAHR Congress: Water Engineering for a Sustainable Environment. Vancouver, BC: International Association of Hydraulic Engineering \& Research. 
Withgott, J., Brennan, S., \& Murck, B. (2010). Environment: The science behind the stories, Canadian edition. Toronto, ON: Pearson Canada Inc.

Wong, T. H. F., Fletcher, T. D., Duncan, H. P., \& Jenkins, G. A. (2006). Modelling urban stormwater treatment - A unified approach. Ecological Engineering, 27, 58-70.

Yousef, Y. A., Hvitved-Jocobsen, T., Sloat, J., \& Lindeman, W. (1994). Sediment accumulation in detention or retention ponds. The Science of the Total Environment, 146/147, 451-456. 